Joachim Höpfner

Seasonal length of day changes and atmospheric angular momentum oscillations in their temporal variability

Scientific Technical Report STR98/10 


\title{
Seasonal length of day changes and atmospheric angular momentum oscillations in their temporal variability
}

\author{
Joachim Höpfner \\ GeoForschungsZentrum Potsdam, Division 1: Kinematics and Dynamics of the Earth,Telegrafenberg, D-14473 \\ Potsdam, Germany; E-mail: ho@gfz-potsdam.de
}

\begin{abstract}
Recently, effective Atmospheric-Angular-Momentum (AAM) functions as calculated from NCEP (formerly NMC) and NCAR Reanalyses have become available from 1968 to 1997 . Concerning the wind terms, the top level in the atmosphere used here is $10 \mathrm{hPa}$. Compared with earlier NMC model versions, which incorporate wind fields up to $100 \mathrm{hPa}$ since 1976 and up to $50 \mathrm{hPa}$ since 1981, the reanalyses have produced improved data series over a longer period than before. The axial AAM component $\chi_{3}$ is associated with changes in Length-Of-Day (LOD). Motivated by better quality and continuity of the series AAM (NCEP) Reanalysis, the problem of the seasonal imbalances in the solid Earth-atmosphere axial angular momentum budget is re-examined. To assess better the estimates of the annual and semiannual oscillations in LOD and AAM and of the residual oscillations derived as difference series between LOD and AAM, the series of LOD data from three analysis centers (IERS, GFZ, JPL) and of AAM data in terms of $\chi_{3}(\mathrm{~W}), \chi_{3}(\mathrm{P})$ and $\chi_{3}(\mathrm{P}+\mathrm{IB})$ from four meteorological centers (NCEP, JMA, ECMWF and UKMO) are used in this study. The main analysis steps were removing gaps, filtering out the seasonal oscillations, calculating optimal estimates of the parameters of the oscillations and calculating the difference series between the LOD and AAM systems as well as the residuals in the axial angular momentum budget in the LOD-AAM systems. The results derived as difference series between the different LOD, AAM and LOD-AAM systems show to which extent the variations reflect systematic differences and significant signals, respectively, which is important for future activities in this field.
\end{abstract}

Key words: Earth's rotation, LOD (length of day), AAM (atmospheric angular momentum), seasonal oscillations, imbalances

\section{Introduction and objective}

The Earth's rotation is a unique global measure of changes within the atmosphere, hydrosphere, cryosphere and interior of the Earth. Assuming the total angular momentum of the Earth as a whole to be conserved, i. e., ignoring external torques, mass movements excite variations of Earth rotation and polar motion. Recently, these Earth Orientation Parameters (EOP) have been measured by high-precision space geodetic techniques, such as Very Long Baseline Interferometry (VLBI), Satellite Laser Ranging (SLR), Lunar Laser Ranging (LLR), and, most recently, Global Positioning System (GPS). Since the Earth rotation variations provide fundamental information about the geophysical processes that occur in all components of the Earth, their study is a problem of great importance for understanding the dynamic interactions between the solid Earth, atmosphere, ocean and other geophysical fluids.

Changes in the angular momentum of a component of the Earth result from redistributions of its mass and from changes in the strength of the motion fields called as mass terms and motion terms, respectively. It is the atmosphere that plays the dominant role in exchanging angular momentum with the solid Earth on time scales of a few years (interannual) and less. Operationally, effective Atmospheric-Angular-Momentum (AAM) functions developed by Barnes et al. (1983) related to Earth rotation are applied to the numerical calculations of the AAM time series by the world's major meteorological centers. Concerning the two origins of the atmospheric excitation of variations in the rotation of the Earth, the motion or wind term dominates the axial component that is related to changes in the Length-Of-Day (LOD) and the mass or pressure terms dominate the equatorial components that are related to the excitation of polar motion (PM). Since the early 1980s, operational AAM time series have been computed by the U. S. National Meteorological Center (NMC). The weather centers in Japan and Europe have started with such calculations some years later. Concerning the data homogeneity, 
occasional algorithm and model changes that lead to systematic errors and step jumps, respectively, must be noted. In addition, there are frequent gaps in the records. By 1989, because of the significance of monitoring the atmospheric signals for the geodetic community, the International Earth Rotation Service (IERS) established a Sub-Bureau for Atmospheric Angular Momentum (SBAAM) at the NMC to collect, distribute, archive, and analyze atmospheric parameters relevant to the Earth orientation parameters. All the data series are available as SBAAM products. For more details, see Salstein et al. (1993).

There are oceanic effects on Earth orientation parameters due to inertia changes forced by atmospheric pressure loading in the oceans, i. e., ocean mass redistribution. AAM calculations include an oceanic contribution using the InvertedBarometer (IB) approximation. Here, the estimated IB effect is based on the assumption of an isostatic response of oceans to barometric pressure changes. Since the actual oceanic contribution is much more complicated than that computed using the IB approximation, accounting for oceanic effects on Earth orientation parameters requires numerical integration of gridded fields from oceanic analysis systems. In a way that is analogous to the calculations from atmospheric general circulation models (GCM), this must be done using oceanic GCMs together with data assimilation. Unlike the IB approximation as a simple isostatic response, Oceanic-Angular-Momentum (OAM) functions that represent LOD and PM excitations consider both variable currents and mass redistributions of the oceans. Also, ocean tides play a role in this momentum exchange. They produce comparable effects from both currents and tidal heights contributing to variations in the Earth's rotation at tidal periods. Using data from altimetry missions, continued refinement of ocean tide models is expected, especially in shallow water. Therefore, improving their predictions is important for further study of the non-tidal portions at tidal time scales.

The continental hydrology appears to play only a minor role in exciting changes in the rotation of the Earth. Here, variations in Hydrological-Angular-Momentum (HAM) are associated with continental storage of water, ice, and snow. At present, a hydrologic data-assimilation model for computing the influence is not yet available. The reasons for this are a lack of pertinent observations on the one side and the difficulty in modelling the effects in a realistic manner on the other side. After all, the objective should be to develop a full climate-system model including atmosphere, ocean, and solid Earth elements that are hydrologically coupled. Over decadal time scales, the Earth's liquid core is thought to play a significant role in momentum exchange, i.e., probably, there is a fluid core angular momentum transfer to the mantle. Here, different types of coupling are possible such as gravitational, viscous, electromagnetic, and topographic coupling. Therefore, we find a long-term drift in LOD data. At present, the IERS makes coordination efforts to include the monitoring of other global geophysical fluids, in addition to the atmosphere (Reigber and Feissel, 1997). This expansion of its activities is important for understanding the Earth's rotation and for improving the underlying space geodetic measuring systems. For more information on the modelling and monitoring of the various geophysical fluids discussed above, see Dehant et al. (1997).

Currently, there are a number of atmospheric reanalysis projects at various meteorological centers. The efforts here are to incorporate data not included in the original operational results and to produce the analysis fields with a fixed arithmetical scheme. The SBAAM takes advantage of this reanalysis to compute the SBAAM parameters in a consistent way. Recently, the AAM components as calculated from U. S. National Centers for Environmental Prediction (NCEP), formerly National Meteorological Center (NMC), and the U. S. National Center for Atmospheric Research (NCAR) Reanalyses are available from 1968 to 1998. For the NCEP/NCAR Reanalysis Project, see Kalnay et al. (1996). Details on the AAM calculations from this reanalysis are given by Salstein and Rosen (1997). Since the new data series labelled AAM (NCEP) Reanalysis is of improved quality with high temporal resolution, its analysis should provide better results. In addition, its time span is longer than before. Therefore, the previous studies on the imbalances in the solid Earthatmosphere axial angular momentum budget at seasonal frequencies presented by Höpfner $(1996,1997)$ are continued. In this study, the annual and semiannual components of LOD and AAM are recovered from LOD data produced by three Earth orientation analysis centers and from AAM data produced by four meteorological centers, in order to assess better the estimates of the LOD and AAM oscillations and of the residual oscillations between themselves and to find out to which extent the variations reflect systematic differences and significant signals. A review of the state of the art in studying the Earth's axial angular momentum balance at seasonal time scales can be found in Höpfner (1997, 1998). Before discussing the data sets used, Section 2 briefly describes the relationship between changes in LOD and AAM.

\section{Changes in LOD and excitation portions}

LOD is the excess of the duration of the day relative to $86400 \mathrm{~s}$. For changes in LOD caused by geophysical processes, the relation to the excitation function $\psi_{3}$ has the form

$\mathrm{LOD}=\psi_{3}+$ constant. 
Publication: Scientific Technical Report

No.: STR98/10

Author: J. Höpfner

Table 1. LOD data used. MJD is the Modified Julian Date

\begin{tabular}{lcc}
\hline Series & \multicolumn{1}{c}{$\begin{array}{c}\text { Entire time span } \\
\text { (in calendar days) }\end{array}$} & $\begin{array}{c}\text { Period } \\
\text { (in MJD) }\end{array}$ \\
\hline EOP (IERS) 97C04 & Jan. 1, 1962 ... July 15, 1997 & $37665.0 \ldots 50644.0$ \\
ERP (GFZ) L04 & July 1, 1983 ... Aug. 10, 1993 & $45516.0 \ldots 49209.0$ \\
+ ERP (GFZ) 97P01 & Jan. 6, 1993 ... July 19, 1997 & $48993.5 \ldots 50648.5$ \\
EOP (JPL) 97C01 & Sept. 28, 1976 ... Feb. 8, 1997 & $43049.0 \ldots 50487.0$ \\
\hline
\end{tabular}

In contrast to excited polar motion, the transfer of the excitation to LOD is frequency-independent and linear. Therefore, a periodic excitation causes a corresponding periodic LOD change; see, e. g., Munk and MacDonald (1960); Höpfner (1995).

Concerning the effective AAM functions as described by Barnes et al. (1983), the equatorial components $\chi_{1}$ and $\chi_{2}$ are related to the excitation to PM, and the axial component $\chi_{3}$ is related to changes in LOD. Each component can be separated into wind and pressure terms. The wind terms give reckoning of changes in the atmosphere's momentum that result from changes in the strength of the motion field, and the pressure terms account for changes in the atmosphere's momentum that are due to changes in its moment of inertia resulting from redistributions of atmospheric mass over the globe.

As noted above, the present study is restricted to the solid Earth-atmosphere axial angular momentum budget at seasonal time scales. Therefore, we are only concerned with the $\chi_{3}$ component, namely with the wind term labelled $\chi_{3}(\mathrm{~W})$ and the pressure term without and with IB response labelled $\chi_{3}(\mathrm{P})$ and $\chi_{3}(\mathrm{P}+\mathrm{IB})$. For the IB response, see in Section 1. Assuming that the solid Earth and the atmosphere form a closed dynamical system, then changes in AAM about the polar axis relative to an Earth-fixed frame must be reflected by compensating changes in the Earth's axial angular momentum. We thus have

$\mathrm{LOD}_{\mathrm{atm}}=-\chi_{3}$,

where $\mathrm{LOD}_{\mathrm{atm}}$ is the atmospheric contribution to LOD inferred from AAM. Unlike to the LOD data expressed in seconds of time (s), the units of the AAM data are non-dimensional. By inverting their signs and multiplying them with the scale factor of $8.64 \times 10^{4}$, the AAM values are converted into LOD atm values (Höpfner 1997, 1998). For more information, see, e. g., Rosen (1993). Note that, in the case of the fluctuations in the axial component of the atmosphere's angular momentum, the wind term is more than an order of magnitude larger than the pressure term.

Focussing on the seasonal imbalances in the solid Earth-atmosphere axial angular momentum budget, we consider the annual and semiannual oscillations in LOD and $\mathrm{LOD}_{\mathrm{atm}}$ and the residual oscillations between themselves. In Section 3 , the different data types, both geodetic and meteorological, used for this in our study are discussed.

\section{Data sets used in this study}

\subsection{LOD series}

The LOD data used are the once-per-day values from the following series of the Earth Orientation Parameters (EOP); also denoted as Earth Rotation Parameters (ERP): EOP (IERS) 97C04 computed by the International Earth Rotation Service (IERS), ERP (GFZ) L04 plus ERP (GFZ) 97P01 computed by the GeoForschungsZentrum Potsdam (GFZ), and EOP (JPL) 97C01, also known as SPACE97, computed by the Jet Propulsion Laboratory Pasadena (JPL), where C stands for a combination of the observing techniques, L for Satellite Laser Ranging (SLR), and P for Global Positioning System (GPS); if the data sets were computed in the year 1997, this is labelled by 97 . Table 1 summarize the various LOD data sets studied, which are described more fully below.

\section{(a) EOP (IERS) 97C04}

This IERS series is consistent with the new reference system 1997. It is the combined daily time series of EOP derived from subsets of the series received from the analysis centers. The individual series used here are selected according to consistency with the reference frames, consistency with IERS Standards, duration, frequency of measurement and precision. Computed over different intervals, it is homogenized, merged and then slightly smoothed. Oscillations due to zonal tides for periods of less than 35 days are present in full size in the series.

Most recently, a new technique employing the Global Positioning System (GPS) has become available to measure Earth orientation. Concerning the combining the independent Earth orientation measurements taken by the spacegeodetic techniques of LLR, SLR, VLBI, and GPS from 1992, four GPS series, namely computed by CODE (Centre 
Publication: Scientific Technical Report

No.: STR98/10

Author: J. Höpfner

Table 2. Uncertainty of one daily LOD value for the different series

\begin{tabular}{lccc}
\hline Period & EOP(IERS) 97C04 & $\begin{array}{c}\text { ERP (GFZ) L04 } \\
\text { ERP (GFZ) 97P01 } \\
(0.1 \mathrm{~ms})\end{array}$ & $\begin{array}{c}\text { EOP (JPL) 97C01 } \\
(0.1 \mathrm{~ms})\end{array}$ \\
\hline $1962 \ldots 1967$ & 14 & & $(0.1 \mathrm{~ms})$ \\
$1968 \ldots 1971$ & 10 & & \\
$1972 \ldots 1979$ & 7 & L04: 0.3 & 0.9 \\
$1980 \ldots 1983$ & 1.5 & $0.2 ;$ P01: 0.04 & 0.6 \\
$1984 \ldots 1995$ & 0.3 & 0.03 & 0.3 \\
$1996 \ldots 1997$ & 0.2 & & 0.3 \\
\hline
\end{tabular}

for Orbit Determination in Europe), NRCan (Natural Resources Canada, formerly Energy, Mines and Resources Canada, abbr. EMR), JPL and GFZ were first combined before the compilation of EOP (IERS). This combination is made by a weighted average of the various series, where the weighting reflects the qualities of the series as well as the long-term and short-term stability. Taking advantage of different long, recently re-analysed individual series of the analysis centers, the time series was also re-computed for the period since 1983. For additional information, see, e. g., the IERS Annual Report of 1996 (IERS 1997).

(b) ERP (GFZ) L04 and ERP (GFZ) 97P01

Both series are individual solutions computed by the GFZ.

ERP (GFZ) L04: This independent GFZ series has been computed using global SLR data to Lageos; see Montag et al. (1993, 1994). Oscillations due to zonal tides with periods up to 35 days are removed from the LOD data, but the tidal effects Sa and Ssa are still contributing to the seasonal oscillations of LOD. Estimated according to IERS 1992 Standards (McCarthy 1992), the series is referred to the old reference system. Their values have gaps between one and seven days and are given since June 1991 till August 1993, namely with MJD from 48425 to 49209, at roughly one-day intervals. As in Höpfner (1996), we have applied linear interpolation to fill short gaps and to produce even-interval data.

ERP (GFZ) 97P01: This independent GFZ series has been computed using the global GPS data; see Gendt et al. (1997). Since the values are modelled according to IERS 1996 Standards, the series is expressed in the new reference system 1997; see Gambis and Eisop 1997.

Note that the data of ERP (GFZ) L04 are computed at $0 \mathrm{~h} \mathrm{UTC}$, but those of ERP (GFZ) 97P01 at $6 \mathrm{~h}$ UTC (UTC Universal Time Coordinated). The LOD series calculated from SLR analysis has to be resampled using linear interpolation to conform to $6 \mathrm{~h}$ UTC daily sampling in order to concatenate it with that calculated from GPS analysis; details are given in Section 4.

(c) EOP (JPL) 97C01

This series is the JPL combined solution that is based on LLR, SLR and VLBI series, GPS series were introduced mid1992. Here, a Kalman filter has been used to combine the independent measurements of the Earth's orientation. Before their combination, corrections for the bias, rate, stated uncertainties and other effects are applied to the independent series to make them consistent with each other. In addition, contributions from the solid tides according to Yoder et al. (1981) with long period ocean corrections (Dickman 1993) are removed; for this reduction, LOD computed by JPL is designated by $\mathrm{LOD}_{\text {red }}$ in this and the following sections. Since the beginning of the series, it is referred in bias to the IERS 1996 solutions, i. e., it is consistent with the new reference system 1997. For generating previous such combinations, see, e.g., Gross (1996).

A summary of the uncertainty of one daily LOD value for the different series is given in Table 2. It shows how the uncertainty improves by replacing the classical method for measuring LOD changes by space-geodetic techniques over the periods. Similar to the combined EOP series derived by IERS, the combination of JPL is carried out. At the beginning of the combination of the independent solutions, the quality of the JPL series is better. Obviously, the reason for this is that only measurements taken by the space-geodetic techniques are used. Both LOD series obtained by GFZ show remarkably small formal uncertainties. Concerning the LOD series derived from observing systems of satellite geodetic techniques like SLR and GPS, it should be mentioned that the integrated series of LOD called Universal Time (UT) is corrupted by the correlation with the longitude of the orbit node. Therefore, UT can be accurately derived only from inertial methods like LLR and VLBI; again, see the 1996 IERS Annual Report (IERS 1997).

The time series of LOD are shown in Figure 1. We can see the LOD variation of the IERS at the top, that of the GFZ at the centre and that of the JPL at the bottom of the figure. Also shown are the trends obtained by low-pass filtering of 
LOD

SERIES EOP (IERS) 97C04 1962-1997

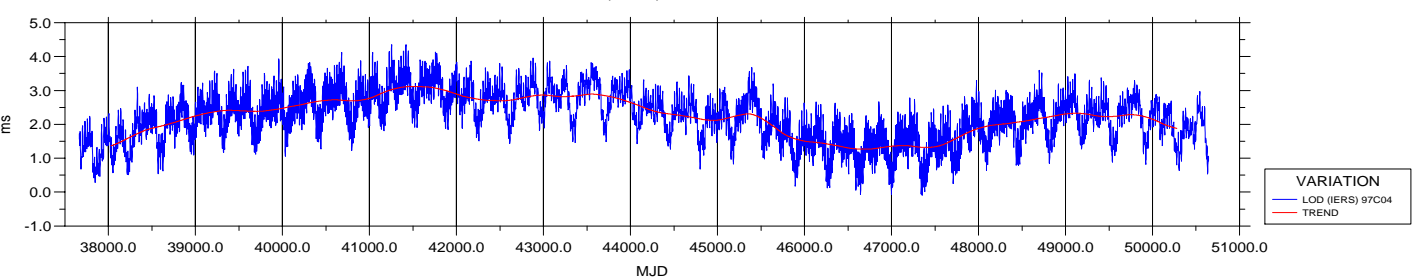

SERIES ERP (GFZ) L04 1983-1993 plus ERP (GFZ) 97P01 1993-1997

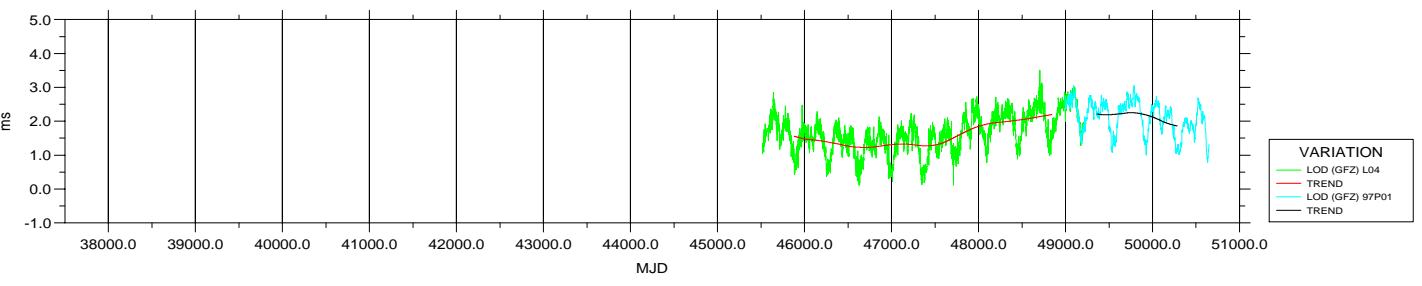

SERIES EOP (JPL) 97C01 1976-1997

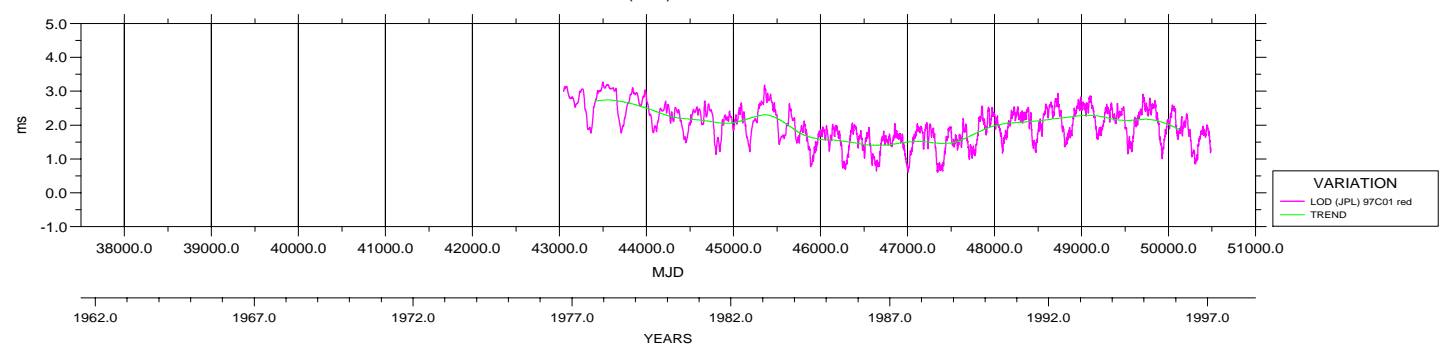

Figure 1. Length-Of-Day variation as computed by the IERS (top), GFZ (centre), and JPL (bottom) defined to be LOD. The trends are shown as smooth lines. LOD red , especially of JPL, means that the variation of LOD is reduced, i. e., the tidal effects are removed

the original data. This large, decadal-scale signal is thought to be caused primarily by core-mantle boundary processes with climatic variations contributing a currently unknown amount to the observed total decadal-scale LOD variation; for the long-term drift in LOD data, also see in Section 1, and compare with Figure 2 (see, e. g., Jochmann and Greiner-Mai 1996). For information about the filtering of the time series, see in Section 4.1.

\subsection{AAM series}

Four meteorological centers that participate in the Sub-bureau for Atmospheric Angular Momentum provide the AAM data used in this study. These are the U. S. National Centers for Environmental Prediction (NCEP), formerly National Meteorological Center (NMC), the Japan Meteorological Agency (JMA), the European Centre for Medium-Range Weather Forecasts (ECMWF), and the U. K. Meteorological Office (UKMO). A summary of the characteristics of the various data sets is given in Table 3. Also, the information concerning the NCEP Reanalysis is included.

Table 3. Characteristics of the AAM data

\begin{tabular}{|c|c|c|c|c|}
\hline Meteorological center & $\begin{array}{l}\text { Entire time span } \\
\text { (in calendar days) }\end{array}$ & $\begin{array}{c}\text { Period } \\
\text { (in MJD) }\end{array}$ & $\begin{array}{l}\text { Sampling interval } \\
\text { (in days) }\end{array}$ & $\begin{array}{l}\text { Top level } \\
\text { (in } \mathrm{hPa} \text { ) }\end{array}$ \\
\hline $\begin{array}{l}\text { NMC } \\
\text { (replaced by NCEP) }\end{array}$ & July $1976 \ldots$ now & $\begin{array}{c}42960.0 \ldots 44605.0 \\
44605.5 \ldots 48793.5 \\
48794.25 \ldots \text { now }\end{array}$ & $\begin{array}{l}1.0 \\
0.5 \\
0.25\end{array}$ & $\begin{array}{c}100 ; \\
50 \text { since Jan. } 1981\end{array}$ \\
\hline NCEP Reanalysis & Jan. 1968 ... June 1997 & $39856.00 \ldots 50629.75$ & 0.25 & 10 \\
\hline JMA & Oct. 1983 ... March 1997 & $\begin{aligned} 45605.0 & \ldots 45672.5 \\
45680.25 & \ldots 46611.25 \\
46612.0 & \ldots 48794.0 \\
48794.00 & \ldots 50538.75\end{aligned}$ & $\begin{array}{l}0.5 \\
1.0 \\
0.5 \\
0.25\end{array}$ & 10 \\
\hline ECMWF & $\begin{array}{c}\text { Jan. } 1988 \ldots \text {... July } 1992 \\
\text { Aug. } 1992 \ldots \text { June } 1996\end{array}$ & $\begin{array}{l}47161.0 \ldots 48834.5 \\
48835.0 \ldots 50264.5\end{array}$ & $\begin{array}{l}0.5 \\
0.25\end{array}$ & 10 \\
\hline UKMO & Nov. 1986 ... March 1997 & $46761.0 \ldots 50538.5$ & 0.5 & about 25 \\
\hline
\end{tabular}




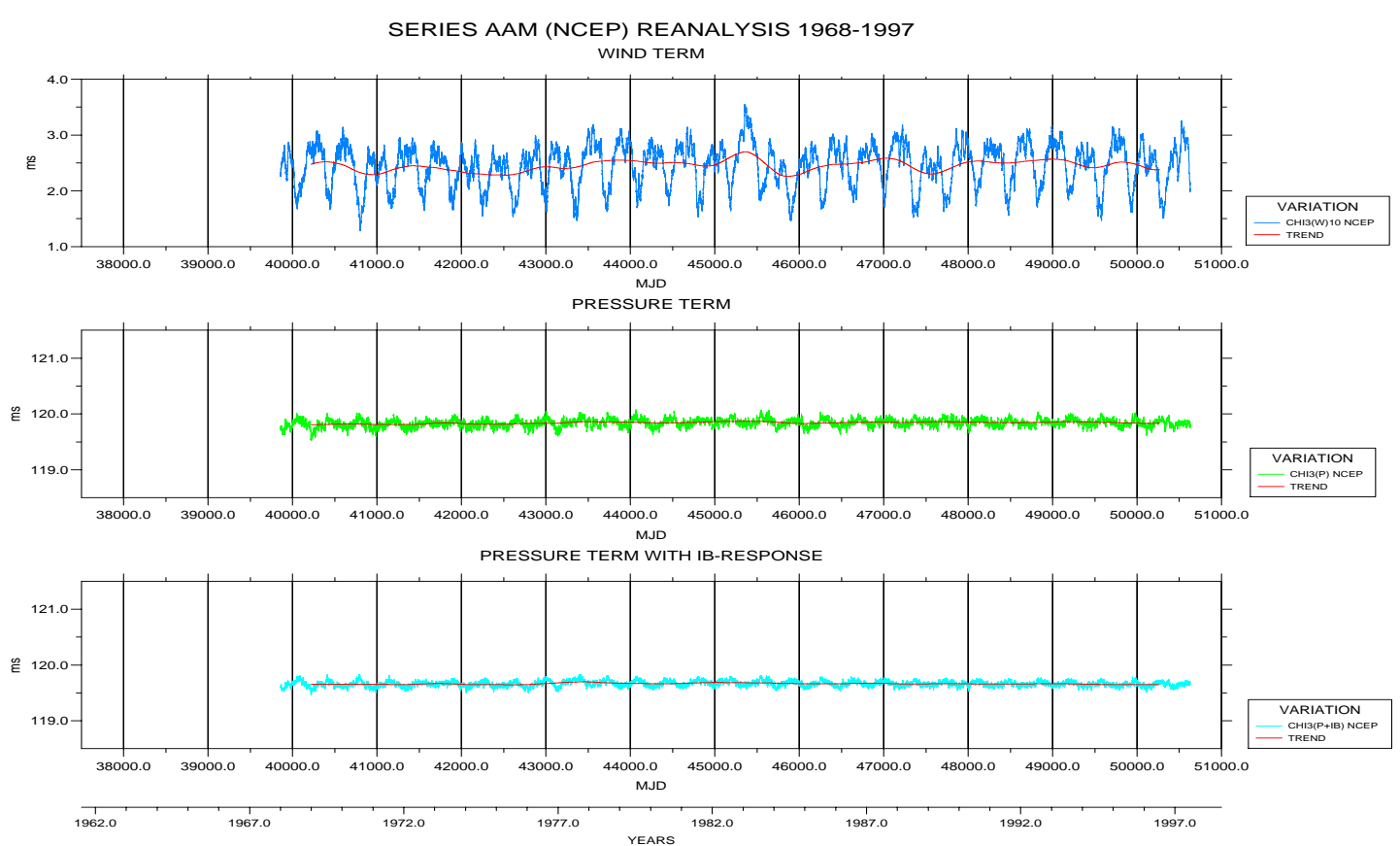

Figure 2. Length-Of-Day variation as inferred by Atmospheric-Angular-Momentum computed by the NCEP Reanalysis defined to be LOD atm: Wind term $\chi_{3}(\mathrm{~W})$ (top), pressure term $\chi_{3}(\mathrm{P})$ (centre), and pressure IB term $\chi_{3}(\mathrm{P}+\mathrm{IB})$ (bottom). The trends are shown as smooth lines

Some comments on the AAM data should be noted: For forecasting the weather, large quantities of meteorological data are assimilated into an atmospheric general circulation model (GCM). Here, several sources of error affect all meteorological estimates. These include various types of measurement error as well as limited geographic data coverage and finite atmospheric model thickness. Using a mathematical simulation of the general circulation of the atmosphere that is based on physical and numerical model approximations, a number of atmospheric parameters, such as wind, pressure, and temperature fields, are continuously updated in the model. By the early eighties, due to progress made in meteorological calculations, it was possible to get the total atmospheric angular momentum variations as a by-product of the global numerical atmospheric model used for operational weather forecasting every few hours or less. Nowadays, these AAM estimates are routinely available from four meteorological centers. Here, the global data assimilation systems implemented operationally at the centers vary.

For the formulas of the effective AAM functions, see Barnes et al. (1983) or Salstein et al. (1993). In particular, the motion or wind terms of AAM are represented by volume integrals of winds. For their computation, there are different pressure levels over the depth of the atmosphere in the global circulation models. See Table 3 for the top levels of each participating center. On the other hand, the mass or pressure terms are represented by surface integrals of pressures. Because the IB response exists to a certain extent, calculations with the IB correction are performed in parallel to computing the regular pressure terms by some centers, namely by the NCEP (formerly NMC) and the JMA, whereas the ECMWF and the UKMO do not consider the IB effect.

To improve the weather forecasts, changes are often made to the GCMs and the algorithms. These lead to improved AAM values, but have also the undesired effect of sometimes causing sudden, step-like changes in the mean AAM value. Especially in the pressure terms, there are such step jumps due to changes in model orography. We know the following dates of NCEP model changes that affect surface pressure: August 18, 1976 (MJD 43008), May 1, 1980 (MJD 44360), May 28, 1986 (MJD 46579), August 12, 1987 (MJD 47020) and March 6, 1991 (MJD 48322); see Rosen et al. (1990) and Höpfner $(1997,1998)$.

There are also other developments and model modifications at the centers such as the adoption of a higher-resolution model. As reported by Salstein et al. (1993) and Kalnay et al. (1996), the operational NCEP system is run at a finer resolution implemented on March 6, 1991 (MJD 48322) and again on January 10, 1995 (MJD 49727). The advances in the resolution and extension of the GCMs are evident from the following information: Since January 1981 (MJD 44605), the NCEP has produced the data sets of the atmospheric parameters at a horizontal resolution of $2.5^{\circ}$ latitude by $2.5^{\circ}$ longitude and 12 levels in the vertical from the surface to $50 \mathrm{hPa}$. This model was modified on March 6, 1991 . According to Kalnay et al. (1996), the global data assimilation system is run at a horizontal resolution of about $105 \mathrm{~km}$ and 28 vertical levels since January 1995 (MJD 49718). Concerning the operational JMA system, a $2.5^{\circ}$ x $2.5^{\circ}$ latitude- 
Publication: Scientific Technical Report

No.: STR98/10

Author: J. Höpfner

Table 4. Characteristics of the digital filters

\begin{tabular}{cccc}
\hline Filter: Component & $\begin{array}{c}\text { Number of points } \\
\text { used in each filtering }\end{array}$ & $\begin{array}{c}\text { Related edge effect: } \\
\text { Points lost at either end }\end{array}$ & $\begin{array}{c}\text { Cut-off period of the low-pass filter; } \\
\text { half-power points at ... and ... } \\
\text { (in days) }\end{array}$ \\
\hline Low-pass: Trend & 731 & 365 & 415 \\
Band-pass: Annual & 1589 & 794 & 324 and 421 \\
Semiannual & 787 & 393 & 160 and 208 \\
\hline
\end{tabular}

longitude grid at 15 standard pressure levels up to $10 \mathrm{hPa}$ was first introduced in the GCM; later a $1.875^{\circ} \mathrm{x} 1.875^{\circ}$ grid is used (Naito et al. 1987; Nastula and Manabe 1997).

Note that the meteorological centers do not compute the uncertainties of the AAM time series. To assess the errors of AAM, there are a number of studies based on a comparison between the different series. For a brief review, see Höpfner (1997, 1998). According to Naito and Kikuchi (1990), the error in the wind term $\chi_{3}(\mathrm{~W})$ in the JMA system is around $3 \%$. Comparable to that is the error in the pressure term $\chi_{3}(\mathrm{P})$, as assessed by Rosen et al. (1990).

To analyze the state of the atmosphere in a consistent way over long periods in supporting the needs of the research and climate monitoring communities, reanalysis projects are started at the meteorological centers. Especially, the reanalyses performed by the NCEP are made using a frozen state-of-the-art global data assimilation system at a truncation of 62 triangular waves, i. e. equivalent to a horizontal resolution of about $210 \mathrm{~km}$, and 28 levels in the vertical up to near to $10 \mathrm{hPa}$ level. In addition, they incorporate data that may have been omitted from original operational results. For details, see Kalnay et al. (1996). From these NCEP reanalyses, AAM (NCEP) Reanalysis quantities have been computed for the period from January 1, 1968 to June 30, 1997, i. e. MJD from 39856.00 to 50629.75, at 6-hour intervals. Accordingly, a 29.5-year data series exists, which is longer than those produced before by the NCEP and the other meteorological centers. Compared with the operational time series of AAM, those calculated from reanalyses are homogeneous over the entire time span and qualitatively better. Therefore, they generally show improved agreement with Earth orientation time series. This suggests to use AAM reanalysis data in this study in order to quantify better the seasonal imbalances in the solid Earth-atmosphere axial angular momentum budget.

In case of the AAM data for this research, we are restricted to the $\chi_{3}$ component with the terms $\chi_{3}(\mathrm{~W}), \chi_{3}(\mathrm{P})$ and $\chi_{3}(\mathrm{P}+\mathrm{IB})$, which suggest LOD - atm; see Section 2. Preparatorily, it is necessary to make available data that are free of gaps and random and systematic errors at even intervals. In the same manner as reported in Höpfner (1997, 1998), the pre-processing of the operational NCEP and JMA LOD atm series was completed and that of the ECMWF and UKMO LOD atm series was carried out. A step jump in $\chi_{3}(\mathrm{P})$ of ECMWF occurred on April 4, 1995 (MJD 49811). It is removed by normalizing the earlier data with respect to the recent model. Note that the gaps filled by linear interpolation and in some cases by a more sophisticated interpolation method are $0 \%$ at twice daily intervals but $17 \%$ at four times daily intervals for the ECMWF series and $13 \%$ for the UKMO twice-daily series; for the periods, see Table 3.

Figure 2 shows the $\mathrm{LOD}_{\text {atm }}$ time series based on the NCEP Reanalysis system. Here, the variation of the wind term $\chi_{3}(\mathrm{~W})$ is plotted at the top, of the pressure term $\chi_{3}(\mathrm{P})$ at the centre, and of the pressure IB term $\chi_{3}(\mathrm{P}+\mathrm{IB})$ at the bottom. Also, the trends separated by low-pass filtering are illustrated; see Section 4 for the filtering. The curves are quite similar to those from the three other centers. For comparison with the data sets of the NMC (replaced by NCEP) system and those of the JMA system, see Höpfner $(1997,1998)$. On the contrary, the data sets of the ECMWF system and those of the UKMO system are not shown. Also, compare LOD ${ }_{\text {atm }}$ with LOD displayed in Figure 1. On the same time scale, the series have been plotted in all figures. Our input data for this study are the LOD series together with those of LOD atm. In Section 4, we discuss the data processing done in form of filtering the time series and calculating optimal estimates of the parameters of the seasonal oscillations.

\section{Data processing}

In a similar manner as reported in Höpfner (1997, 1998), the time series of LOD and LOD atm are processed. The two steps are (1) separating the major components, in particular trend and seasonal oscillations, by filtering the time series; and (2) calculating optimal estimates of the parameters of the seasonal oscillations.

\subsection{Filtering the time series}

To separate the major components from the data, we applied zero-phase digital filters designed by Höpfner (1996). There are a low-pass filter for isolating the long-term trend and two band-pass filters for isolating the seasonal oscillations. The 

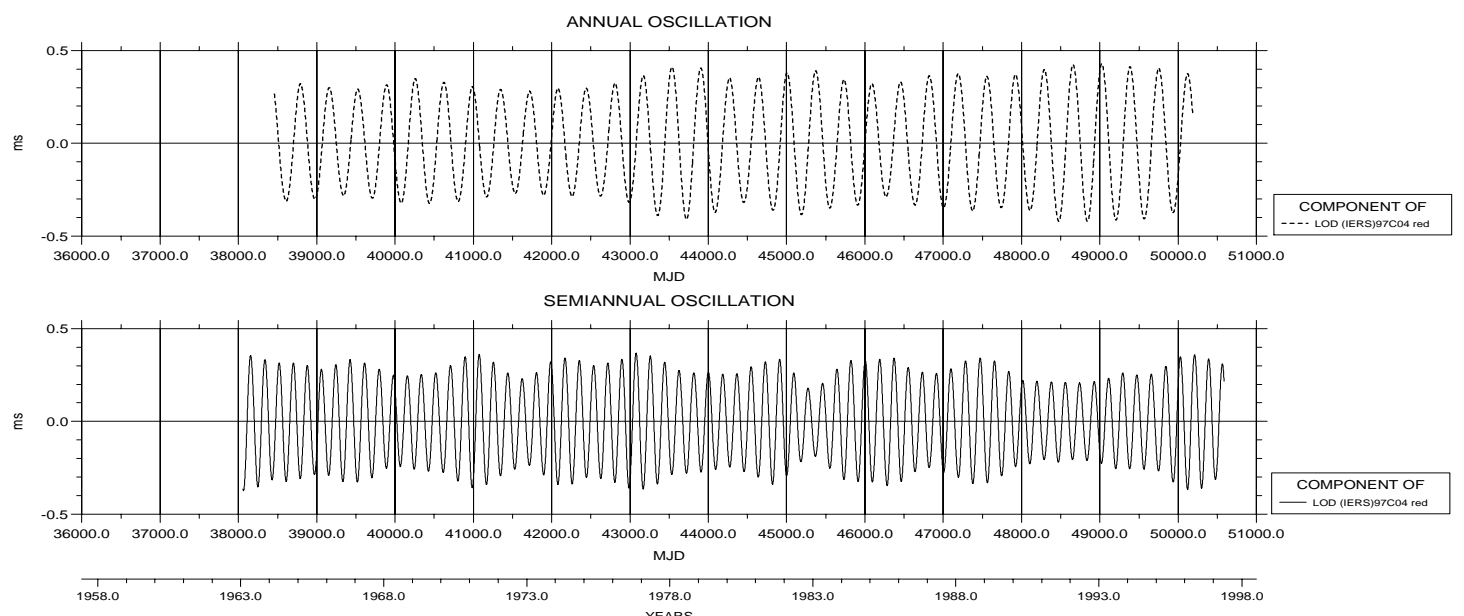

Figure 3. Seasonal oscillations of the LOD variation as computed by the IERS. Top: Annual oscillation without tidal effect Sa. Bottom: Semiannual oscillation without tidal effect Ssa
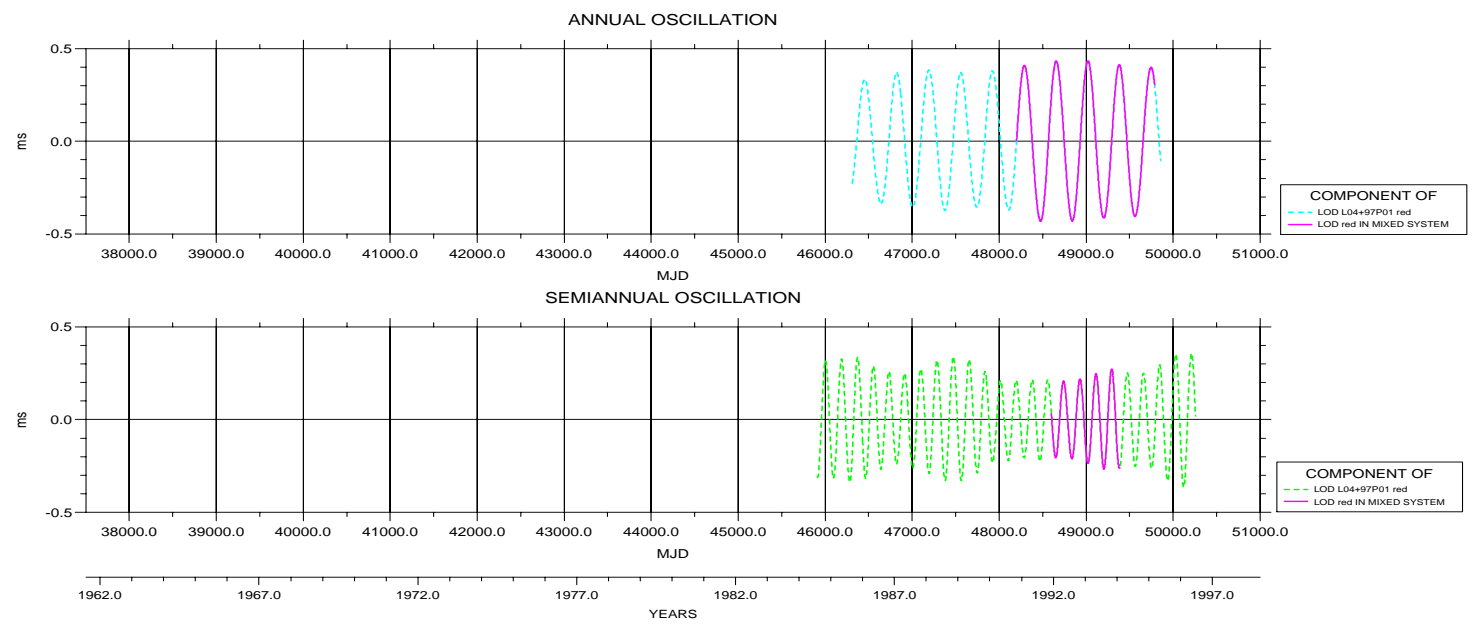

Figure 4. Same as Fig. 3, but for seasonal oscillations of the LOD variation as computed by the GFZ 

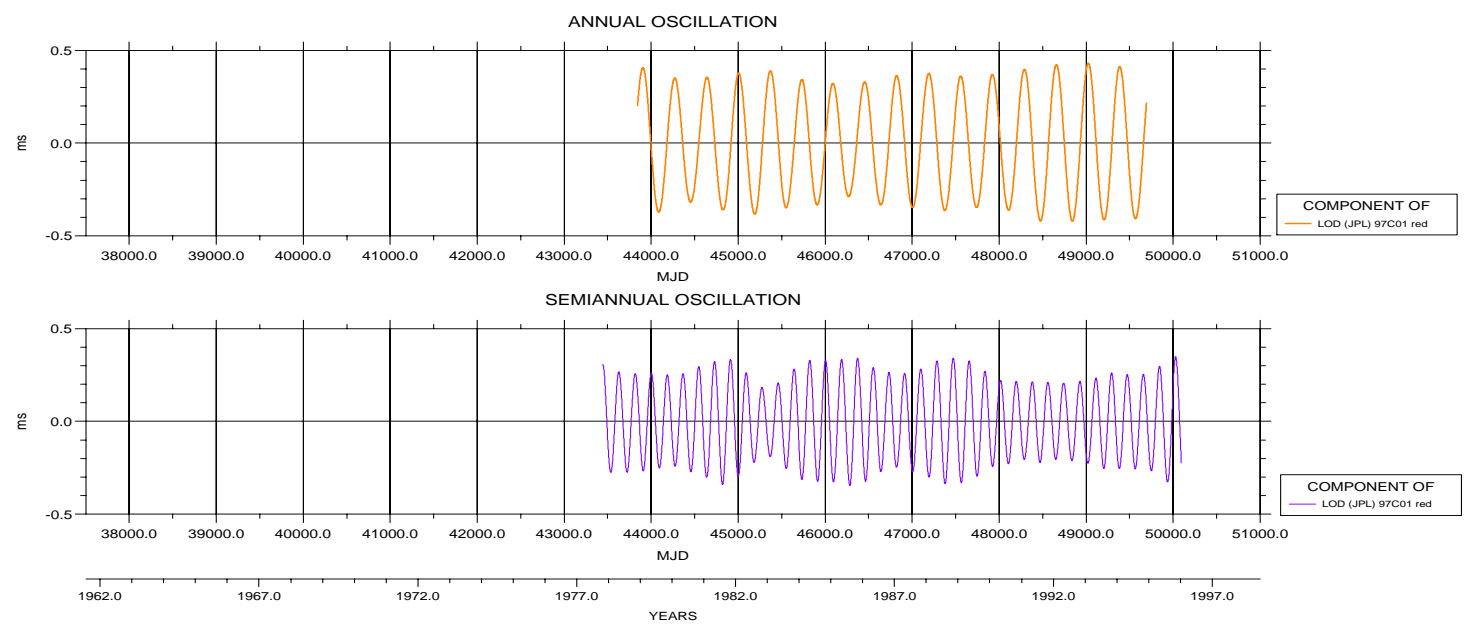

Figure 5. Same as Fig. 3, but for seasonal oscillations of the LOD variation as computed by the JPL

characteristics of the digital filters used at one-day intervals are summarized in Table 4. For more details on the filters, see Höpfner (1996, 1997).

Using the low-pass filter, we first filtered out the trends from the LOD series. As known from Section 3.1., there are these series and their trends plotted in Figure 1. For the time spans of the trends, see Table 5. Then, by interpolating linearly the difference between the values at the end of the trend series in the L04 system and at the beginning of that in the 97P01 system and adding this difference as a correction to the LOD series in the L04 system, i. e. MJD from 48844.5 to 48992.5 , we concatenated the two GFZ series of LOD. Here, therefore, the series in the L04 system was used from July 1, 1983 to January 5, 1993, i. e. MJD from 45516.5 to 48992.5 (compare with Table 1). Note that LOD computed by the GFZ stands for the total LOD series in this and the following sections.

In order to isolate the annual and semiannual oscillations in the LOD series, we applied the band-pass filters to the LOD data. For comparisons with the annual and semiannual oscillations of the LOD ${ }_{\mathrm{atm}}$, the annual and semiannual LOD oscillations should be corrected for the tidal effects Sa and Ssa. As pointed out in Section 3.1., the LOD data in the IERS system include all oscillations due to zonal tides, whereas those in the JPL system do not. Therefore, only after removing the tidal contribution from the LOD (IERS) data by adopting IERS Conventions (1996) according to Yoder

Table 5. Time spans of the main components filtered out from the LOD series given in calendar days and MJD

\begin{tabular}{|c|c|c|c|}
\hline Center / System & Trend & Annual oscillation & Semiannual oscillation \\
\hline IERS & $\begin{array}{c}\text { Jan. } 1963 \ldots \text { July } 1996 \\
38030.0 \ldots 50279.0\end{array}$ & $\begin{array}{c}\text { March } 1964 \ldots \text { May } 1995 \\
38459.0 \ldots 49850.0\end{array}$ & $\begin{array}{c}\text { Jan. } 1963 \ldots \text { June } 1996 \\
38058.0 \ldots 50251.0\end{array}$ \\
\hline GFZ, L04 system & $\begin{array}{c}\text { June } 1984 \ldots \text { Aug. } 1992 \\
45881.5 \ldots 48843.5\end{array}$ & $\begin{array}{c}\text { Sept. } 1985 \ldots \text { Nov. } 1990 \\
46310.5 \ldots 48198.5\end{array}$ & $\begin{array}{c}\text { July } 1984 \ldots \text { Dec. } 1991 \\
45909.5 \ldots 48599.5\end{array}$ \\
\hline mixed system & & $\begin{array}{c}\text { Nov. } 1990 \ldots \text {... March } 1995 \\
48199.5 \ldots 49786.5\end{array}$ & $\begin{array}{c}\text { Dec. } 1991 \ldots \text { Feb. } 1994 \\
48600.5 \ldots 49385.5\end{array}$ \\
\hline 97P01 system & $\begin{array}{c}\text { Jan. } 1994 \ldots \text { July } 1996 \\
49358.5 \ldots 50283.5\end{array}$ & $\begin{array}{c}\text { March } 1995 \ldots \text { May } 1995 \\
49787.5 \ldots 49854.5\end{array}$ & $\begin{array}{c}\text { Feb. } 1994 \ldots \text { June } 1996 \\
49386.5 \ldots 50255.5\end{array}$ \\
\hline JPL & $\begin{array}{c}\text { Sept. } 1977 \ldots \text { Feb. } 1996 \\
43414.0 \ldots 50122.0\end{array}$ & $\begin{array}{c}\text { Dec. } 1978 \ldots \text { Dec. } 1994 \\
43843.0 \ldots 49693.0\end{array}$ & $\begin{array}{c}\text { Oct. } 1977 \ldots \text {. Jan. } 1996 \\
43442.0 \ldots 50094.0\end{array}$ \\
\hline
\end{tabular}



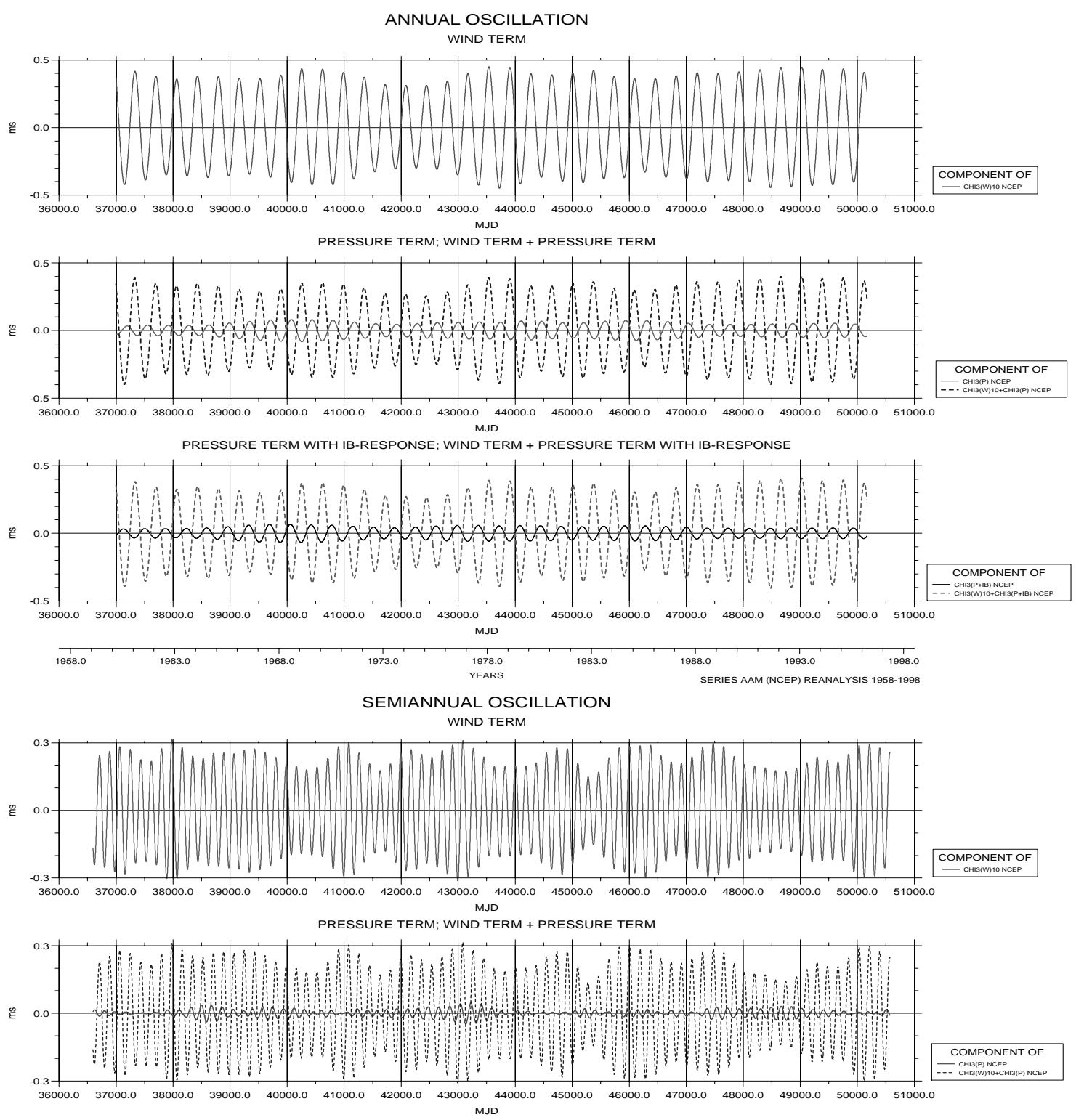

PRESSURE TERM WITH IB RESPONSE; WIND TERM + PRESSURE TERM WITH IB RESPONSE

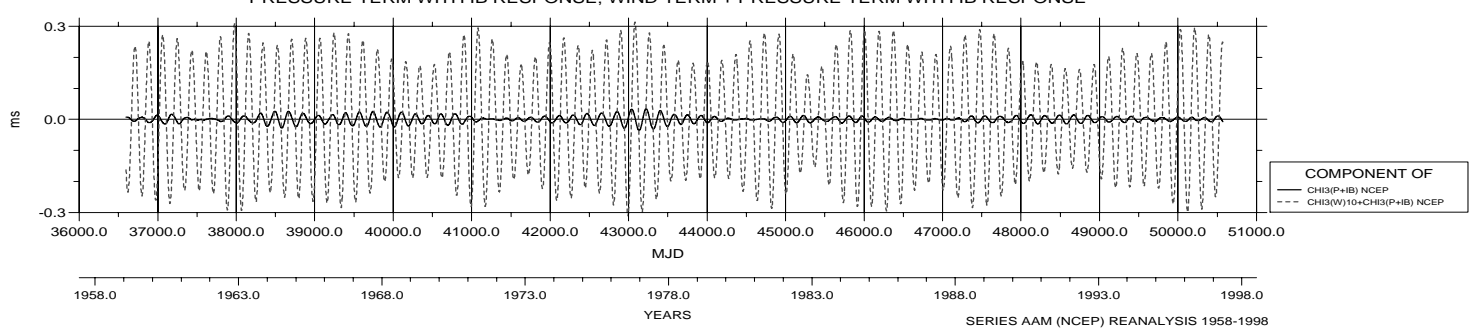

Figure 6. Seasonal oscillations of the LOD atm variations in the NCEP Reanalysis system. Upper part: Annual components. Lower part: Semiannual components. In either case, the ncomponent of the wind term $\chi_{3}(\mathrm{~W})$ (top), the components of the pressure term $\chi_{3}(\mathrm{P})$ and of the wind plus pressure term $\chi_{3}(\mathrm{~W})+\chi_{3}(\mathrm{P})$ (centre) and those of the pressure IB term $\chi_{3}(\mathrm{P}+\mathrm{IB})$ and of the wind plus pressure IB term $\chi_{3}(\mathrm{~W})+\chi_{3}(\mathrm{P}+\mathrm{IB})(\mathrm{bottom})$ are shown 
Publication: Scientific Technical Report

No.: STR98/10

Author: J. Höpfner

Table 6. Time spans of the main components filtered out from the $\mathrm{LOD}_{\mathrm{atm}}$ series given in calendar days and MJD

\begin{tabular}{lccc}
\hline Center / System & Trend & Annual oscillation & Semiannual oscillation \\
\hline NMC,100 hPa system & July $1977 \ldots$ Jan. 1980 & Sept. $1978 \ldots$ Oct. 1978 & July $1977 \ldots$ Dec. 1979 \\
& $43325.0 \ldots 44239.0$ & $43754.0 \ldots 43810.0$ & $43353.0 \ldots 44211.0$ \\
mixed system & Jan. $1980 \ldots$ Jan. 1982 & Oct. $1978 \ldots$ March 1983 & Dec. $1979 \ldots$ Jan. 1982 \\
& $44240.0 \ldots 44970.0$ & $43811.0 \ldots 45399.0$ & $44212.0 \ldots 44998.0$ \\
50 hPa system & Jan. $1982 \ldots$ Dec. 1994 & March $1983 \ldots$ Oct. 1993 & Jan. $1982 \ldots$ Dec. 1994 \\
& $44971.0 \ldots 49717.0$ & $45400.0 \ldots 49288.0$ & $44999.0 \ldots 49689.0$ \\
NCEP Reanalysis & & & \\
& Dec. $1968 \ldots$ June 1996 & March $1970 \ldots$ April 1995 & Jan. $1969 \ldots$ June 1996 \\
JMA & $40221.0 \ldots 50264.0$ & $40650.0 \ldots 49835.0$ & $40249.0 \ldots 50236.0$ \\
ECMWF & Sept. $1984 \ldots$ March 1996 & Nov. $1985 \ldots$ Jan. 1995 & Oct. $1984 \ldots$ March 1996 \\
& $45970 \ldots 50173.0$ & $46399.0 \ldots 49744.0$ & $45998.0 \ldots 50145.0$ \\
UKMO & Dec. $1988 \ldots$ July 1995 & March $1990 \ldots$ April 1994 & Jan. $1989 \ldots$ June 1995 \\
& $47526.0 \ldots 49899.0$ & $47955.0 \ldots 49470.0$ & $47554.0 \ldots 49871.0$ \\
& Nov. $1987 \ldots$ March 1996 & Jan. $1989 \ldots$ Jan. 1995 & Dec. $1987 \ldots$ March 1996 \\
\hline
\end{tabular}

et al. (1981) modified by the ocean effects derived from Dickman (1991), the resulting IERS data that are analogous to those of the JPL were filtered. Using the original LOD (GFZ) data as input data, the tidal effects Sa and Ssa still contribute to the seasonal oscillations of LOD in the GFZ system, for which reason these periodic components have been removed. Directly, the JPL results obtained by filtering of the original data are the seasonal oscillations without the tidal effects Sa and Ssa. See again Table 5, for the time spans of the periodic components filtered out. Also, note the time spans of the resulting GFZ series in the L04, a mixed and the 97P01 systems. Figure 3 shows the seasonal oscillations of the LOD variation in the IERS system. Here, the annual oscillation without the tidal effect Sa is plotted at the top and the semiannual oscillation without the tidal effect Ssa at the bottom. The same is shown in Figures 4 and 5, but for the seasonal oscillations of LOD in the GFZ and JPL systems, respectively. Especially in Figure 4, the curves are plotted for their three system-dependent intervals in conformity with Table 5.

In the same manner as for the LOD data, the $\mathrm{LOD}_{\text {atm }}$ series in the NCEP Reanalysis, JMA, ECMWF and UKMO systems, respectively, any of them including the wind term $\chi_{3}(\mathrm{~W})$, the pressure term $\chi_{3}(\mathrm{P})$ and, if calculated, the pressure IB term $\chi_{3}(\mathrm{P}+\mathrm{IB})$ data, were low-pass and band-pass filtered. For the time spans of the resulting series of the trend and the seasonal oscillations, see Table 6. Also given are the time intervals in the NMC system, including the model change on January 1, 1981 (MJD 44605) at the top level in the vertical of $100 \mathrm{hPa}$ to $50 \mathrm{hPa}$, concerning the data analyzed by Höpfner (1997). See again Section 3.2. Here, in Figure 2, the $\mathrm{LOD}_{\text {atm }}$ variation and its trend are shown by the example of the LOD atm series in the NCEP Reanalysis system in terms of the wind term $\chi_{3}(\mathrm{~W})$, the pressure term $\chi_{3}(\mathrm{P})$ and the pressure IB term $\chi_{3}(\mathrm{P}+\mathrm{IB})$. Figure 6 presents the annual and semiannual oscillations of the LOD atm variations in the same system. The annual components are shown in the upper part and the semiannual components in the lower part, with the component of the wind term $\chi_{3}(\mathrm{~W})$ plotted at the top, the components of the pressure term $\chi_{3}(\mathrm{P})$ and of the wind plus pressure term $\chi_{3}(\mathrm{~W})+\chi_{3}(\mathrm{P})$ at the centre and the components of the pressure IB term $\chi_{3}(\mathrm{P}+\mathrm{IB})$ and of the wind plus pressure IB term $\chi_{3}(\mathrm{~W})+\chi_{3}(\mathrm{P}+\mathrm{IB})$ at the bottom, respectively. For the LOD atm variations in the systems of NMC, JMA, ECMWF and UKMO, the seasonal oscillations are not shown here. But, those of the NMC and JMA systems can be found in Höpfner (1997).

The following points should be noted:

(1) The seasonal signals of LOD and $\mathrm{LOD}_{\mathrm{atm}}$ are quasi-periodic and vary with time (see Figures 3 to 6). To quantify their temporal changes, we should optimally estimate the three parameters amplitude, period and phase of the oscillations.

(2) All the LOD and LOD atm components that are comparable with each other are very similar on the same, but relatively small scales. To make visible the small differences between them, we should compute the residuals as difference series. As discussed by Höpfner (1997), the total seasonal signals of $\mathrm{LOD}_{\mathrm{atm}}$, incorporating both wind and pressure terms, should better coincide with those of LOD corrected for the tidal effects Sa and Ssa.

\subsection{Calculating optimal estimates of the parameters of the seasonal oscillations}

The objective is to obtain an optimal estimate of the parameters of the seasonal oscillations filtered out from the different LOD and LOD ${ }_{\mathrm{atm}}$ series with time. This is achieved through a method described in Höpfner (1997). In particular, the procedure for deriving amplitude, period and phase changes is based on the maximum, zero passage and minimum of a periodic function. For information about the steps necessary to calculate the amplitude, period and phase-angle time 

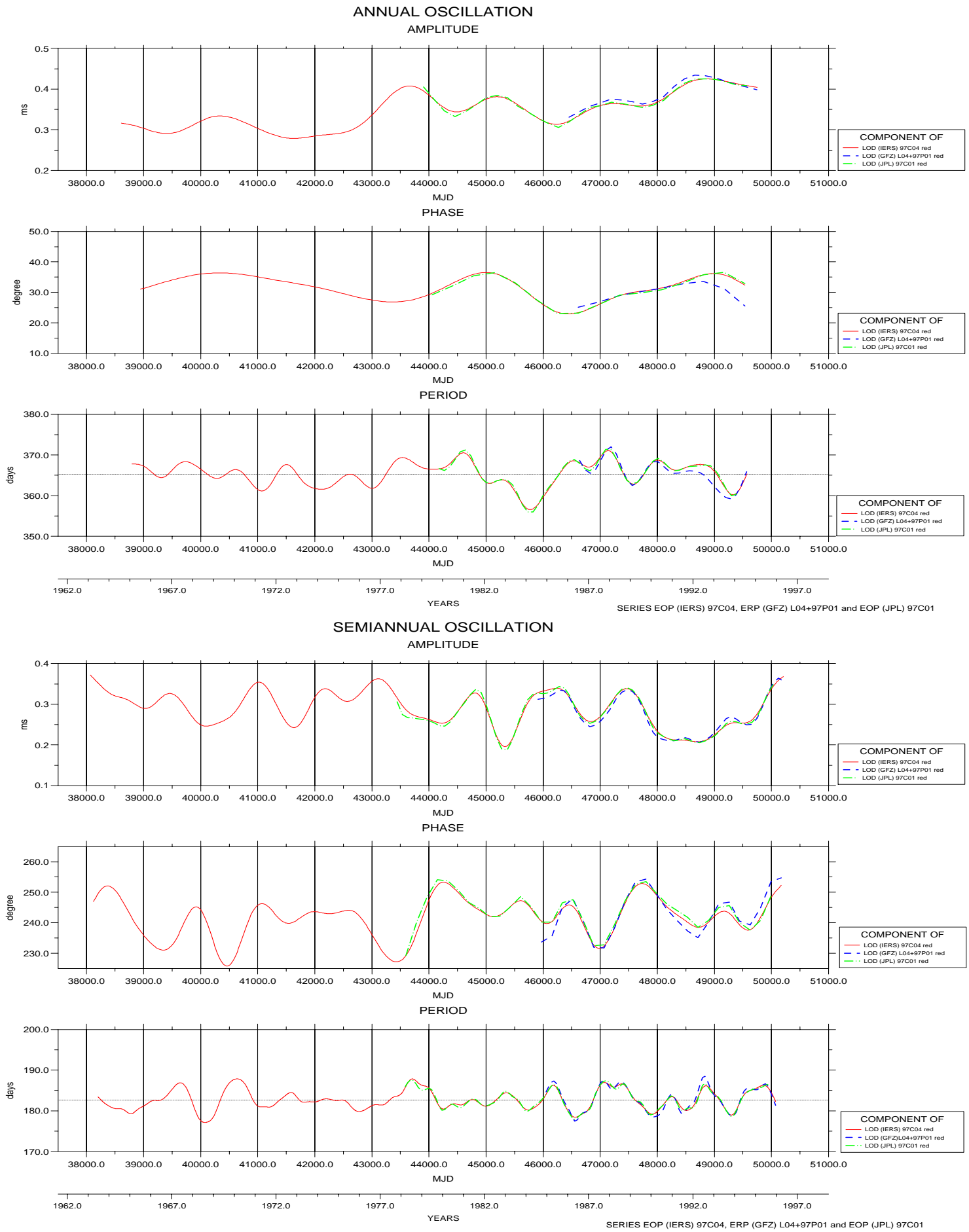

Figure 7. Parameter variability with time of the seasonal oscillations in LOD. Upper part: That of the annual oscillations. Lower part: That of the semiannual oscillations. In either case, amplitude (top), phase (centre) and period (bottom) variations in the IERS, GFZ and JPL systems are shown 

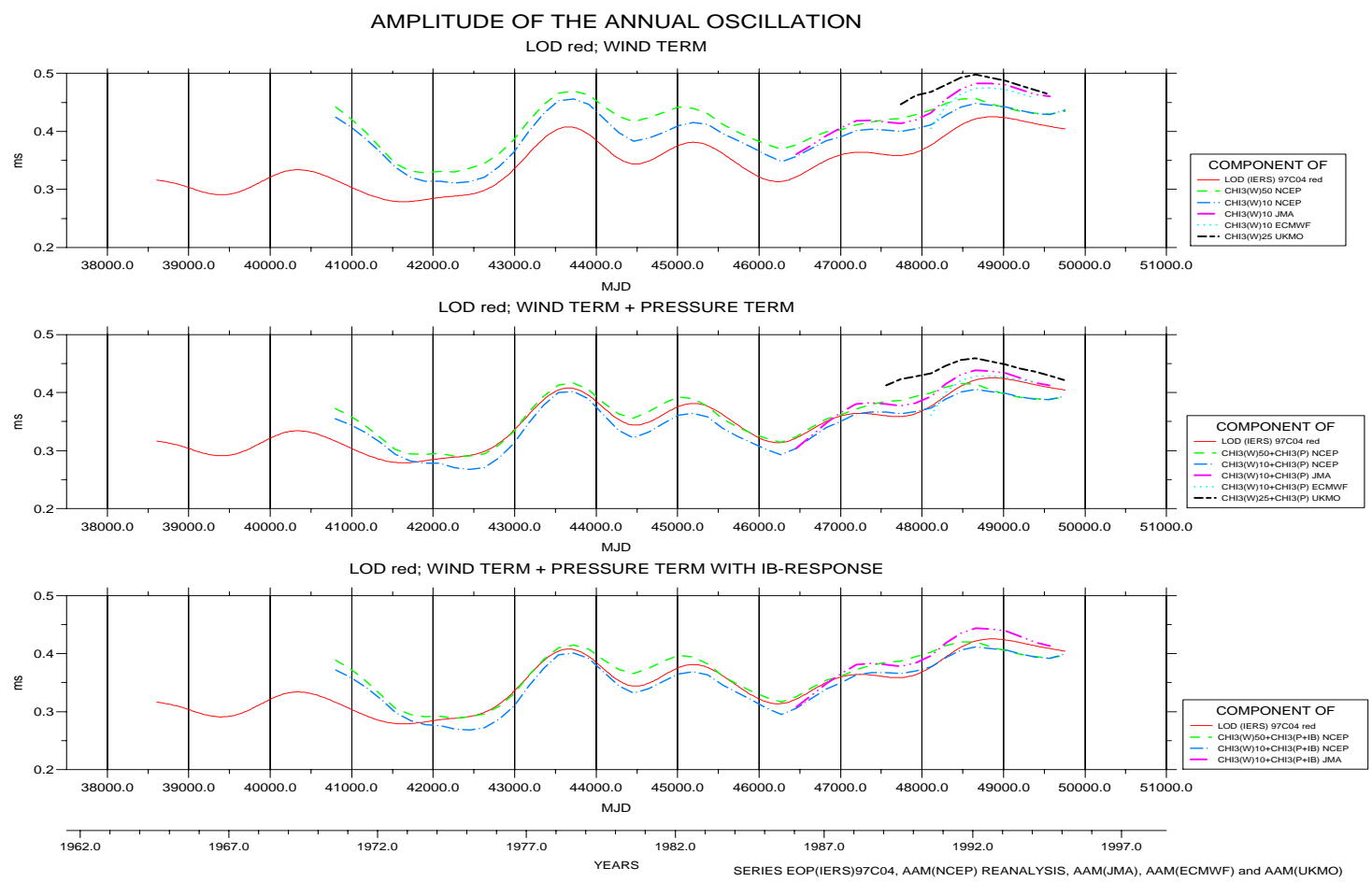

AMPLITUDE OF THE SEMIANNUAL OSCILLATION LOD red; WIND TERM

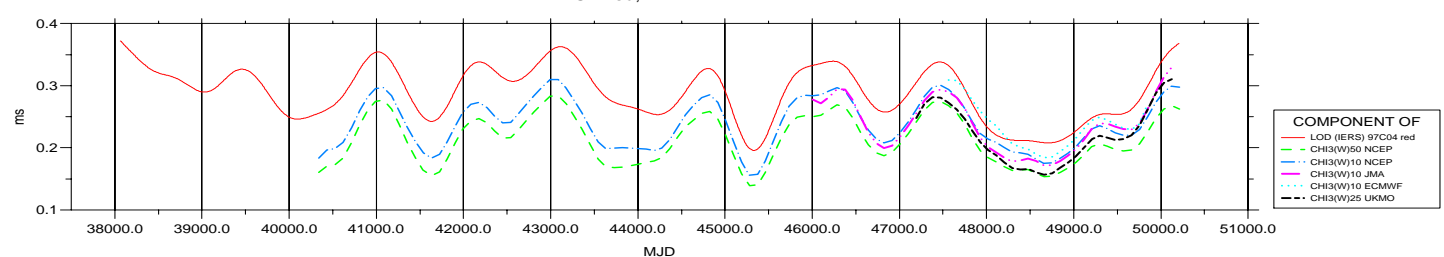

LOD red; WIND TERM + PRESSURE TERM

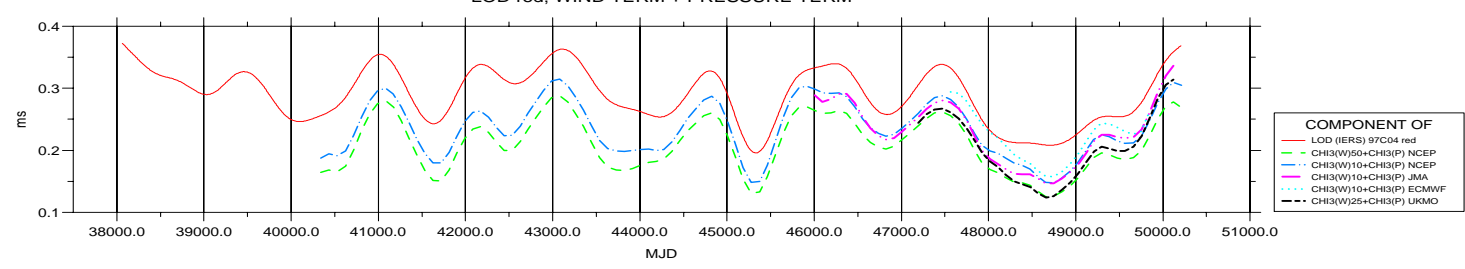

LOD red; WIND TERM + PRESSURE TERM WITH IB-RESPONSE

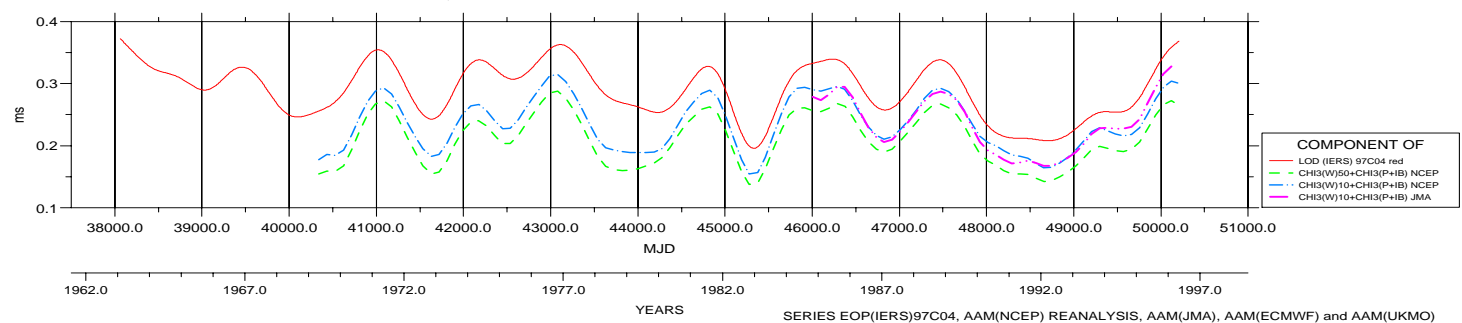

Figure 8. Amplitude variability with time of the seasonal oscillations in LODatm. Upper part: That of the annual components. Lower part: That of the semiannual components. In either case, the amplitude variations of the wind term $\chi_{3}(\mathrm{~W})$ (top), those of the wind plus pressure term $\chi_{3}(\mathrm{~W})+$ $\chi_{3}(\mathrm{P})$ (centre) and those of the wind plus pressure IB term $\chi_{3}(\mathrm{~W})+\chi_{3}(\mathrm{P}+\mathrm{IB})$ (bottom) in the NCEP Reanalysis, JMA, ECMWF and UKMO systems are shown 
Publication: Scientific Technical Report

No.: STR98/10
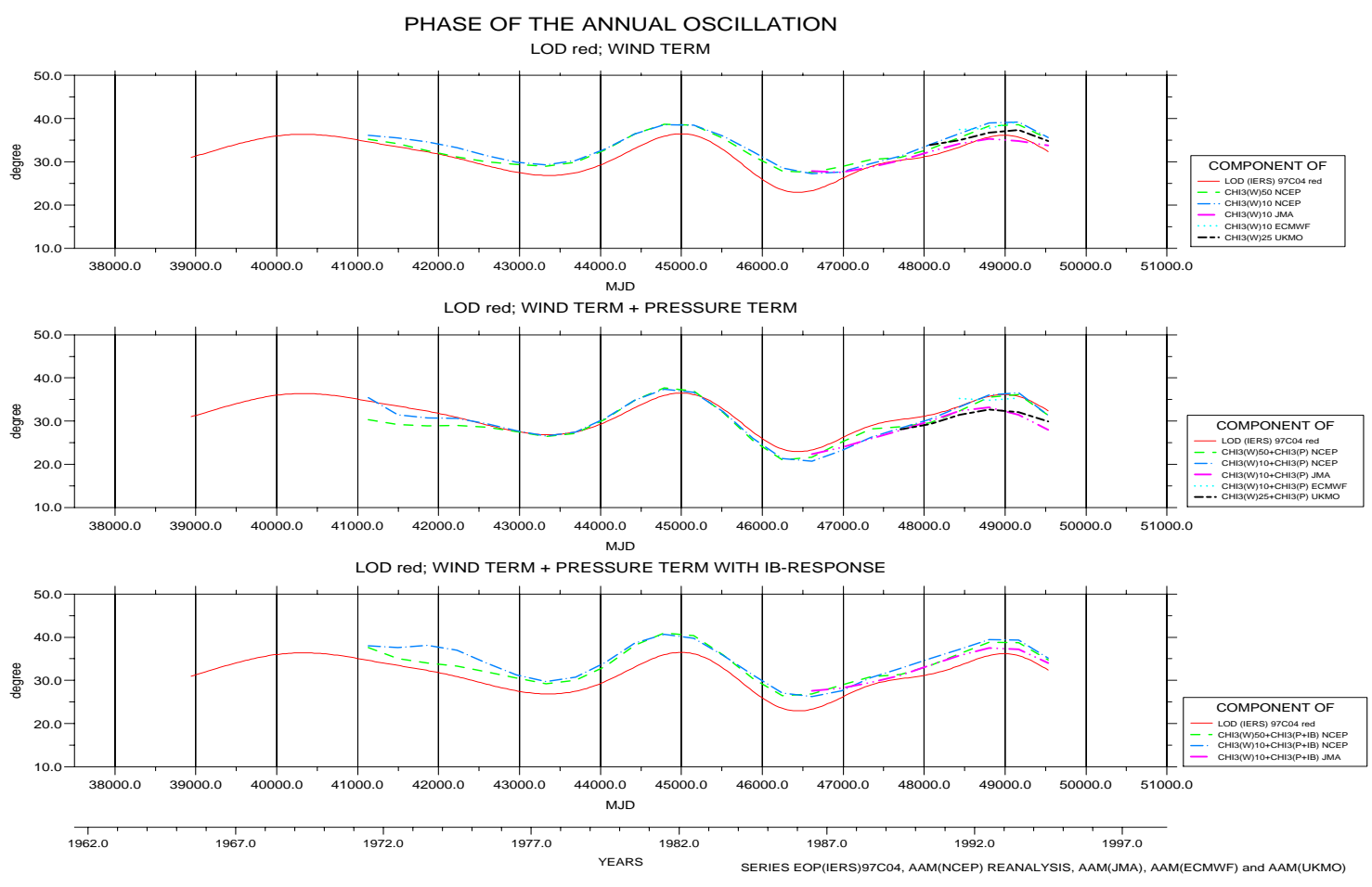

PHASE OF THE SEMIANNUAL OSCILLATION
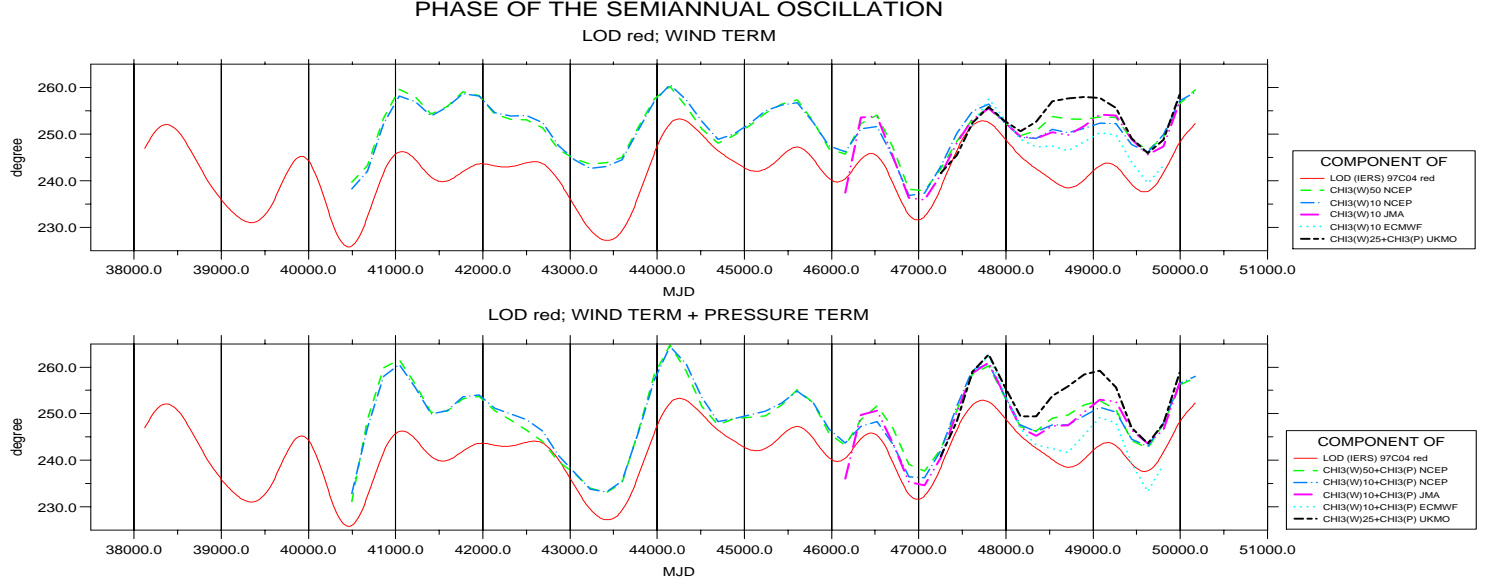

LOD red; WIND TERM + PRESSURE TERM WITH IB-RESPONSE

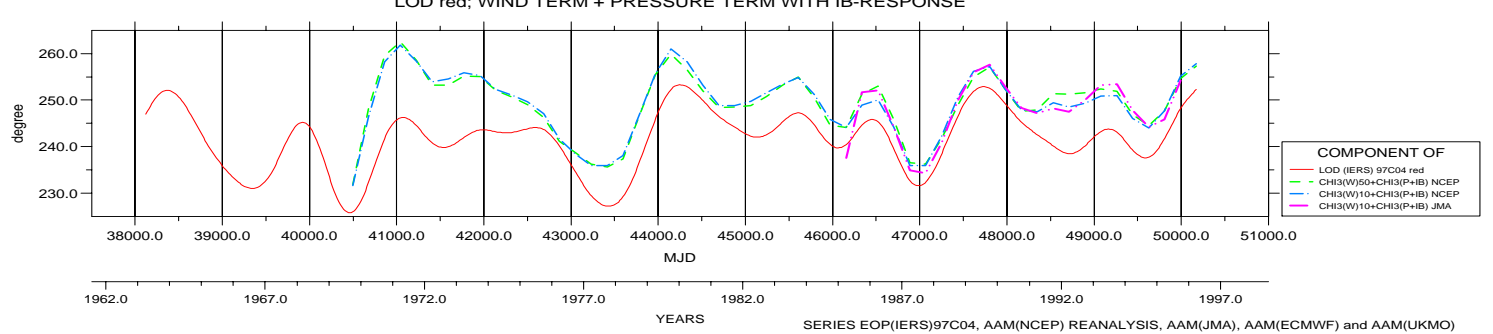

Figure 9. Same as Fig. 8, but for the phase variability 
Publication: Scientific Technical Report

No.: STR98/10
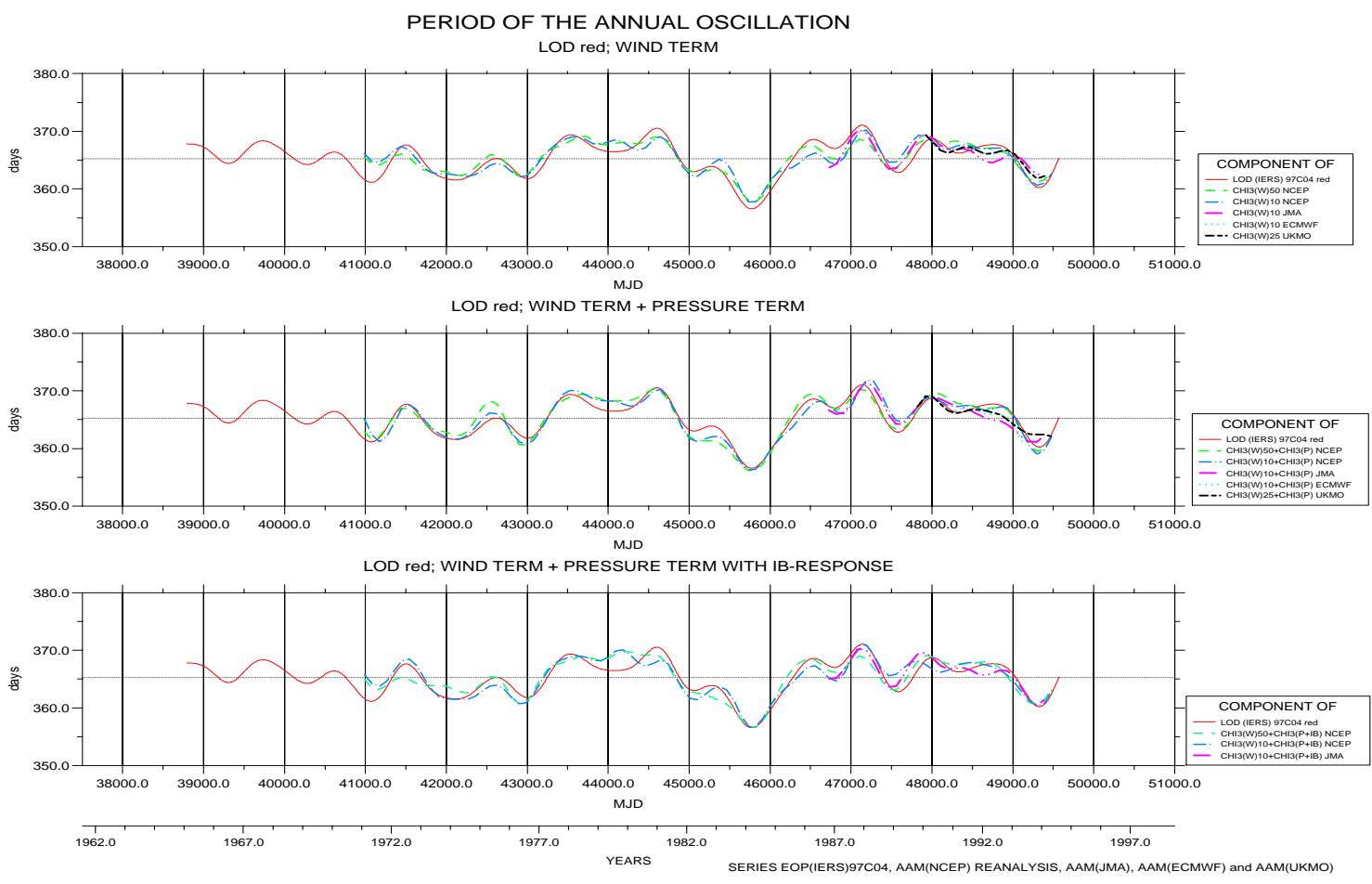

PERIOD OF THE SEMIANNUAL OSCILLATION
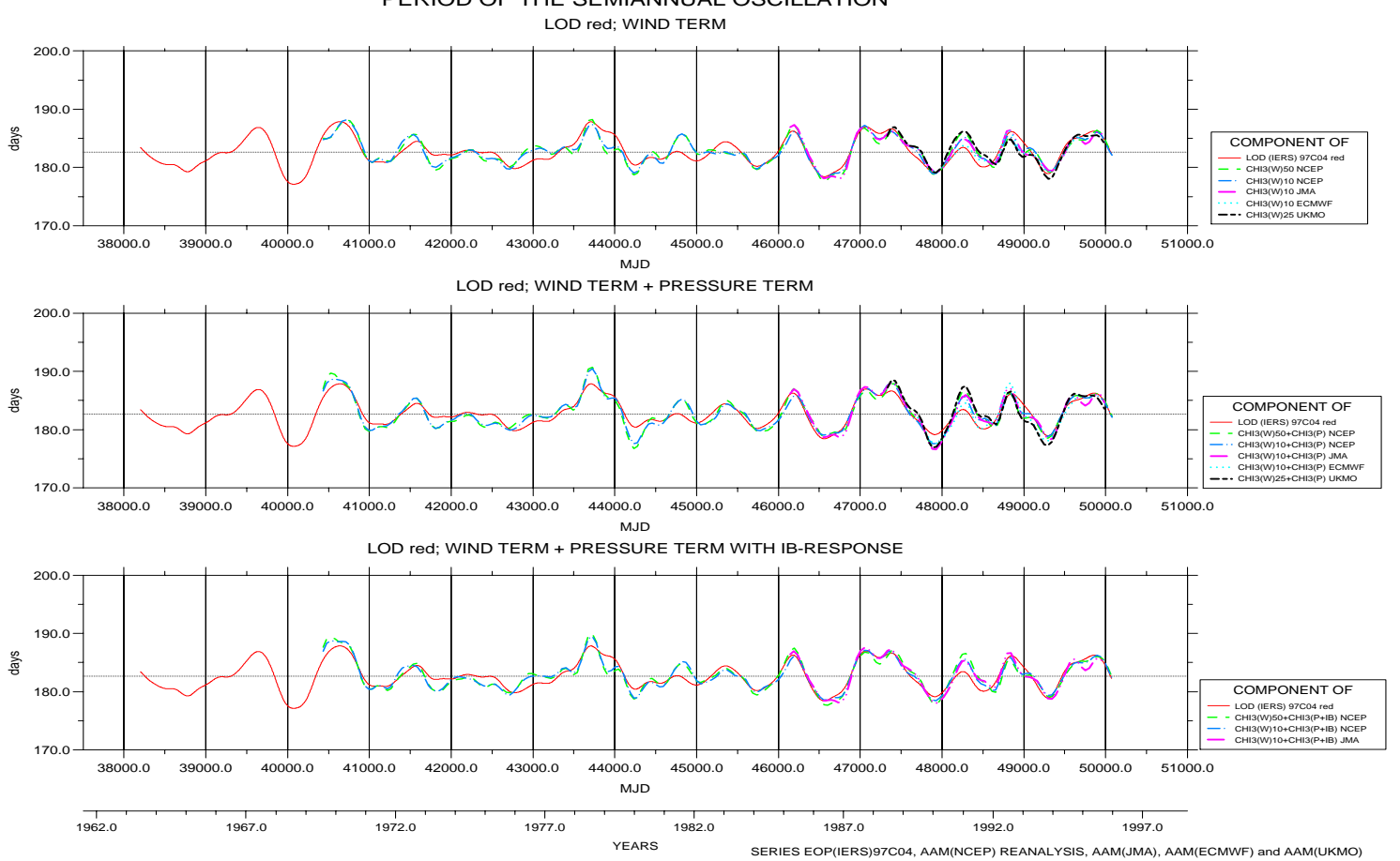

Figure 10. Same as Fig. 8, but for the period variability 
Table 7. Ranges of the seasonal LOD variations in amplitude, phase and period including the standard errors of the estimates. Min, minimum; Max, maximum; Dif, difference between maximum and minimum; $\mathrm{s}_{0}$, standard error of a single estimate; $\mathrm{s}_{\text {amplitude }}$, standard error of an amplitude mean; $\mathrm{s}_{\text {phase }}$, standard error of a phase mean; $\mathrm{s}_{\text {period }}$, standard error of a period three-point mean; $\mathrm{n}$, number of the pairs; in case of the period, number of the differences

\begin{tabular}{ccccccc}
\hline Center / System & \multicolumn{3}{c}{ Ranges of the variations } & \multicolumn{3}{c}{ Standard deviations } \\
& Min & Max & Dif & $\mathrm{s}_{0}$ & Smean & $\mathrm{n}$ \\
\hline
\end{tabular}

\begin{tabular}{|c|c|c|c|c|c|c|}
\hline \multicolumn{7}{|c|}{ (a) Annual oscillation } \\
\hline \multicolumn{7}{|c|}{ Amplitude estimates (in $\mathrm{ms}$ ); $\mathrm{s}_{\text {mean }}=\mathrm{s}_{\mathrm{amplitude}}$} \\
\hline IERS 97C04 & 0.270 & 0.429 & 0.159 & \pm 0.015 & \pm 0.010 & 31 \\
\hline GFZ L04+97P01 & 0.333 & 0.433 & 0.100 & \pm 0.010 & \pm 0.007 & 9 \\
\hline JPL 97 C01 & 0.289 & 0.429 & 0.141 & \pm 0.014 & \pm 0.010 & 16 \\
\hline \multicolumn{7}{|c|}{ Phase estimates (in degrees); $\mathrm{s}_{\text {mean }}=\mathrm{s}_{\mathrm{phase}}$} \\
\hline IERS 97C04 & 22.07 & 36.83 & 14.77 & \pm 2.34 & \pm 1.65 & 30 \\
\hline GFZ L04+97P01 & 25.10 & 33.58 & 8.48 & \pm 2.60 & \pm 1.84 & 9 \\
\hline JPL 97C01 & 22.29 & 36.67 & 14.38 & \pm 2.22 & \pm 1.57 & 16 \\
\hline \multicolumn{7}{|c|}{ Period estimates (in days); $\mathbf{s}_{\text {mean }}=\mathrm{s}_{\text {period }}$} \\
\hline IERS 97C04 & 356.06 & 371.79 & 15.73 & \pm 2.67 & \pm 1.54 & 60 \\
\hline GFZ L04+97P01 & 359.15 & 372.14 & 12.99 & \pm 3.02 & \pm 1.75 & 17 \\
\hline JPL 97C01 & 355.80 & 371.52 & 15.72 & \pm 2.41 & \pm 1.39 & 30 \\
\hline \multicolumn{7}{|c|}{ (b) Semiannual oscillation } \\
\hline \multicolumn{7}{|c|}{ Amplitude estimates (in $\mathrm{ms}$ ); $\mathrm{s}$ mean $=\mathrm{s}_{\text {amplitude }}$} \\
\hline IERS 97C04 & 0.180 & 0.374 & 0.194 & \pm 0.012 & \pm 0.008 & 67 \\
\hline GFZ L04+97P01 & 0.206 & 0.365 & 0.160 & \pm 0.011 & \pm 0.008 & 24 \\
\hline JPL 97C01 & 0.183 & 0.348 & 0.165 & \pm 0.014 & \pm 0.010 & 36 \\
\hline \multicolumn{7}{|c|}{ Phase estimates (in degrees); $\mathrm{s}_{\text {mean }}=\mathrm{s}_{\text {phase }}$} \\
\hline IERS 97C04 & 222.95 & 254.45 & 31.50 & \pm 2.19 & \pm 1.55 & 67 \\
\hline GFZ L04+97P01 & 231.05 & 254.95 & 23.91 & \pm 2.36 & \pm 1.67 & 24 \\
\hline JPL 97C01 & 229.42 & 255.28 & 25.87 & \pm 1.85 & \pm 1.31 & 36 \\
\hline \multicolumn{7}{|c|}{ Period estimates (in days) $; \mathrm{s}_{\text {mean }}=\mathrm{s}_{\text {period }}$} \\
\hline IERS 97C04 & 177.15 & 188.34 & 11.19 & \pm 1.09 & \pm 0.63 & 131 \\
\hline GFZ L04+97P01 & 177.34 & 188.71 & 11.38 & \pm 1.34 & \pm 0.77 & 45 \\
\hline JPL 97C01 & 177.87 & 187.54 & 9.68 & \pm 1.13 & \pm 0.65 & 71 \\
\hline
\end{tabular}

series including the standard deviations of the estimates, see the original paper (Höpfner 1997).

The mathematical expression used for representing the oscillations has the form $c \cos (2 \pi t / T-\alpha)$, where $c$ is the amplitude, $\alpha$ the phase and $T$ the period.

Using the procedure developed for deriving amplitude, period and phase changes, the seasonal oscillations of the LOD data in the IERS, GFZ and JPL systems were processed. In Figure 7, the results obtained for the annual oscillations are illustrated in the upper part and those obtained for the semiannual oscillations in the lower part, with the variations in amplitude plotted at the top, those in phase at the centre and those in period at the bottom, respectively. For the phase, the changes have a reference baseline of 365.25 days for the annual components and 182.625 days for the semiannual components. Each panel shows three curves, namely for the systems of IERS, GFZ and JPL. They are smoothed with a 5-point average.

In the same manner to the seasonal periodic LOD components, those of the LOD atm were processed with respect to the amplitude, phase and period variations. Figures 8 to 10 present the results for the NCEP Reanalysis, JMA, ECMWF and UKMO systems. Here, the curves show the estimates after application of a 5-point smoothing procedure. Similar to Figure 7, the upper part gives the results at the annual period and the lower part those at the semiannual period. In particular, Figure 8 show the amplitude variability with time in the seasonal oscillations of LOD atm, Figure 9 the variability in phase and Figure 10 that in period. In each figure, the curves of the wind term $\chi_{3}(\mathrm{~W})$ are shown in the top panels, those of the wind plus pressure term $\chi_{3}(\mathrm{~W})+\chi_{3}(\mathrm{P})$ in the middle panels and those of the wind plus pressure IB term $\chi_{3}(\mathrm{~W})+\chi_{3}(\mathrm{P}+\mathrm{IB})$ in the bottom panels. For purposes of comparison, the LOD results in one system, namely 
Table 8. Ranges of the seasonal $\mathrm{LOD}_{\text {atm }}$ variations in amplitude, phase and period including the standard errors of the estimates. Min, minimum; Max, maximum; Dif, difference between maximum and minimum; $s_{0}$, standard error of a single estimate; $s_{\text {amplitude }}$, standard error of an amplitude mean; $s_{\text {phase }}$, standard error of a phase mean; $s_{\text {period }}$, standard error of a period three-point mean; $n$, number of the pairs; in case of the period, number of the differences

\begin{tabular}{|c|c|c|c|c|c|c|}
\hline \multirow{2}{*}{$\begin{array}{l}\text { Center / System } \\
\text { Component }\end{array}$} & \multicolumn{3}{|c|}{ Ranges of the variations } & \multicolumn{2}{|c|}{ Standard deviations } & \multirow[b]{2}{*}{$\mathrm{n}$} \\
\hline & Min & Max & Dif & $\mathrm{s}_{0}$ & Smean & \\
\hline \multicolumn{7}{|l|}{ (a) Annual oscillation } \\
\hline \multicolumn{7}{|c|}{ Amplitude estimates (in ms); $\mathrm{s}_{\text {mean }}=\mathrm{s}_{\text {amplitude }}$} \\
\hline NCEP Wind $(50 \mathrm{hPa})$ & 0.324 & 0.469 & 0.146 & \pm 0.012 & \pm 0.008 & 25 \\
\hline+ Pressure & 0.283 & 0.420 & 0.138 & \pm 0.012 & \pm 0.009 & 25 \\
\hline + Pressure + IB & 0.282 & 0.423 & 0.141 & \pm 0.012 & \pm 0.008 & 25 \\
\hline NCEP Wind (10 hPa) & 0.306 & 0.456 & 0.150 & \pm 0.014 & \pm 0.010 & 25 \\
\hline + Pressure & 0.258 & 0.407 & 0.149 & \pm 0.014 & \pm 0.010 & 25 \\
\hline + Pressure + IB & 0.264 & 0.413 & 0.149 & \pm 0.013 & \pm 0.010 & 25 \\
\hline JMA Wind $(10 \mathrm{hPa})$ & 0.361 & 0.488 & 0.127 & \pm 0.009 & \pm 0.006 & 9 \\
\hline+ Pressure & 0.305 & 0.441 & 0.136 & \pm 0.010 & \pm 0.007 & 9 \\
\hline+ Pressure + IB & 0.309 & 0.447 & 0.138 & \pm 0.010 & \pm 0.007 & 9 \\
\hline ECMWF Wind $(10 \mathrm{hPa})$ & 0.406 & 0.480 & 0.074 & \pm 0.014 & \pm 0.010 & 4 \\
\hline+ Pressure & 0.361 & 0.435 & 0.074 & \pm 0.014 & \pm 0.010 & 4 \\
\hline UKMO Wind (about $25 \mathrm{hPa}$ ) & 0.445 & 0.498 & 0.053 & \pm 0.011 & \pm 0.008 & 5 \\
\hline+ Pressure & 0.414 & 0.463 & 0.049 & \pm 0.009 & \pm 0.007 & 6 \\
\hline \multicolumn{7}{|c|}{ Phase estimates (in degrees); $\mathrm{S}_{\text {mean }}=\mathrm{s}_{\text {phase }}$} \\
\hline NCEP Wind $(50 \mathrm{hPa})$ & 27.31 & 41.48 & 14.17 & \pm 1.65 & \pm 1.16 & 24 \\
\hline+ Pressure & 21.20 & 40.60 & 19.41 & \pm 2.37 & \pm 1.68 & 24 \\
\hline+ Pressure + IB & 26.18 & 42.93 & 16.74 & \pm 1.90 & \pm 1.34 & 24 \\
\hline NCEP Wind $(10 \mathrm{hPa})$ & 26.96 & 41.43 & 14.46 & \pm 1.66 & \pm 1.18 & 24 \\
\hline+ Pressure & 20.68 & 40.78 & 20.10 & \pm 2.23 & \pm 1.58 & 24 \\
\hline+ Pressure + IB & 25.90 & 42.88 & 16.99 & \pm 2.12 & \pm 1.50 & 24 \\
\hline JMA Wind (10 hPa) & 27.63 & 35.29 & 7.66 & \pm 1.69 & \pm 1.19 & 9 \\
\hline+ Pressure & 22.40 & 33.57 & 11.18 & \pm 2.08 & \pm 1.47 & 9 \\
\hline + Pressure + IB & 27.54 & 37.37 & 9.84 & \pm 1.02 & \pm 0.72 & 9 \\
\hline ECMWF Wind $(10 \mathrm{hPa})$ & 37.45 & 39.29 & 1.84 & \pm 1.04 & \pm 0.74 & 3 \\
\hline + Pressure & 34.54 & 35.33 & 0.48 & \pm 1.83 & \pm 1.29 & 3 \\
\hline UKMO Wind (about $25 \mathrm{hPa}$ ) & 33.88 & 37.33 & 3.45 & \pm 1.04 & \pm 0.74 & 5 \\
\hline+ Pressure & 28.06 & 32.86 & 4.80 & \pm 2.13 & \pm 1.51 & 6 \\
\hline \multicolumn{7}{|c|}{ Period estimates (in days) $; \mathrm{s}_{\text {mean }}=\mathrm{s}_{\mathrm{period}}$} \\
\hline NCEP Wind $(50 \mathrm{hPa})$ & 358.34 & 371.14 & 12.80 & \pm 1.76 & \pm 1.01 & 48 \\
\hline + Pressure & 355.97 & 372.35 & 16.38 & \pm 2.11 & \pm 1.22 & 48 \\
\hline + Pressure + IB & 357.03 & 372.03 & 15.00 & \pm 2.01 & \pm 1.16 & 48 \\
\hline NCEP Wind $(10 \mathrm{hPa})$ & 357.63 & 370.27 & 12.65 & \pm 2.00 & \pm 1.15 & 48 \\
\hline+ Pressure & 356.26 & 371.95 & 15.69 & \pm 2.45 & \pm 1.41 & 48 \\
\hline + Pressure + IB & 356.62 & 371.10 & 14.48 & \pm 2.29 & \pm 1.32 & 48 \\
\hline JMA Wind (10 hPa) & 362.38 & 370.47 & 8.09 & \pm 2.16 & \pm 1.25 & 16 \\
\hline+ Pressure & 361.11 & 371.53 & 10.42 & \pm 2.38 & \pm 1.38 & 16 \\
\hline+ Pressure + IB & 360.41 & 370.41 & 10.00 & \pm 1.98 & \pm 1.14 & 16 \\
\hline ECMWF Wind $(10 \mathrm{hPa})$ & 363.61 & 367.22 & 3.60 & \pm 1.61 & \pm 0.93 & 6 \\
\hline+ Pressure & 361.24 & 366.97 & 5.73 & \pm 2.23 & \pm 1.29 & 6 \\
\hline UKMO Wind (about $25 \mathrm{hPa}$ ) & 361.79 & 369.32 & 7.53 & \pm 1.40 & \pm 0.81 & 9 \\
\hline+ Pressure & 362.09 & 369.19 & 7.10 & \pm 2.23 & \pm 1.37 & 10 \\
\hline
\end{tabular}

those in the IERS system, are also displayed. As in the previous figures, the results are depicted on the same time scale. Note that the number added to each $\chi_{3}(\mathrm{~W})$ in the figures is to reflect the upper level in the atmosphere in $\mathrm{hPa}$ used in calculating the values. Thus, the NCEP Reanalysis results refer to two types including the atmosphere from the surface up to the $50 \mathrm{hPa}$ and $10 \mathrm{hPa}$ level, respectively, in the vertical for computing the wind term $\chi_{3}(\mathrm{~W})$. This is done to assess better the impact of winds in the $50-10 \mathrm{hPa}$ atmospheric layer to seasonal oscillations in LOD.

Table 7 gives a summary of the range of the variations of the parameters amplitude, phase and period for the annual

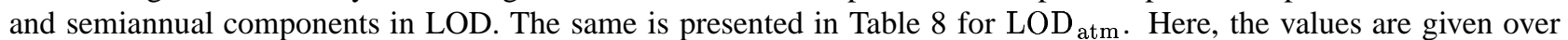
the time spans as listed in Tables 5 and 6, respectively. Also, the standard errors of the estimates and means computed from double measurements are included in both tables. As mentioned above, see Höpfner (1997) for details of their calculation.

In Section 5, we compare and discuss the LOD and LOD atm results referred to the different systems. For this purpose, we also form and display the difference series between the components of LOD on the one side and LOD atm on the other side. 
Publication: Scientific Technical Report

No.: STR98/10

Author: J. Höpfner

Table 8. Continued

\begin{tabular}{|c|c|c|c|c|c|c|}
\hline \multirow{2}{*}{$\begin{array}{l}\text { Center / System } \\
\text { Component }\end{array}$} & \multicolumn{3}{|c|}{ Ranges of the variations } & \multicolumn{2}{|c|}{ Standard deviations } & \multirow[b]{2}{*}{$\mathrm{n}$} \\
\hline & Min & $\operatorname{Max}$ & Dif & $\mathrm{s}_{0}$ & $\mathrm{~S}_{\text {mean }}$ & \\
\hline \multicolumn{7}{|c|}{ (b) Semiannual oscillation } \\
\hline \multicolumn{7}{|c|}{ Amplitude estimates (in $\mathrm{ms}$ ); $\mathrm{s}_{\text {mean }}=\mathrm{s}_{\text {amplitude }}$} \\
\hline NCEP Wind $(50 \mathrm{hPa})$ & 0.120 & 0.294 & 0.174 & \pm 0.017 & \pm 0.012 & 54 \\
\hline+ Pressure & 0.100 & 0.287 & 0.187 & \pm 0.016 & \pm 0.012 & 54 \\
\hline + Pressure + IB & 0.117 & 0.290 & 0.173 & \pm 0.016 & \pm 0.011 & 54 \\
\hline NCEP Wind (10 hPa) & 0.136 & 0.318 & 0.182 & \pm 0.017 & \pm 0.012 & 54 \\
\hline+ Pressure & 0.121 & 0.314 & 0.193 & \pm 0.016 & \pm 0.012 & 54 \\
\hline+ Pressure + IB & 0.136 & 0.315 & 0.179 & \pm 0.016 & \pm 0.011 & 54 \\
\hline JMA Wind (10 hPa) & 0.146 & 0.313 & 0.167 & \pm 0.011 & \pm 0.008 & 23 \\
\hline+ Pressure & 0.124 & 0.325 & 0.201 & \pm 0.011 & \pm 0.008 & 23 \\
\hline + Pressure + IB & 0.144 & 0.316 & 0.173 & \pm 0.011 & \pm 0.008 & 23 \\
\hline ECMWF Wind (10 hPa) & 0.183 & 0.312 & 0.129 & \pm 0.010 & \pm 0.007 & 13 \\
\hline + Pressure & 0.157 & 0.295 & 0.138 & \pm 0.010 & \pm 0.007 & 13 \\
\hline UKMO Wind (about $25 \mathrm{hPa}$ ) & 0.155 & 0.311 & 0.156 & \pm 0.010 & \pm 0.007 & 16 \\
\hline+ Pressure & 0.123 & 0.314 & 0.191 & \pm 0.011 & \pm 0.008 & 16 \\
\hline \multicolumn{7}{|c|}{ Phase estimates (in degrees) $; \mathrm{s}_{\text {mean }}=\mathrm{s}_{\text {phase }}$} \\
\hline NCEP Wind $(50 \mathrm{hPa})$ & 235.87 & 260.85 & 24.98 & \pm 2.96 & \pm 2.09 & 54 \\
\hline+ Pressure & 231.10 & 264.35 & 33.25 & \pm 3.51 & \pm 2.49 & 54 \\
\hline + Pressure + IB & 231.82 & 263.79 & 31.98 & \pm 3.11 & \pm 2.20 & 54 \\
\hline NCEP Wind $(10 \mathrm{hPa})$ & 235.92 & 261.68 & 25.75 & \pm 2.68 & \pm 1.90 & 54 \\
\hline+ Pressure & 233.12 & 265.17 & 32.05 & \pm 3.09 & \pm 2.18 & 54 \\
\hline+ Pressure + IB & 231.66 & 263.34 & 31.67 & \pm 2.70 & \pm 1.91 & 54 \\
\hline JMA Wind $(10 \mathrm{hPa})$ & 233.70 & 257.98 & 24.28 & \pm 2.62 & \pm 1.85 & 22 \\
\hline+ Pressure & 232.89 & 261.78 & 28.88 & \pm 2.74 & \pm 1.94 & 22 \\
\hline+ Pressure + IB & 232.83 & 260.95 & 28.12 & \pm 2.36 & \pm 1.67 & 22 \\
\hline ECMWF Wind (10 hPa) & 238.97 & 257.66 & 18.69 & \pm 1.81 & \pm 1.28 & 13 \\
\hline+ Pressure & 232.79 & 262.63 & 29.83 & \pm 2.82 & \pm 2.00 & 13 \\
\hline UKMO Wind (about $25 \mathrm{hPa}$ ) & 241.78 & 259.07 & 17.29 & \pm 2.44 & \pm 1.72 & 16 \\
\hline+ Pressure & 241.04 & 263.58 & 22.55 & \pm 2.31 & \pm 2.00 & 13 \\
\hline \multicolumn{7}{|c|}{ Period estimates (in days) $; \mathbf{s}_{\text {mean }}=\mathbf{s}_{\text {period }}$} \\
\hline NCEP Wind $(50 \mathrm{hPa})$ & 175.44 & 191.62 & 16.19 & \pm 2.65 & \pm 1.53 & 107 \\
\hline + Pressure & 173.28 & 194.07 & 20.79 & \pm 2.66 & \pm 1.53 & 107 \\
\hline + Pressure + IB & 175.37 & 192.24 & 16.86 & \pm 2.58 & \pm 1.49 & 107 \\
\hline NCEP Wind $(10 \mathrm{hPa})$ & 175.98 & 189.90 & 13.92 & \pm 2.31 & \pm 1.33 & 107 \\
\hline+ Pressure & 174.40 & 192.00 & 17.60 & \pm 2.36 & \pm 1.36 & 107 \\
\hline + Pressure + IB & 176.65 & 191.40 & 14.75 & \pm 2.24 & \pm 1.29 & 107 \\
\hline JMA Wind (10 hPa) & 178.03 & 187.26 & 9.23 & \pm 1.09 & \pm 0.63 & 43 \\
\hline + Pressure & 176.63 & 188.18 & 11.55 & \pm 1.31 & \pm 0.76 & 43 \\
\hline + Pressure + IB & 178.02 & 187.57 & 9.55 & \pm 1.27 & \pm 0.73 & 43 \\
\hline ECMWF Wind $(10 \mathrm{hPa})$ & 179.19 & 186.37 & 7.18 & \pm 0.96 & \pm 0.56 & 23 \\
\hline+ Pressure & 177.54 & 188.20 & 10.66 & \pm 1.47 & \pm 0.85 & 23 \\
\hline UKMO Wind (about $25 \mathrm{hPa}$ ) & 177.97 & 186.97 & 9.00 & \pm 1.06 & \pm 0.61 & 30 \\
\hline+ Pressure & 176.86 & 188.47 & 11.61 & \pm 1.58 & \pm 0.91 & 30 \\
\hline
\end{tabular}

\section{Comparisons and discussion of the results}

To compare the seasonal oscillations of the LOD and $\mathrm{LOD}_{\mathrm{atm}}$ data in the different systems, it is appropriate that we first compute the seasonal residual oscillations in terms of the difference series between the seasonal oscillations in the LOD systems and those in the $\mathrm{LOD}_{a t m}$ systems, respectively, over common time intervals. Then, using the residual oscillations together with the variations in amplitude, phase and period of the oscillations filtered out from the time series, we can compare, discuss and assess the LOD and $\mathrm{LOD}_{\mathrm{atm}}$ results relating to the different systems more easily.

\subsection{LOD results}

As difference series between the LOD results in the IERS, GFZ and JPL systems, the seasonal residual oscillations between the different LOD systems are derived over common intervals given in Table 9. Figure 11 shows the seasonal residual oscillations between the different LOD systems. As in previous figures, the annual residual oscillations are displayed in the upper part and the semiannual residual oscillations in the lower part, with the top panel showing the component from IERS and JPL values, the middle panel that from IERS and GFZ values and the bottom panel that from JPL and GFZ values, respectively. Here, the curves of the difference series in the system of the IERS and GFZ and those in the system of the JPL and GFZ are illustrated for the three intervals with respect to the GFZ system (see Table 5).

A comparison of the LOD results illustrated in Figures 7 and 11 reveals the role of the systematic errors. For the ranges of the seasonal variations in amplitude, phase and period including the standard errors of the estimates, see Table 7 . We 

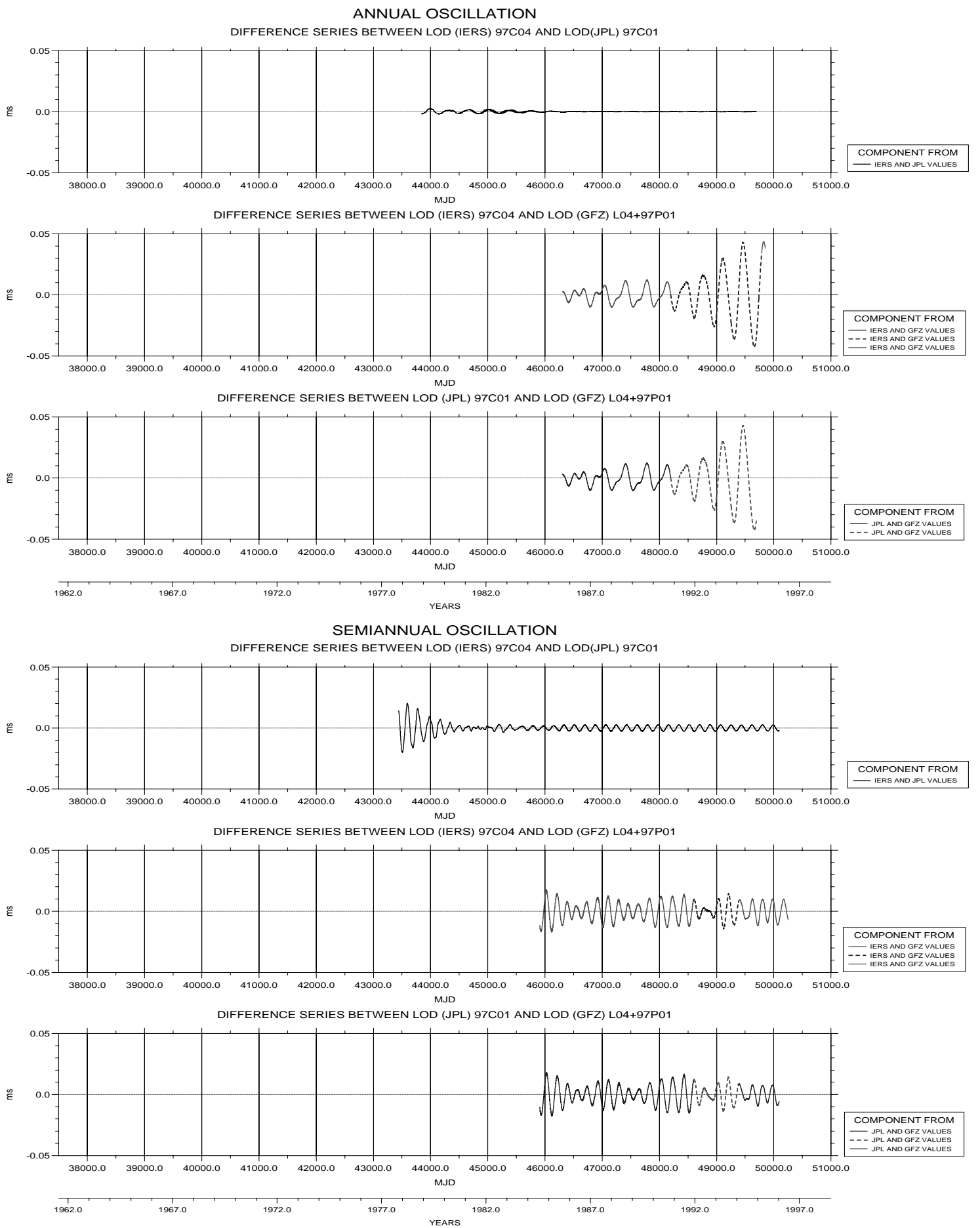

Figure 11. Seasonal residual oscillations between the different LOD systems, namely from IERS and JPL (top), IERS and GFZ (centre) and JPL and GFZ values (bottom). Oscillations at the annual frequency (upper part) and at the semiannual frequency (lower part) 
Publication: Scientific Technical Report

No.: STR98/10

Author: J. Höpfner

Table 9. Time spans of the seasonal residual oscillations derived as difference series between LOD results in the different systems given in calendar days and MJD. The time spans for the annual frequency are given on the left below and those for the semiannual frequency on the right above

\begin{tabular}{lccr}
\hline Center / System & IERS & GFZ & \multicolumn{1}{c}{ JPL } \\
\hline IERS & & July 1984 ... June 1996 & Oct. 1977 ... Jan. 1996 \\
& & $45909.0 \ldots 50251.0$ & $43442.0 \ldots 50094.0$ \\
GFZ & Sept. 1984 ... May 1995 & & July 1984 ... Jan. 1996 \\
& $46310.0 \ldots 49850.0$ & & $45909.0 \ldots 50094.0$ \\
JPL & Dec. $1978 \ldots$ Dec. 1994 & Sept. 1985 ... Dec. 1994 & \\
& $43843.0 \ldots 49693.0$ & $46310.0 \ldots 49693.0$ & \\
\hline
\end{tabular}

shall discuss separately the annual and semiannual oscillations referred to the different systems:

\section{(a) Annual LOD oscillations}

As the upper part of Figure 7 shows, there are similar variations with time in amplitude, phase and period of the annual oscillations of LOD in the IERS, GFZ and JPL systems. But, note in the top panel that the annual oscillation in the GFZ system is slightly larger than those in the IERS and JPL systems. Further, as can be seen in the middle and bottom panels, the phase and period curves in the GFZ system disagree with those in the other systems over the second half of the GFZ interval.

Concerning the differences between the systems, the upper part of Figure 11 shows to which extent small significant annual residual oscillations exist. According to the top panel, the difference series between the IERS and JPL values is small with an amplitude of just $0.002 \mathrm{~ms}$ over the first third of the common interval and only $0.0002 \mathrm{~ms}$ over the two other thirds of the interval. In contrast, the residual oscillation in the IERS-GFZ system is characterized by an amplitude growing steadily with time (see the middle panel). Note the same for the residual oscillation in the JPL-GFZ system in the bottom panel. Numerically, the amplitude is between $0.006 \mathrm{~ms}$ at the beginning and $0.042 \mathrm{~ms}$ at the end of both series.

Next, we compare the middle and bottom panels of the upper part of Figure 11: Since the residual oscillations computed from the values between the IERS and GFZ systems and those between the JPL and GFZ systems are similar in their variations with time, the obvious reason for this is the annual GFZ oscillation filtered out from the LOD series that comprises the two individual GFZ series (see Section 4.1.). Relating to the GFZ system-dependent intervals, we notice a systematic growth in amplitude over the interval of the mixed GFZ system. Possibly, this fact reflects an unmodelled part of the orbit node motion in deriving LOD data from GPS observations; see Section 3.1. and for more details the 1996 IERS Annual Report (IERS 1997) and the 1998 IERS Gazette, No 27 (IERS 1998).

(b) Semiannual LOD oscillations

The lower part of Figure 7 shows the variations with time in amplitude, phase and period of the semiannual oscillations of LOD in the IERS, GFZ and JPL systems. Generally, there is good agreement in the variability of the parameters. In the top panel, the amplitude in the JPL system is somewhat smaller than that in the IERS system at the beginning of the JPL interval. The same applies to the amplitude in the GFZ system, where a small systematic difference is present over two-thirds of the GFZ interval. In the middle panel, the phase curve in the GFZ system differs from those in the IERS and JPL systems at the beginning and during the interval of the mixed GFZ system. On the contrary, the period curves in the three systems agree with each other extremely well (see the bottom panel).

The lower part of Figure 11 shows that the difference series obtained from the semiannual oscillations between the different LOD systems are significant residual oscillations like those at the annual frequency. In the top panel, we see that the curve in the IERS-JPL system has an amplitude of about $0.020 \mathrm{~ms}$ at the beginning. There is an amplitude decrease by $0.018 \mathrm{~ms}$ over a relatively short time. After that, the oscillation varies with an amplitude value of about $0.002 \mathrm{~ms}$. Compared to the annual residual oscillation, the behaviour is analogous, but larger by an order of magnitude. The curve in the IERS-GFZ system plotted in the middle panel is rather similar to that in the JPL-GFZ system shown in the bottom panel. Note that there is a small beat effect in amplitude for both curves near $0.010 \mathrm{~ms}$. As for the annual oscillation, we should notice that the cause for it is the LOD series in the GFZ system, from which the semiannual GFZ oscillation is filtered out. Seasonal LOD amplitude variations are also shown in Gross et al. (1996). They agree well with our results at the semiannual frequency plotted at the top panel in the lower part of Figure 7.

Finally, it is necessary to judge the LOD results in the different systems. According to the seasonal residual oscillations between the IERS and JPL systems, we can say that the seasonal oscillations in the IERS and JPL systems over the common interval are of the same quality, except at the beginning of the JPL interval, where the uncertainty of the LOD series computed by the JPL is better (see Section 3.1. and for the uncertainties Table 2). Here, compared to the standard 
Publication: Scientific Technical Report

No.: STR98/10

Author: J. Höpfner

Table 10. Time spans of the seasonal residual oscillations derived as difference series between LOD atm results in the different systems given in calendar days and MJD. The time spans for the annual frequency are given on the left below and those for the semiannual frequency on the right above

\begin{tabular}{lccr}
\hline Center / System & NCEP Reanalysis & JMA & ECMWF \\
\hline NCEP Reanalysis & & Oct. 1984 .. March 1996 & Jan. 1989 ... June 1995 \\
& & $45998.0 \ldots 50145.0$ & $47554.0 \ldots 49871.0$ \\
JMA & Nov. 1985 ... Jan. 1995 & & Jan. 1989 ... June 1995 \\
& $46399.0 \ldots 49744.0$ & & $47554.0 \ldots 49871.0$ \\
ECMWF & March 1990 ... April 1994 & March 1990 ... April 1994 & \\
& $47955.0 \ldots 49470.0$ & $47955.0 \ldots 49470.0$ & \\
\hline
\end{tabular}

deviations of the parameter estimates of the oscillations given in Table 7, the systematic differences vary within the uncertainties calculated for the amplitude. Concerning the LOD results in the GFZ system, the systematic discrepancies to those in the IERS and JPL systems are visibly smaller over the interval of the old system than over the intervals of the mixed and new systems at the annual frequency. This differs from the behaviour at the semiannual frequency, where a small beat effect in amplitude over the total interval exists. Since the LOD (GFZ) series includes two independent solutions, it should be emphasized that the LOD results obtained from the LOD data in the old GFZ L04 system show clearly smaller systematic differences to the IERS and JPL oscillations on the annual scale (see Figure 11 and for the different systems and intervals Table 5).

\subsection{LOD atm results}

We formed the difference series between the seasonal LOD ${ }_{\text {atm }}$ oscillations in the NCEP Reanalysis, JMA and ECMWF systems over common intervals. Analogous to the seasonal residual oscillations between the different LOD systems, the resulting series are the seasonal residual oscillations between the different $\mathrm{LOD}_{\mathrm{atm}}$ systems. For their time spans see Table 10 .

The results are illustrated in Figures 12 to 14. Again as in the previous figures, the annual residual oscillations are displayed in the upper part and the semiannual ones in the lower part. In particular in Figure 12, each curve indicates the remaining discrepancies for the wind term $\chi_{3}(\mathrm{~W}) 10$ between the different LOD atm systems. Figure 13 shows the same as Figure 12, but for the pressure term $\chi_{3}(\mathrm{P})$. Also the same as Figure 12 displays Figures 14, but for the wind plus pressure terms $\chi_{3}(\mathrm{~W}) 10+\chi_{3}(\mathrm{P})$. Concerning the three panels in the upper and lower parts of the figures, the component from NCEP Reanalysis and JMA values is shown in the top panel, that from JMA and ECMWF values in the middle panel and that from NCEP Reanalysis and ECMWF values in the bottom panel. In case of the wind terms, as in previous figures, the added numbers are to reflect the top level in the atmosphere in hPa used in calculating the $\chi_{3}(\mathrm{~W})$ values. Regarding the inverted barometer response at both seasonal scales, see the curves at the annual frequency in the upper part and those at the semiannual frequency in the lower part of Figure 15, with, respectively, the IB oscillations in the NCEP system (top) and in the JMA system (centre) and the residual oscillations of the IB terms and of the wind plus pressure IB terms $\chi_{3}(\mathrm{~W}) 10+\chi_{3}(\mathrm{P}+\mathrm{IB})$ between both systems (bottom).

For comparisons of the $\mathrm{LOD}_{\mathrm{atm}}$ results, we use Figures 8 to 10 and Figures 12 to 15 . For the ranges of the seasonal variations in amplitude, phase and period including the standard errors of the estimates, see Table 8 . The following discussion will distinguish between the annual and semiannual oscillations relating to the different systems:

(a) Annual LOD atm oscillations

The variations with time in amplitude, phase and period of the annual oscillations of the wind terms $\chi_{3}(\mathrm{~W})$, the wind plus pressure terms $\chi_{3}(\mathrm{~W})+\chi_{3}(\mathrm{P})$ and the wind plus pressure IB terms $\chi_{3}(\mathrm{~W})+\chi_{3}(\mathrm{P}+\mathrm{IB})$ in the systems of NCEP Reanalysis, JMA, ECMWF and UKMO are shown in the upper parts of Figures 8, 9 and 10, respectively. Compared to the amplitude estimates of LOD, those of the wind terms $\chi_{3}(\mathrm{~W})$ are significantly larger by about $0.030 \mathrm{~ms}$. This does not apply to the amplitude estimates of the wind plus pressure terms $\chi_{3}(\mathrm{~W})+\chi_{3}(\mathrm{P})$ and of the wind plus pressure IB terms $\chi_{3}(\mathrm{~W})+\chi_{3}(\mathrm{P}+\mathrm{IB})$, except at the beginning of the NCEP interval. In case of the phase, there is a significant difference over two-thirds of the interval in the top and bottom panels, not but in the centre panel. In contrast to this, no obvious systematic differences exist for the period. We note that a pronounced parallelism of the amplitude, phase and period curves with time exists.

At the annual frequency, the systematic residual oscillations among the three $\mathrm{LOD}_{\text {atm }}$ systems having the top level of the atmosphere in the GCMs at $10 \mathrm{hPa}$ are shown in the upper part of Figures 12 to 15 . Here, the difference curve for the wind terms $\chi_{3}(\mathrm{~W}) 10$ referred to the NCEP Reanalysis and JMA systems has an amplitude between 0.015 and $0.050 \mathrm{~ms}$. In the JMA-ECMWF system, the remaining oscillation varies with an amplitude of 0.030 ms. Note the same 
ANNUAL OSCILLATION
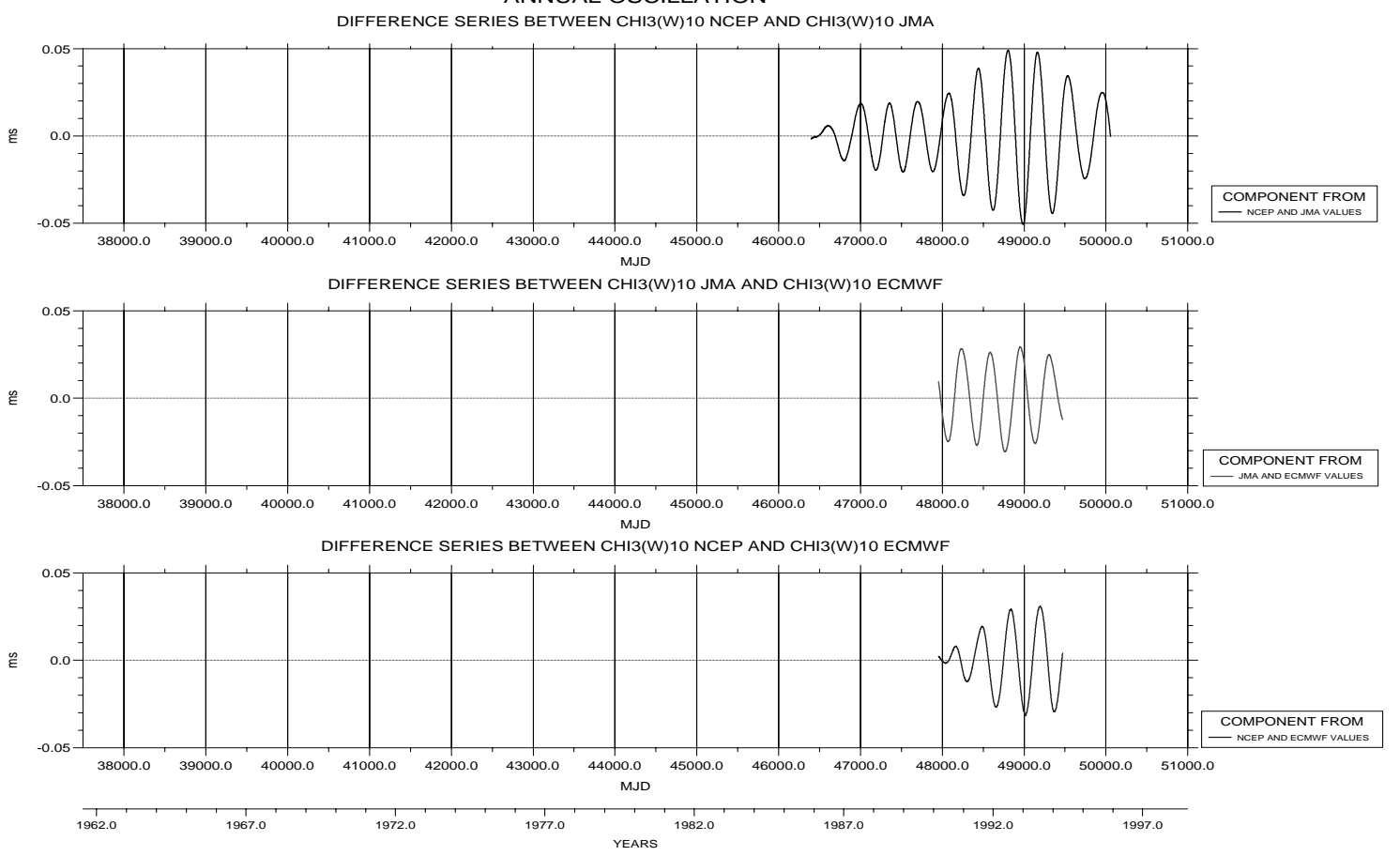

SEMIANNUAL OSCILLATION
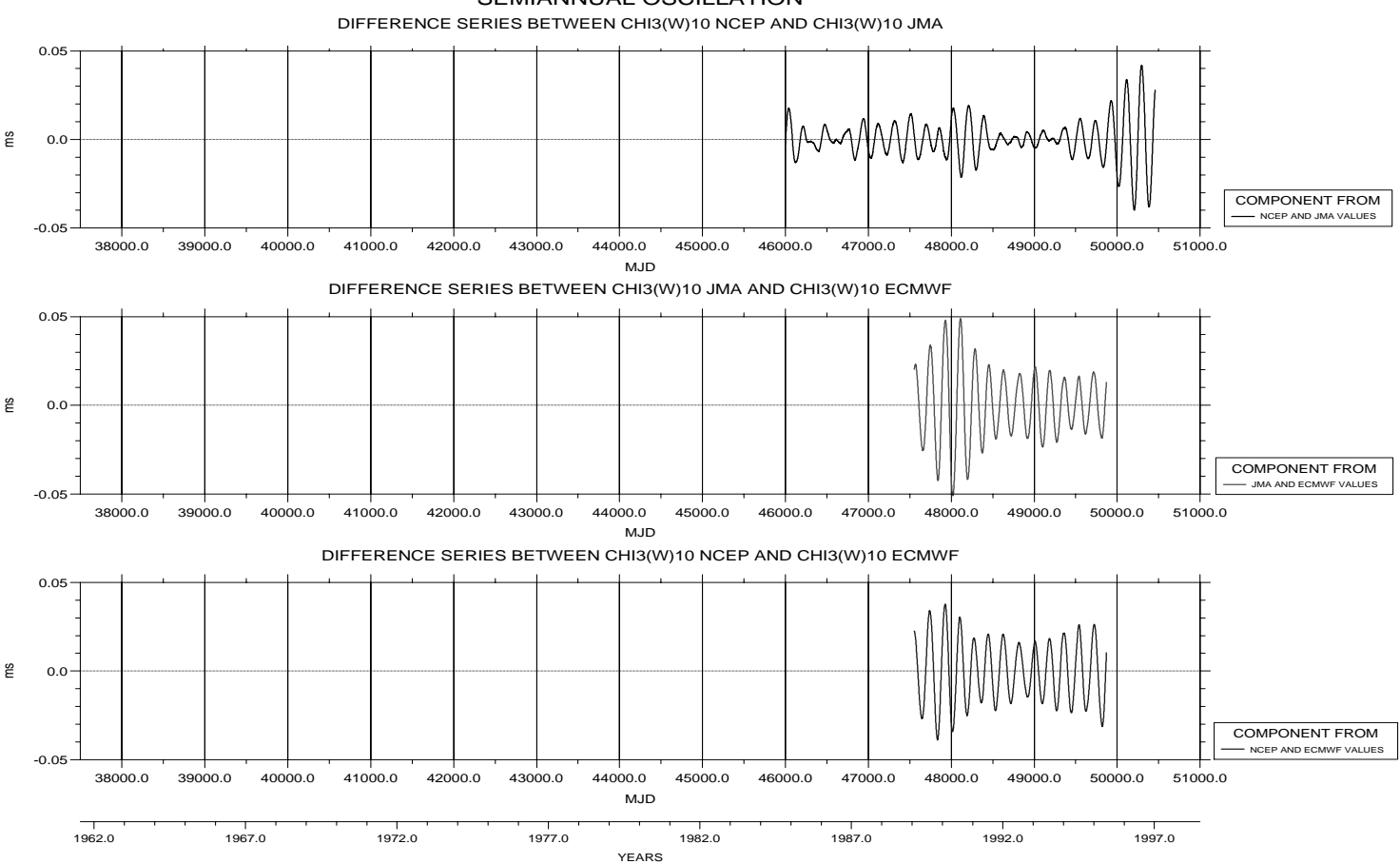

Figure 12. Seasonal residual oscillations for the wind term $\chi_{3}(\mathrm{~W}) 10$ between the different LOD atm systems, namely from NCEP Reanalysis and JMA (top), JMA and ECMWF (middle) and NCEP Reanalysis and ECMWF values (bottom). Oscillations at the annual frequency (upper part) and at the semiannual frequency (lower part) 
Publication: Scientific Technical Report

No.: STR98/10

ANNUAL OSCILLATION

DIFFERENCE SERIES BETWEEN CHI3(P) NCEP AND CHI3(P) JMA

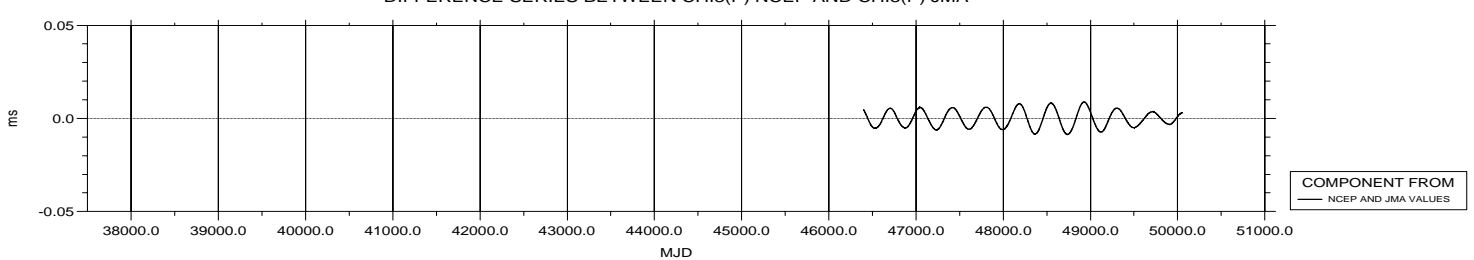

DIFFERENCE SERIES BETWEEN CHI3(P) JMA AND CHI3(P) ECMWF

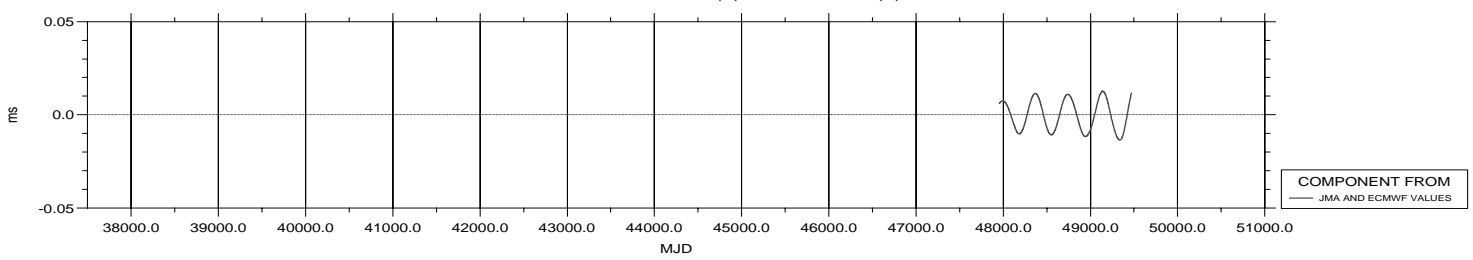

DIFFERENCE SERIES BETWEEN CHI3(P) NCEP AND CHI3(P) ECMWF

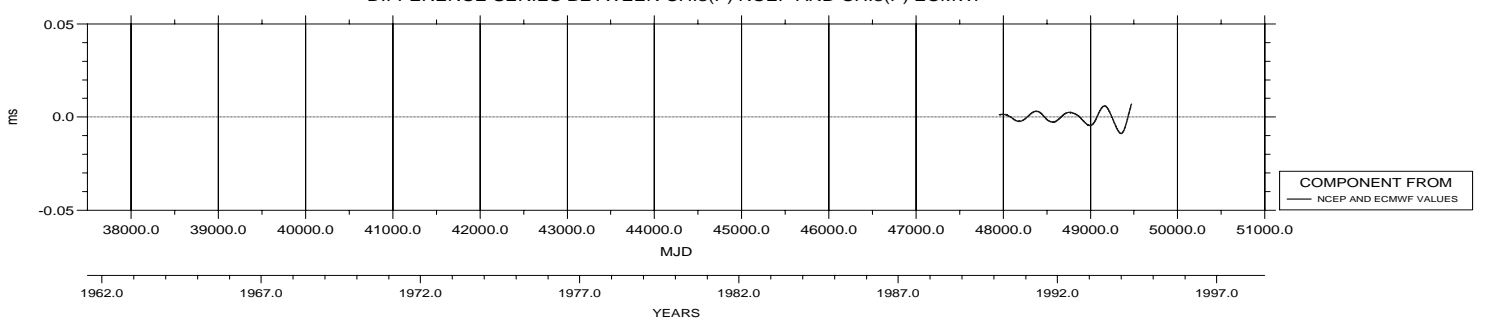

SEMIANNUAL OSCILLATION
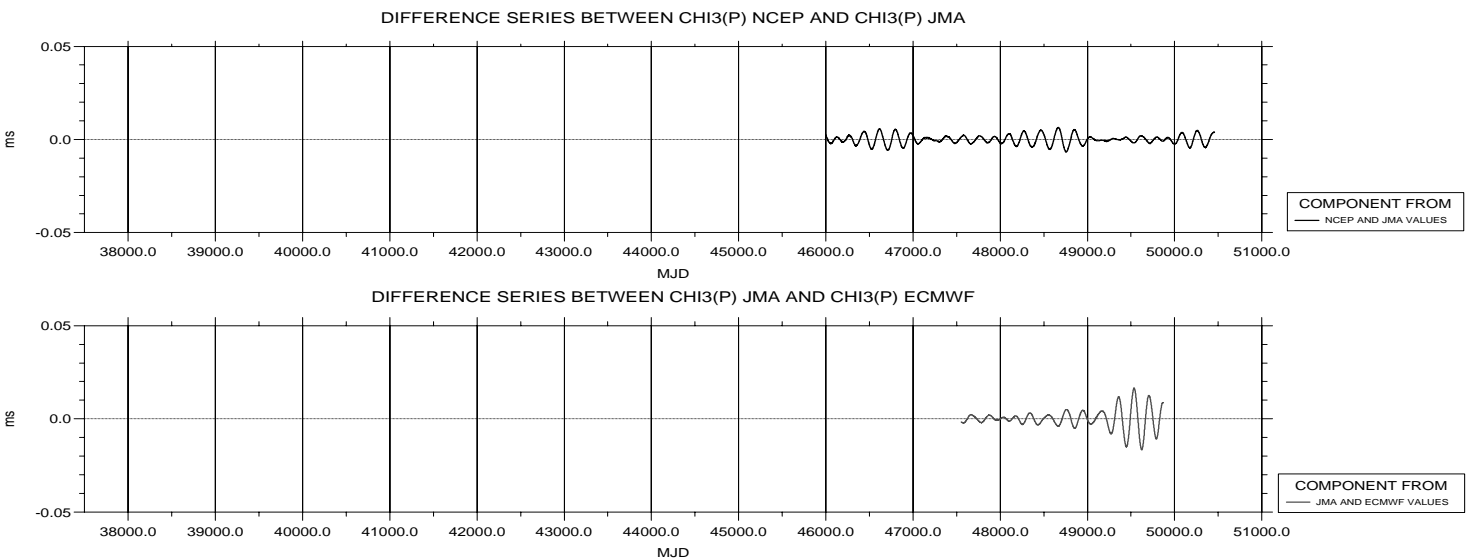

DIFFERENCE SERIES BETWEEN CHI3(P) NCEP AND CHI3(P) ECMWF

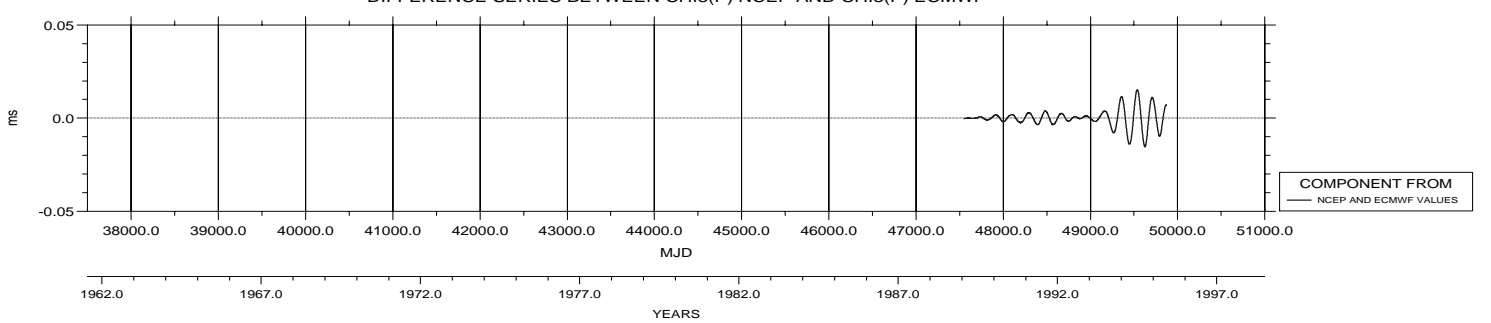

Figure 13. Same as Fig. 12, but for the pressure term $\chi_{3}(\mathrm{P})$ 
Publication: Scientific Technical Report

No.: STR98/10

ANNUAL OSCILLATION

DIFFERENCE SERIES BETWEEN CHI3(W)10+CHI3(P) IN THE NCEP AND JMA SYSTEMS

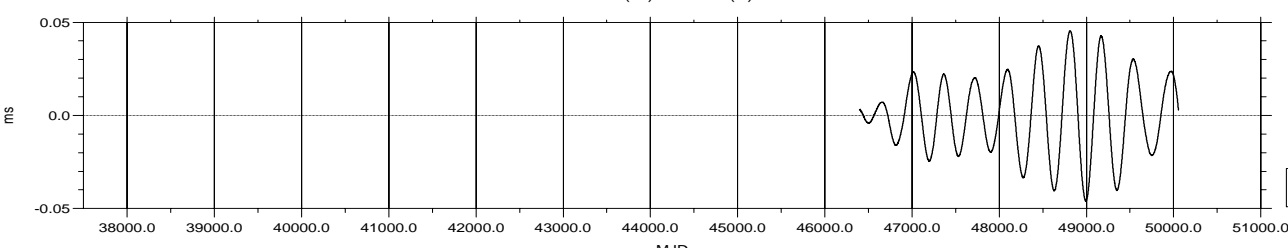

DIFFERENCE SERIES BETWEEN CHI3(W)10+CHI3(P) IN THE JMA AND ECMWF SYSTEMS
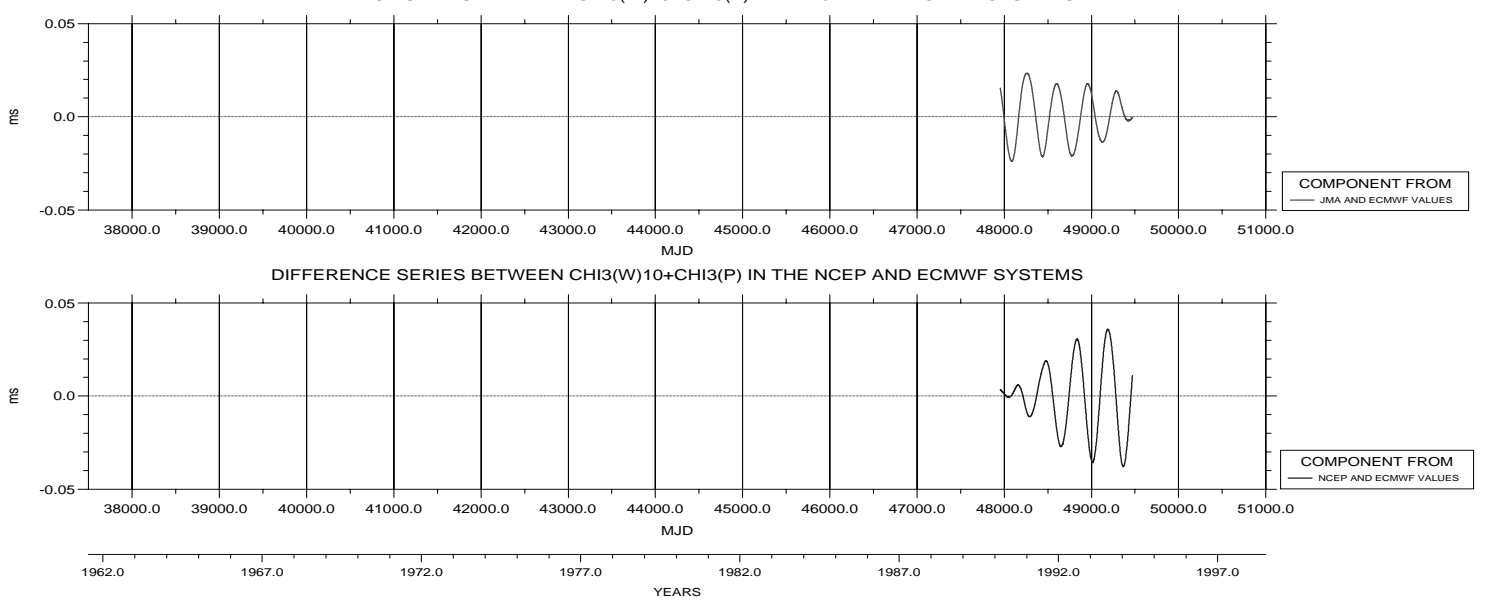

SEMIANNUAL OSCILLATION
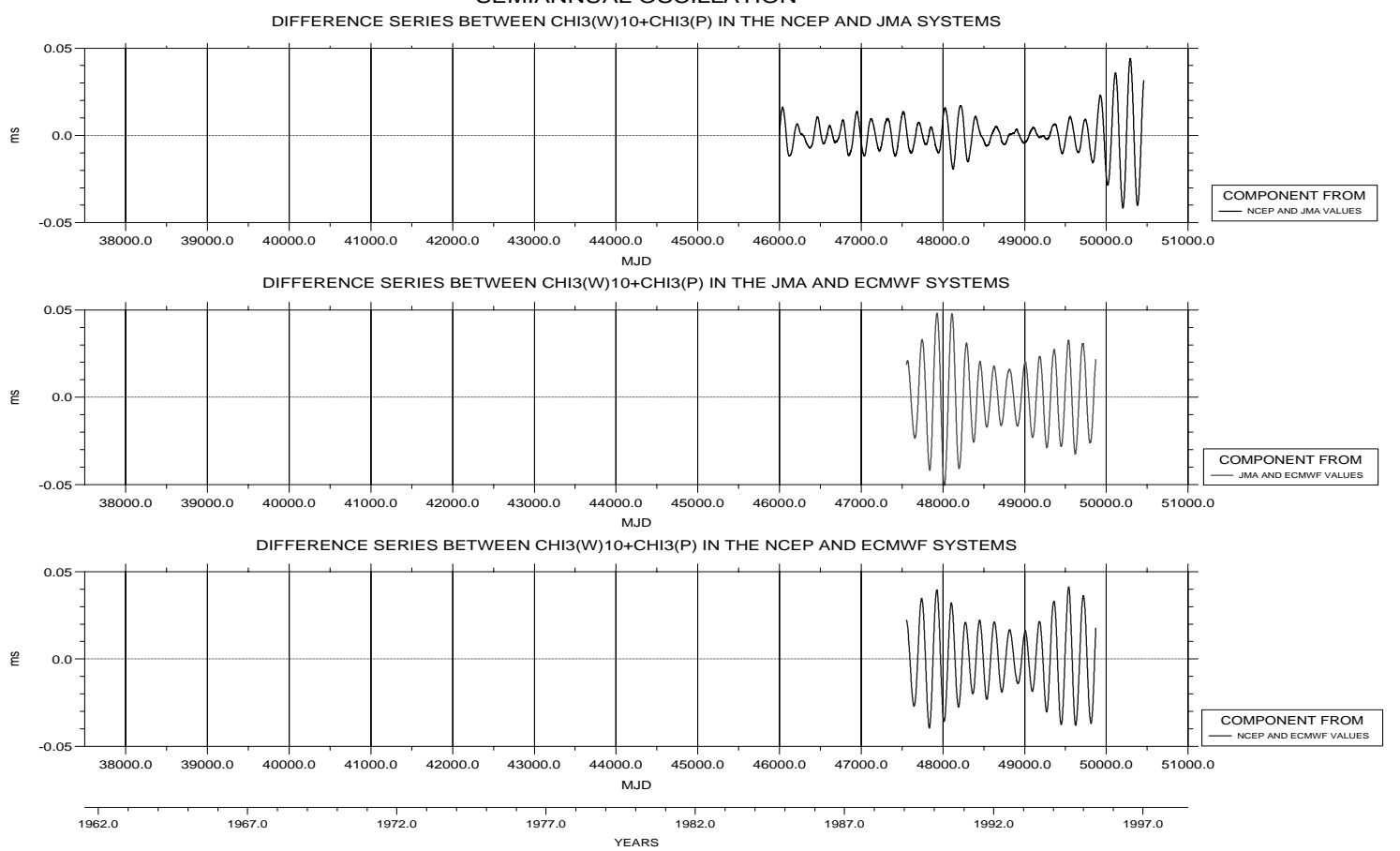

Figure 14. Same as Fig. 12, but for the wind plus pressure terms $\chi_{3}(\mathrm{~W}) 10+\chi_{3}(\mathrm{P})$ 

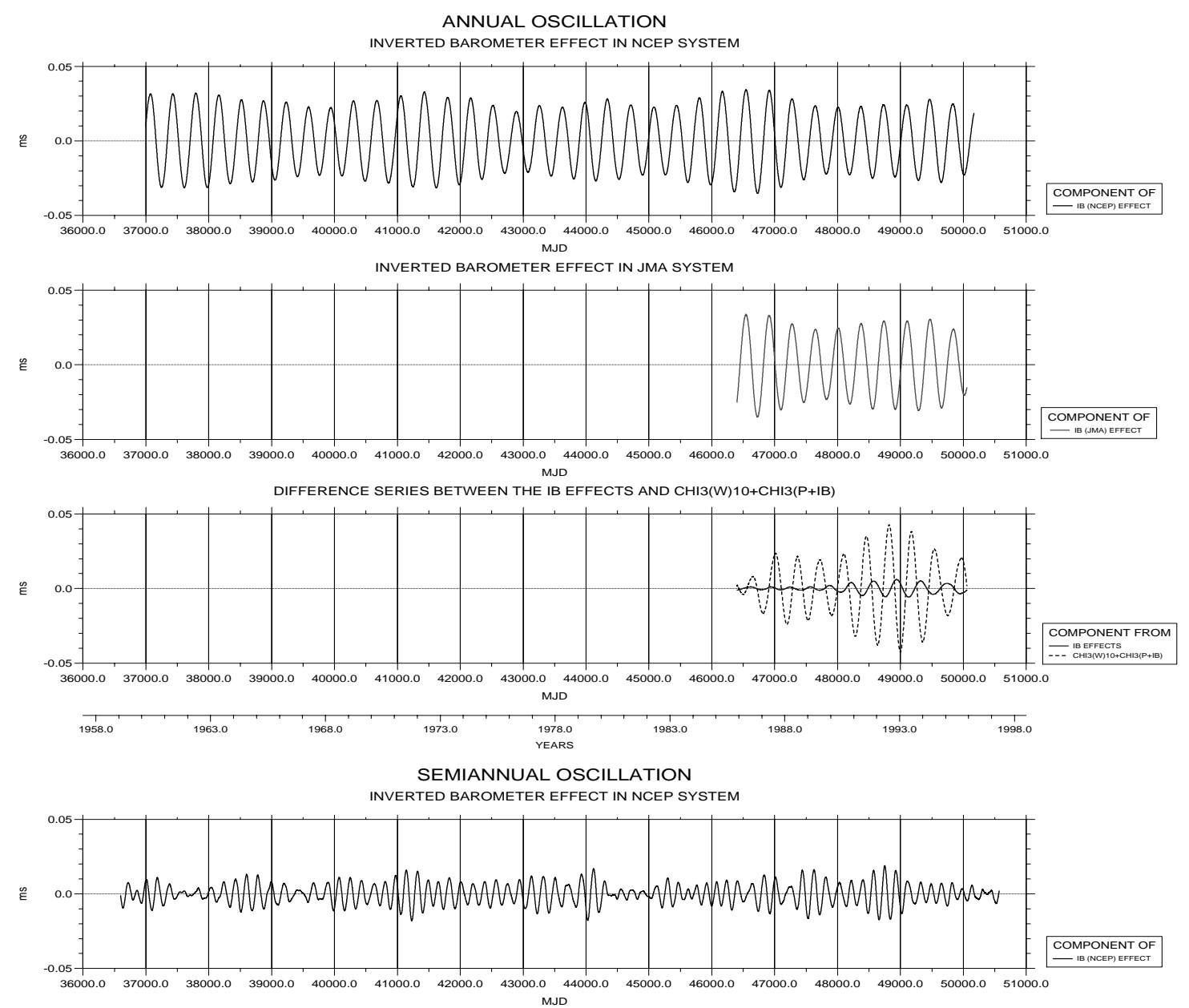

INVERTED BAROMETER EFFECT IN JMA SYSTEM
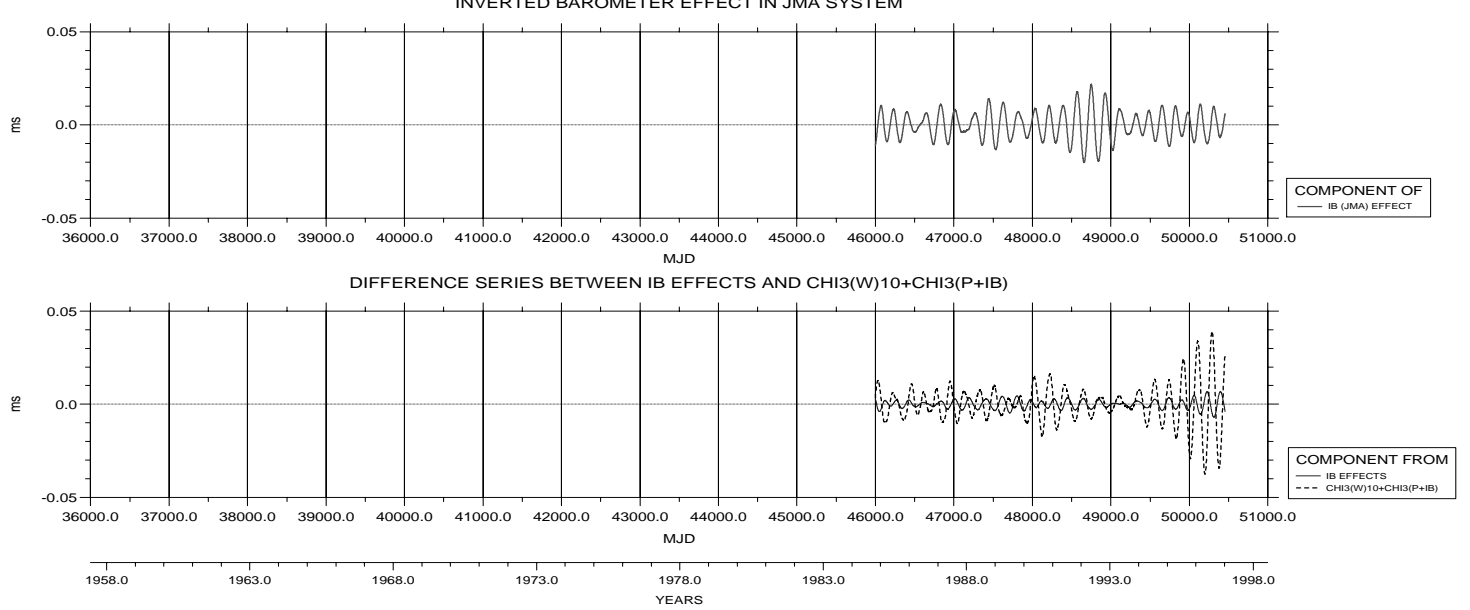

Figure 15. Seasonal oscillations of the IB effect in the NCEP system (top) and in the JMA system (centre) and the residual oscillations of the IB terms and of the wind plus pressure IB terms $\chi_{3}(\mathrm{~W}) 10+\chi_{3}(\mathrm{P})$ between both systems (bottom). Oscillations at the annual frequency (upper part) and at the semiannual frequency (lower part) 
amplitude size in the NCEP-ECMWF system. The remaining oscillations of the pressure terms $\chi_{3}(\mathrm{P})$ alone have an amplitude of about $0.008 \mathrm{~ms}$ in the NCEP-JMA system, about $0.010 \mathrm{~ms}$ in the JMA-ECMWF system and about 0.005 $\mathrm{ms}$ in the NCEP-ECMWF system. Incorporating both wind and pressure terms $\chi_{3}(\mathrm{~W}) 10+\chi_{3}(\mathrm{P})$, the remaining oscillations are slightly smaller for NCEP-JMA and for JMA-ECMWF but somewhat larger for NCEP-ECMWF. The IB effect difference curve in the NCEP-JMA system is about $0.005 \mathrm{~ms}$ in amplitude. If it is included in the remaining oscillation of $\chi_{3}(\mathrm{~W}) 10+\chi_{3}(\mathrm{P})$, i. e., the total difference series is computed for $\chi_{3}(\mathrm{~W}) 10+\chi_{3}(\mathrm{P}+\mathrm{IB})$ in the NCEP-JMA system, then the amplitude is also somewhat smaller.

(b) Semiannual $\mathrm{LOD}_{\text {atm }}$ oscillations

The lower parts of Figures 8, 9 and 10 show the temporal variations in amplitude, phase and period, respectively, of the semiannual oscillations of the wind terms $\chi_{3}(\mathrm{~W})$, the wind plus pressure terms $\chi_{3}(\mathrm{~W})+\chi_{3}(\mathrm{P})$ and the wind plus pressure IB terms $\chi_{3}(\mathrm{~W})+\chi_{3}(\mathrm{P}+\mathrm{IB})$ in the systems of NCEP Reanalysis, JMA, ECMWF and UKMO. Generally, the amplitude estimates of $\mathrm{LOD}_{\mathrm{atm}}$ in terms of both the wind terms $\chi_{3}(\mathrm{~W})$, the wind plus pressure terms $\chi_{3}(\mathrm{~W})+\chi_{3}(\mathrm{P})$ and the wind plus pressure IB terms $\chi_{3}(\mathrm{~W})+\chi_{3}(\mathrm{P}+\mathrm{IB})$ are consistently smaller than those of LOD by $0.060 \mathrm{~ms}$. For the phase, the values of all the $\mathrm{LOD}_{\text {atm }}$ terms are substantially larger than those of LOD. As for the annual period variation, the semiannual results of the $\mathrm{LOD}_{\mathrm{atm}}$ terms show good agreement with each other and with those of LOD. In contrast to the annual parameter variability, both the amplitude and phase in the different $\mathrm{LOD}_{\mathrm{atm}}$ systems vary less conformably with time on the same range of the scale.

The systematic residual oscillations among the three $\mathrm{LOD}_{\mathrm{atm}}$ systems with $10 \mathrm{hPa}$ top level at the semiannual frequency are presented in the lower parts of Figures 12 to 15 . The remaining oscillation of the wind terms $\chi_{3}(\mathrm{~W}) 10$ in the NCEP-JMA system shows variations in amplitude between 0.010 and $0.020 \mathrm{~ms}$. In the JMA-ECMWF system, there exists a residual oscillation with an amplitude changing from 0.050 to $0.020 \mathrm{~ms}$. The difference curve referred to the NCEP-ECMWF system has similar behaviour but its amplitude is between 0.040 and 0.015 ms. The remaining oscillation of the pressure terms $\chi_{3}(\mathrm{P})$ between the systems of NCEP Reanalysis and JMA is small and varies in amplitude only by about $0.005 \mathrm{~ms}$. Compared to it, the residual oscillation in the JMA-ECMWF system is similar to that in the NCEP-ECMWF system. Here, the amplitude is only $0.005 \mathrm{~ms}$ over the first half of the interval and $0.015 \mathrm{~ms}$ over the second half. Because of the conformity of both remaining oscillations, we can conclude that the ECMWF oscillation differs systematically from the NCEP and JMA oscillations. A comparison of the remaining oscillations of both the wind and pressure terms $\chi_{3}(\mathrm{~W}) 10+\chi_{3}(\mathrm{P})$ with those of the wind terms $\chi_{3}(\mathrm{~W}) 10$ alone reveals a small amplitude increase in the NCEP-JMA system according to the related remaining $\chi_{3}(\mathrm{P})$ oscillation. Of interest are also the larger amplitude values for the residual oscillations referred to the JMA-ECMWF and NCEP-ECMWF systems, respectively, which are produced by the ECMWF $\chi_{3}(\mathrm{P})$ oscillation mentioned above. Including the IB effect difference between the NCEP Reanalysis and JMA systems in the suitable $\chi_{3}(\mathrm{~W}) 10+\chi_{3}(\mathrm{P})$ remainder, the systematic total remaining oscillation, namely of $\chi_{3}(\mathrm{~W}) 10+\chi_{3}(\mathrm{P}+\mathrm{IB})$, shows an amplitude being a little smaller like to the issue at the annual frequency.

Also shown in Figures 8 to 10 is the parameter variability with time of the seasonal oscillations of the LOD atm data in the UKMO system. As described in Section 3.2, the top level in the atmosphere used in computing the $\chi_{3}(\mathrm{~W})$ term is about $25 \mathrm{hPa}$. We notice in Figure 8 that the amplitude of the annual UKMO oscillation is larger by 0.050 and 0.025 ms than that of NCEP Reanalysis and JMA, respectively, whereas, at the semiannual frequency, the UKMO amplitude is slightly smaller than those in the other systems. We may also consider the contribution of the stratospheric layer between the 50- and 10-hPa levels to seasonal oscillations of LOD ${ }_{\mathrm{atm}}$ in the NCEP Reanalysis system. Figure 8 shows that the annual amplitude of the wind term $\chi_{3}(\mathrm{~W}) 50$ without and with the pressure term $\chi_{3}(\mathrm{P})$ is larger than that of the wind term $\chi_{3}(\mathrm{~W}) 10$ without and with the pressure term $\chi_{3}(\mathrm{P})$. In case of the semiannual frequency, the facts are reversed, $i$. e. the amplitude of the semiannual oscillations in the wind term $\chi_{3}(\mathrm{~W}) 50$ is significantly smaller than that in the wind term $\chi_{3}(\mathrm{~W}) 10$. Figure 16 shows the annual contribution of the upper stratosphere between 50 and $10 \mathrm{hPa}$ to the LOD excitation in the top panel and the semiannual contribution of the same layer in the bottom panel. Note that the amplitude is about $0.025 \mathrm{~ms}$ at the annual frequency and about $0.030 \mathrm{~ms}$ at the semiannual frequency. A comparison with Figure 6 shows that the annual impact is negative whereas the semiannual impact is positive.

Assessing the LOD ${ }_{\text {atm }}$ results in the NCEP Reanalysis, JMA and ECMWF systems based on their intercomparisons, some points to note are as follows: There are significant differences between the seasonal oscillations referred to the three systems over the common intervals. Especially at the annual frequency, the amplitude values differ by 0.030 to $0.050 \mathrm{~ms}$. Obviously, the agreement is better between the JMA and ECMWF results incorporating both wind and pressure terms $\chi_{3}(\mathrm{~W}) 10+\chi_{3}(\mathrm{P})$ than between those of NCEP Reanalysis and JMA and of NCEP Reanalysis and ECMWF, respectively. On the other hand, at the semiannual frequency, the difference series between $\chi_{3}(\mathrm{~W}) 10+\chi_{3}(\mathrm{P})$ in the NCEP Reanalysis and JMA systems has an amplitude of only about $0.015 \mathrm{~ms}$. Accordingly, it is by $0.015 \mathrm{~ms}$ smaller than that from JMA and ECMWF estimates and also from NCEP Reanalysis and ECMWF estimates. This suggests a continuation of studies in the field.

In Section 6, the seasonal discrepancies in the solid Earth-atmosphere axial angular momentum budget computed 


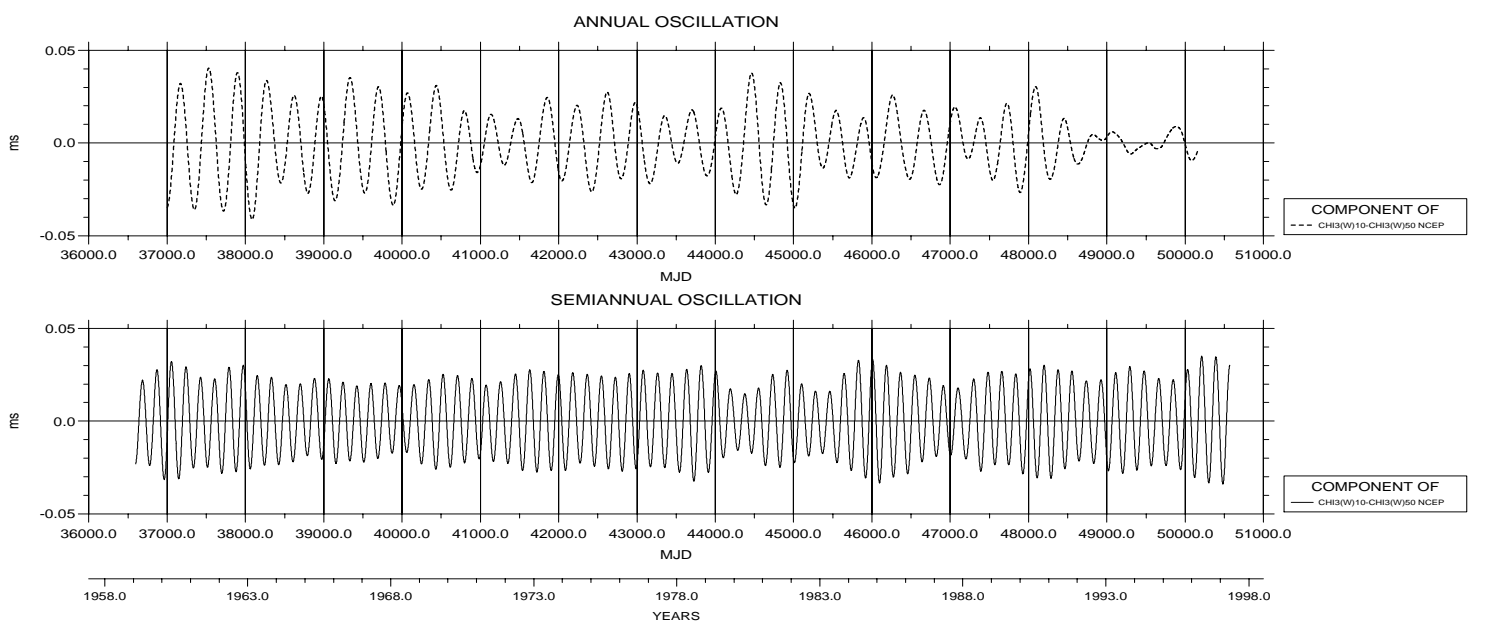

Figure 16. Seasonal contributions of the upper stratosphere between the 50- and 10-hPa levels to the LOD excitation in the NCEP Reanalysis system. Contribution at the annual frequency (top) and at the semiannual frequency (bottom)

between the annual and semiannual oscillations of the LOD and LOD atm data in the different systems are shown and discussed.

\section{Seasonal discrepancies in the solid Earth-atmosphere axial angular momentum budget}

To assess the remaining seasonal discrepancies in the solid Earth-atmosphere axial angular momentum budget, we computed the seasonal residual oscillations between the different LOD and LOD ${ }_{\text {atm }}$ systems. They are obtained by subtracting the seasonal oscillations of the $\mathrm{LOD}_{\mathrm{atm}}$ series in the systems of NCEP Reanalysis, JMA, ECMWF and UKMO from the seasonal oscillations of the LOD series in the systems of IERS, GFZ and JPL over the same time spans. Table 11 compiles the common intervals used for calculating the seasonal residual oscillations.

Figures 17 to 22 present the results referred to the three $\mathrm{LOD}_{\mathrm{atm}}$ systems that have the top level of the atmosphere in their GCMs at $10 \mathrm{hPa}$. Here, the remainders obtained at the annual frequency are plotted in Figures 17 to 19 and those obtained at the semiannual frequency in Figures 20 to 22. In particular, the curves relating to the LOD system of the IERS are given in Figure 17, of the GFZ in Figure 18 and of the JPL in Figure 19 and correspondingly in Figures 20 to 22. In each figure, the upper part shows the results for the wind plus pressure terms $\chi_{3}(\mathrm{~W}) 10+\chi_{3}(\mathrm{P})$ and the lower part those for the wind plus pressure IB terms $\chi_{3}(\mathrm{~W}) 10+\chi_{3}(\mathrm{P}+\mathrm{IB})$ of the three $\chi_{3}(\mathrm{~W}) 10$-related LODatm systems in three panels, respectively. The component referred to the NCEP Reanalysis values is illustrated in the top panel, that referred to the JMA values in the middle panel and that referred to the ECMWF values in the bottom panel. Figure 23 shows the remainders referred to the $\mathrm{LOD}_{\text {atm }}$ system of the UKMO with about 25-hPa top level. Unlike Figures 17 to 19 and 20 to 22, the annual curves are now given in the upper part and the semiannual curves in the lower part, with the three panels exhibiting the residual oscillations referred to the three LOD systems, namely the top panel relating to the IERS system, the middle panel relating to the GFZ system and the bottom panel relating to the JPL system. In Table 12 , the ranges of the variations in amplitude, phase and period including the standard deviations of the seasonal residual oscillations between the LOD data in IERS system and the LOD ${ }_{\text {atm }}$ data in the NCEP Reanalysis, JMA, ECMWF and UKMO systems are compiled. In case of discontinuities existing in the residual oscillations, amplitude, phase and period estimates are computed using the input data without the discontinuities as for the component with the terms of $\chi_{3}(\mathrm{~W}) 10$ $+\chi_{3}(\mathrm{P})$ in the NCEP Reanalysis system, of $\chi_{3}(\mathrm{~W}) 10+\chi_{3}(\mathrm{P}+\mathrm{IB})$ in the JMA system and of $\chi_{3}(\mathrm{~W}) 25+\chi_{3}(\mathrm{P})$ in the UKMO system at the annual frequency and for the component with the term of $\chi_{3}(\mathrm{~W}) 10+\chi_{3}(\mathrm{P})$ in the ECMWF system at the semiannual frequency. 
ANNUAL OSCILLATION

DIFFERENCE SERIES BETWEEN LOD (IERS) 97C04 AND CHI3(W)10+CHI3(P) NCEP

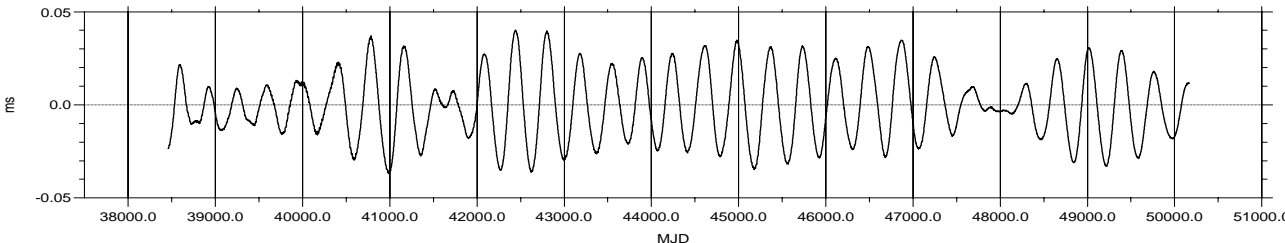

\section{(1)}

DIFFERENCE SERIES BETWEEN LOD (IERS) 97C04 AND CHI3(W)10+CHI3(P) JMA

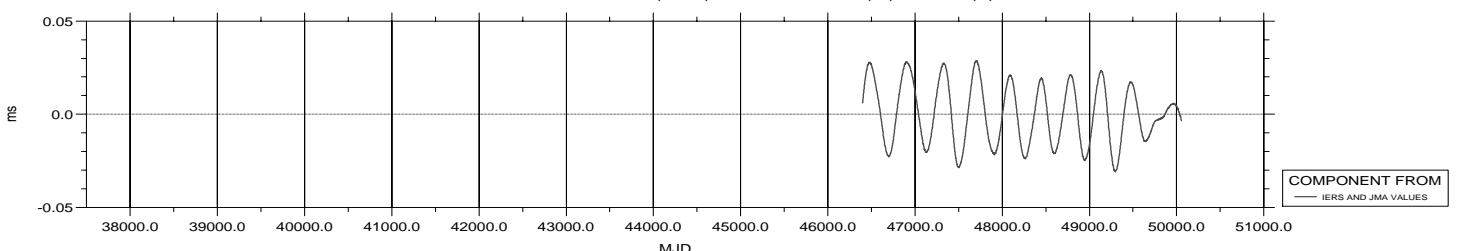

DIFFERENCE SERIES BETWEEN LOD (IERS) $97 \mathrm{C04}$ AND CHI3(W)10+CHI3(P) ECMWF

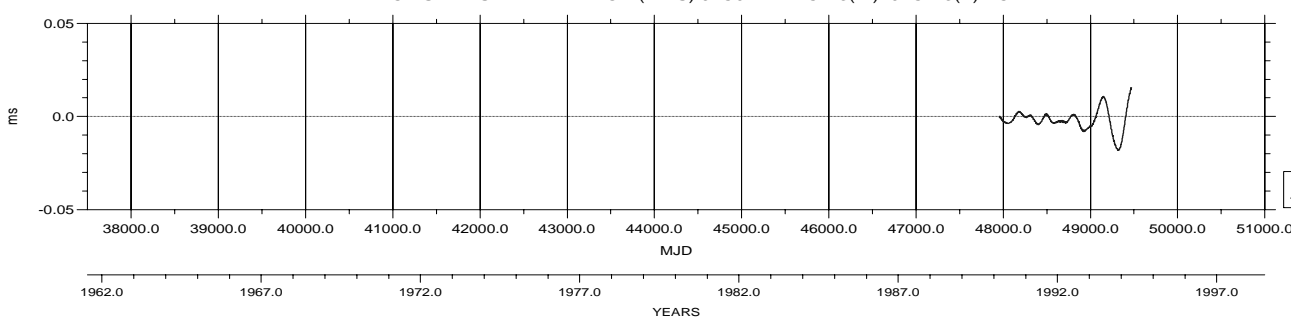

ANNUAL OSCILLATION

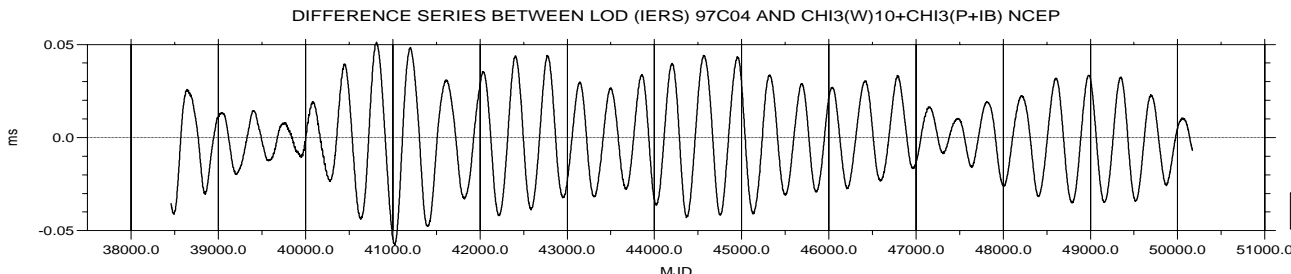

DIFFERENCE SERIES BETWEEN LOD (IERS) 97C04 AND CHI3(W)10+CHI3(P+IB) JMA

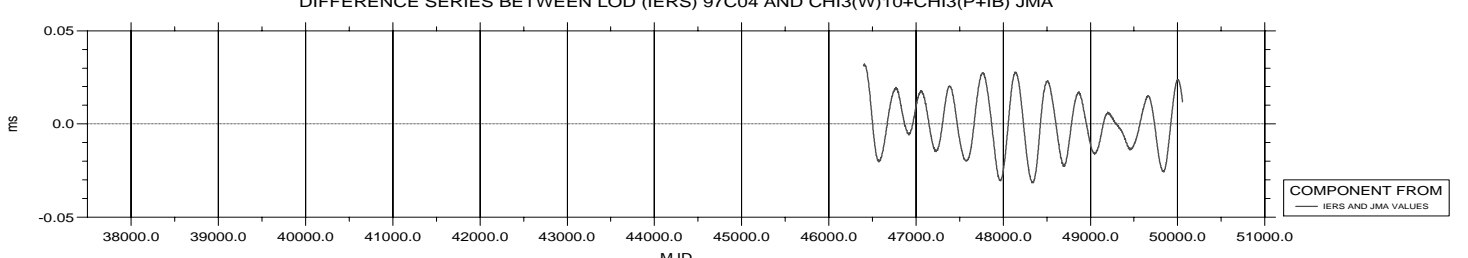

DIFFERENCE SERIES BETWEEN LOD (IERS) $97 \mathrm{CO} 4$ AND CHI3(W)10+CHI3(P+IB) ECMWF

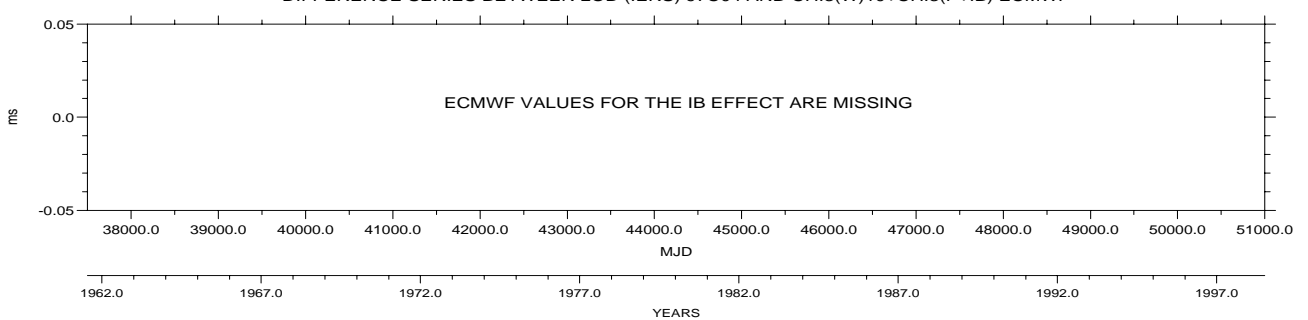

Figure 17. Annual oscillation of the difference series between the LOD data in the IERS system and the LOD atm data in the system of NCEP Reanalysis (top), of JMA (centre) and of ECMWF (bottom). Upper part: The LOD atm data are those of the wind plus pressure terms $\chi_{3}(\mathrm{~W}) 10+$ $\chi_{3}(\mathrm{P})$. Lower part: The $\mathrm{LOD}_{\mathrm{atm}}$ data are those of the wind plus pressure IB terms $\chi_{3}(\mathrm{~W}) 10+\chi_{3}(\mathrm{P}+\mathrm{IB})$ 
ANNUAL OSCILLATION

DIFFERENCE SERIES BETWEEN LOD (GFZ) L04+97P01 AND CHI3(W)10+CHI3(P) NCEP
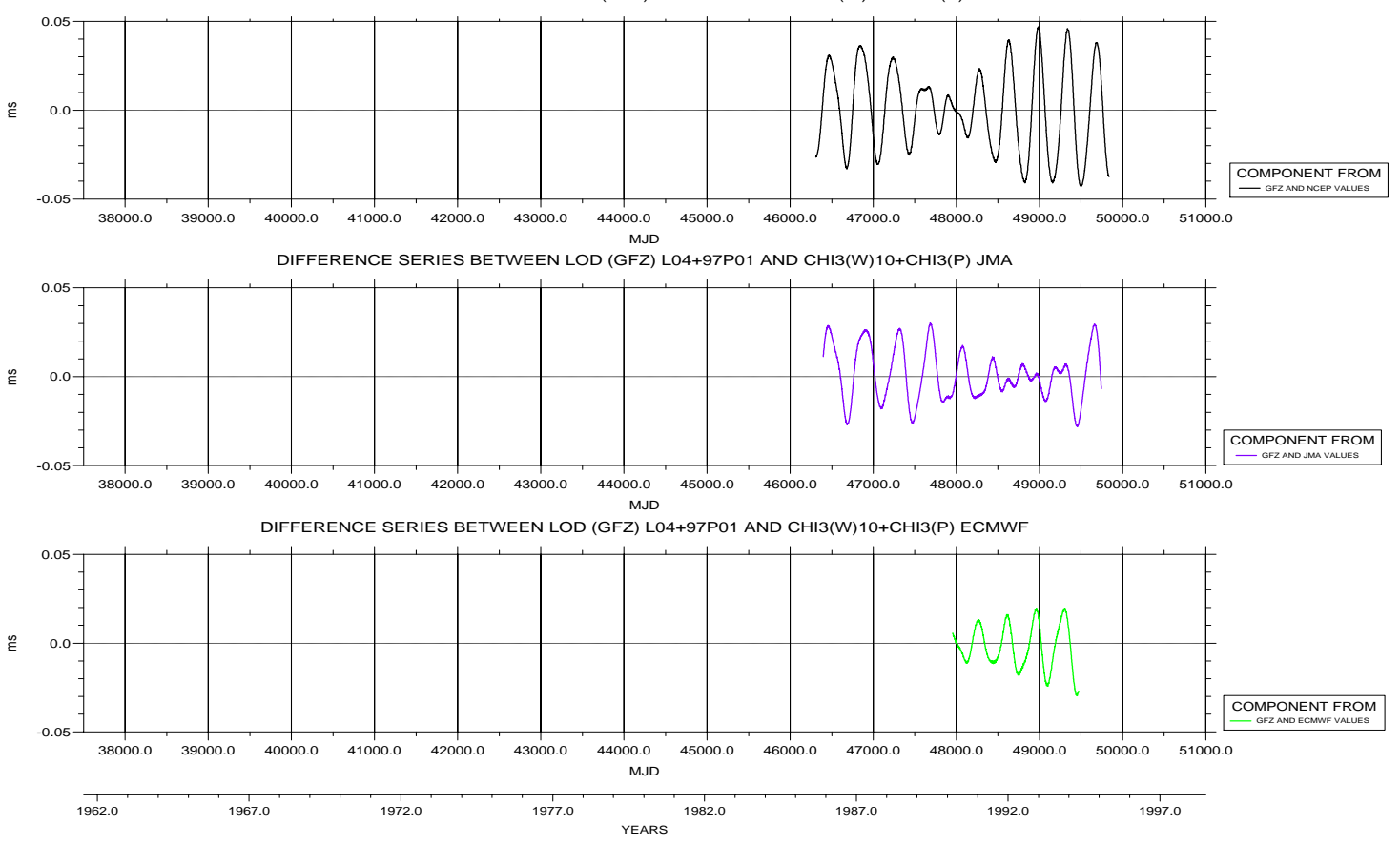

ANNUAL OSCILLATION
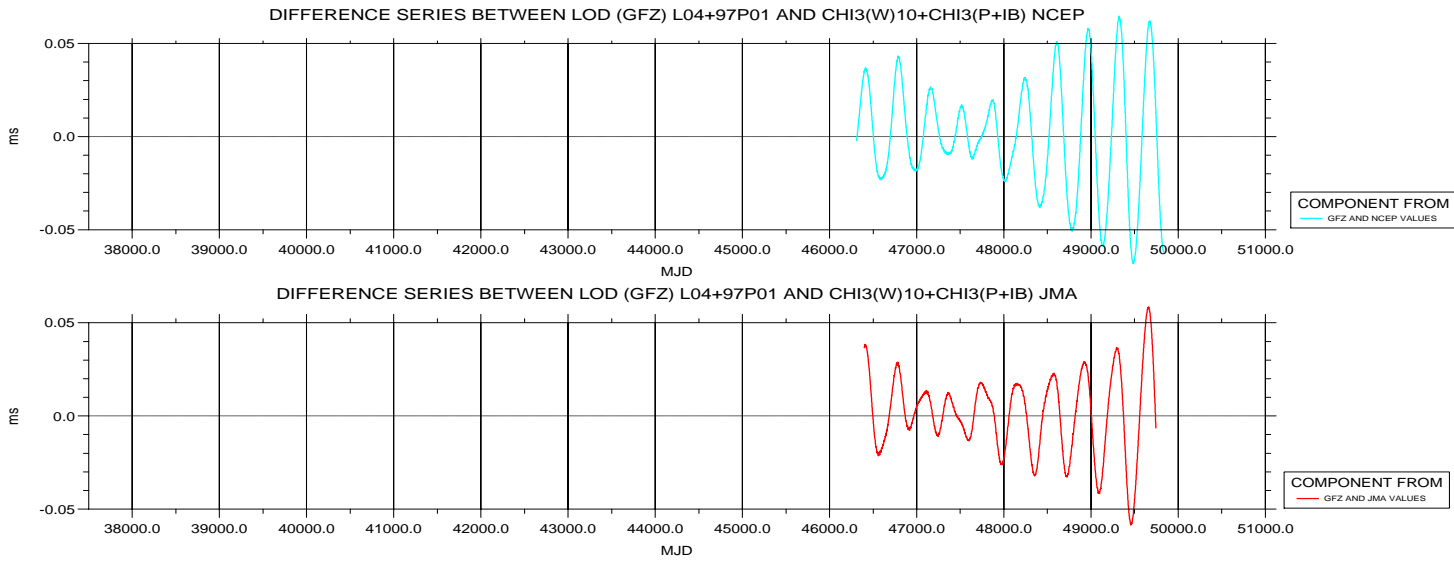

DIFFERENCE SERIES BETWEEN LOD (GFZ) L04+97P01 AND CHI3(W) 10+CHI3(P+IB) ECMWF

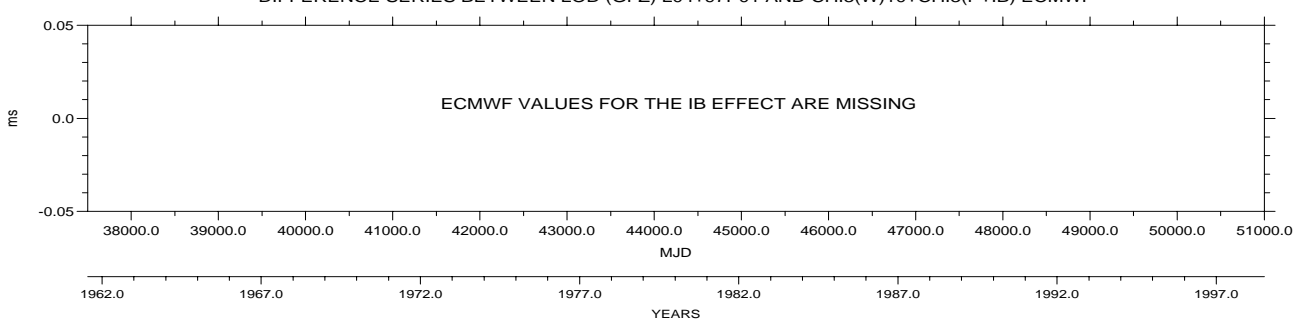

Figure 18. Same as Fig. 17, but for the LOD data in the GFZ system 
ANNUAL OSCILLATION

DIFFERENCE SERIES BETWEEN LOD (JPL) 97C01 AND CHI3(W)10+CHI3(P) NCEP
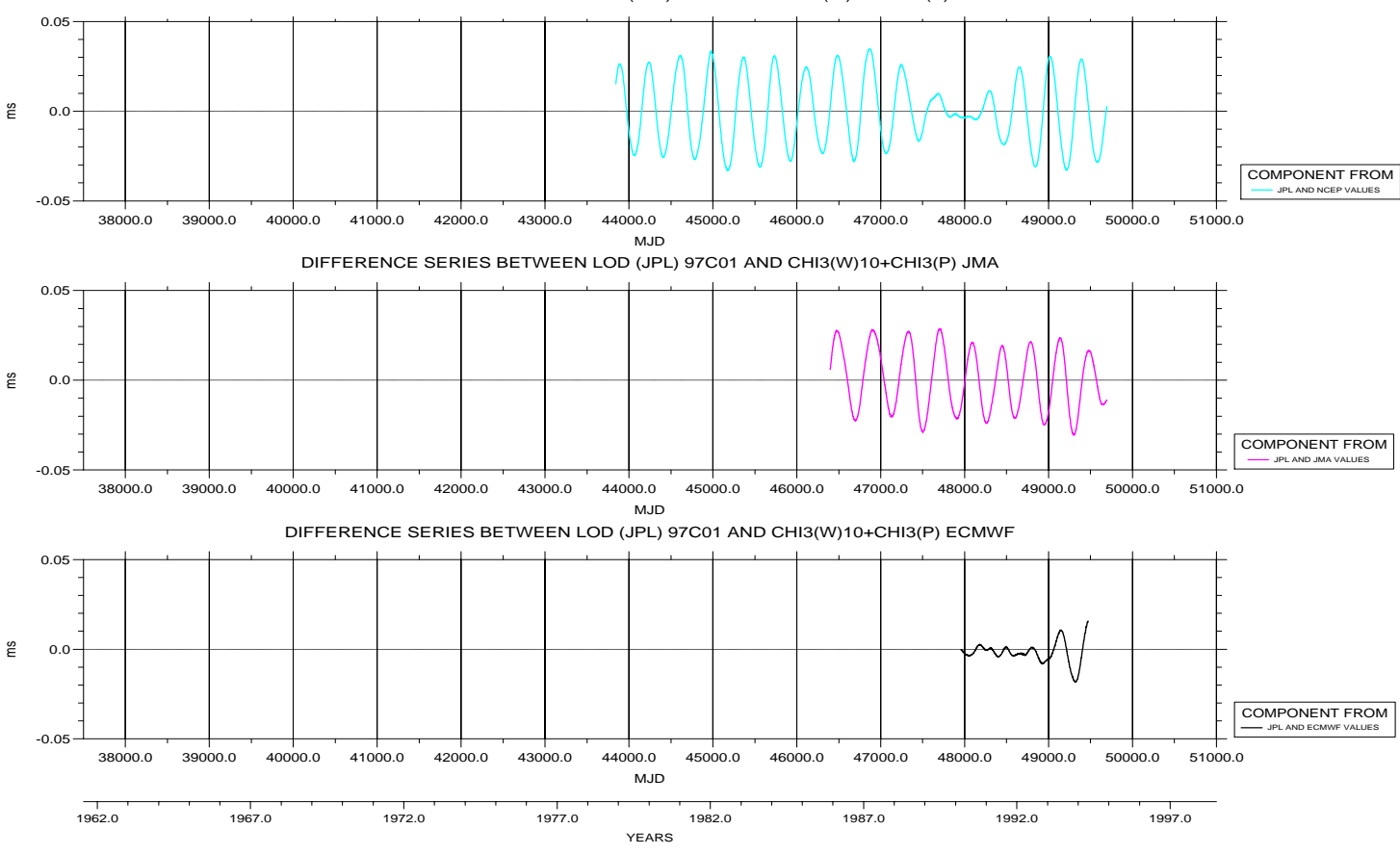

ANNUAL OSCILLATION
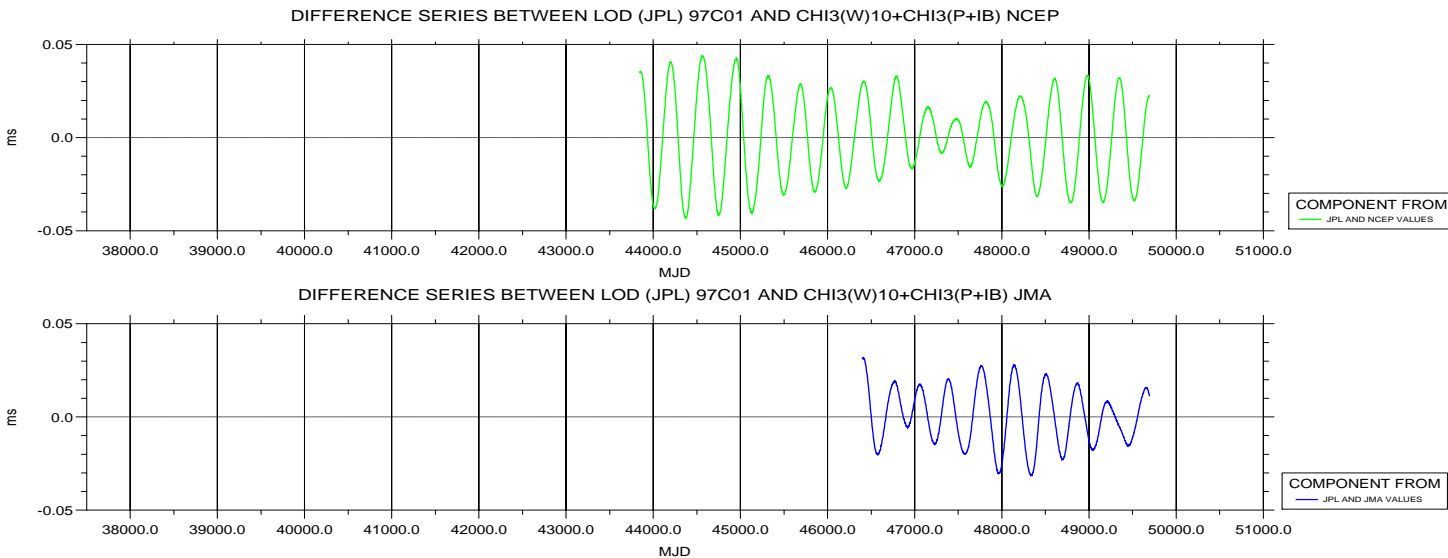

DIFFERENCE SERIES BETWEEN LOD (JPL) 97C01 AND CHI3(W)10+CHI3(P+IB) ECMWF

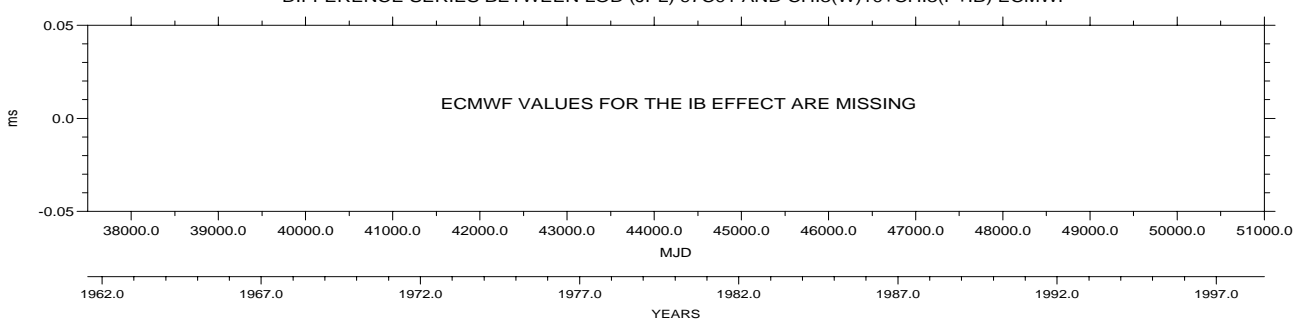

Figure 19. Same as Fig. 17, but for the LOD data in the JPL system 
Publication: Scientific Technical Report

No.: STR98/10

SEMIANNUAL OSCILLATION

DIFFERENCE SERIES BETWEEN LOD (IERS) $97 \mathrm{C0} 4$ AND CHI3(W)10+CHI3(P) NCEP

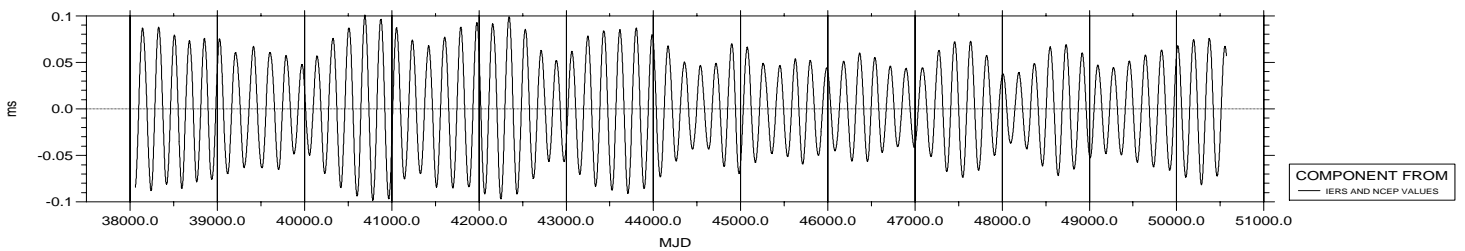

(IERS) $97 \mathrm{CO} 4$ AND CHI3(W)10+CHI3(P) JMA

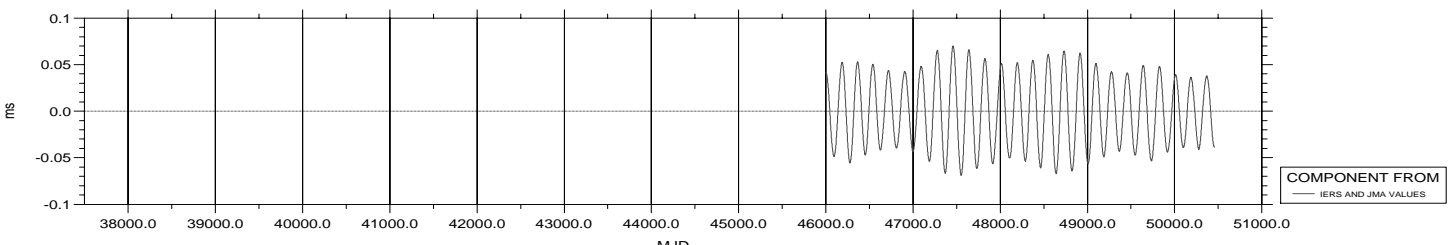

DIFFERENCE SERIES BETWEEN LOD (IERS) $97 \mathrm{C0} 4$ AND CHI3(W)10+CHI3(P) ECMWF

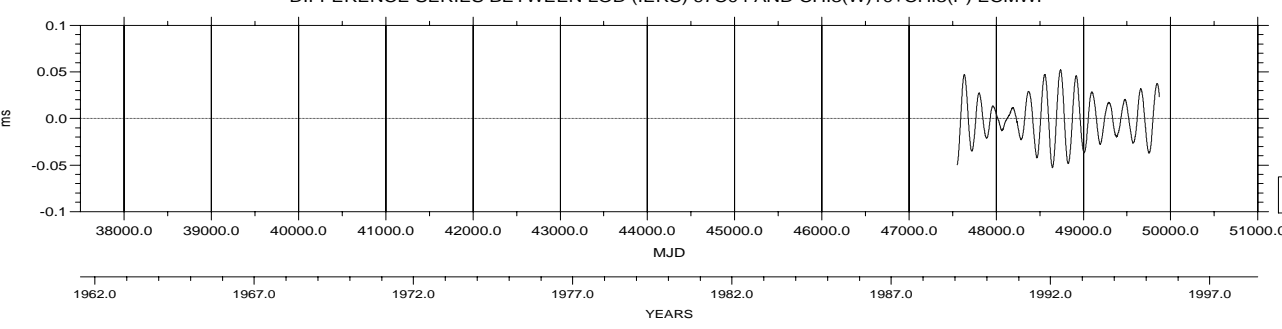

SEMIANNUAL OSCILLATION

DIFFERENCE SERIES BETWEEN LOD (IERS) $97 \mathrm{C0} 4$ AND CHI3(W)10+CHI3(P+IB) NCEP

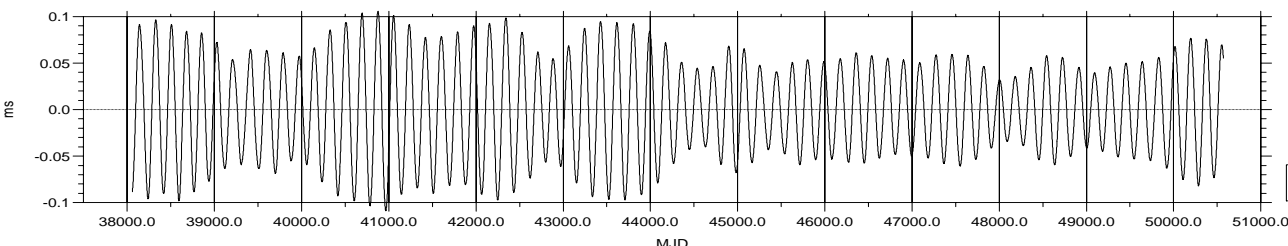

COMPONENT FROM

DIFFERENCE SERIES BETWEEN LOD (IERS) 97C04 AND CHI3(W)10+CHI3(P+IB) JMA

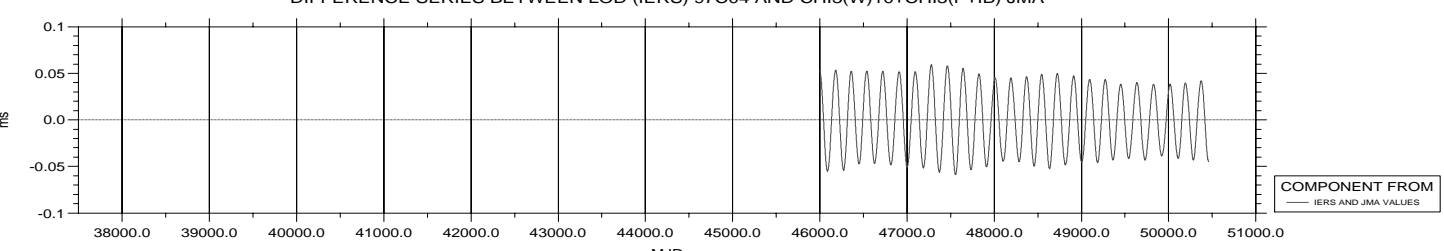

DIFFERENCE SERIES BETWEEN LOD (IERS) $97 \mathrm{CO} 4$ AND CHI3(W)10+CHI3(P+IB) ECMWF

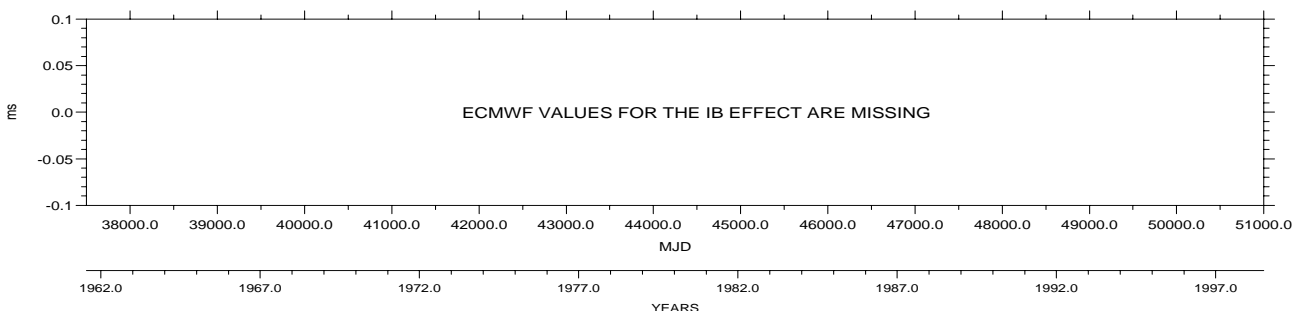

Figure 20. Semiannual oscillation of the difference series between the LOD data in the IERS system and the LOD atm data in the system of NCEP Reanalysis (top), of JMA (centre) and of ECMWF (bottom). Upper part: The LOD atm data are those of the wind plus pressure terms $\chi_{3}$ (W) $10+$ $\chi_{3}(\mathrm{P})$. Lower part: The $\mathrm{LOD}_{\mathrm{atm}}$ data are those of the wind plus pressure IB terms $\chi_{3}(\mathrm{~W}) 10+\chi_{3}(\mathrm{P}+\mathrm{IB})$ 
Publication: Scientific Technical Report

No.: STR98/10

SEMIANNUAL OSCILLATION

DIFFERENCE SERIES BETWEEN LOD (GFZ) L04+97P01 AND CHI3(W)10+CHI3(P) NCEP

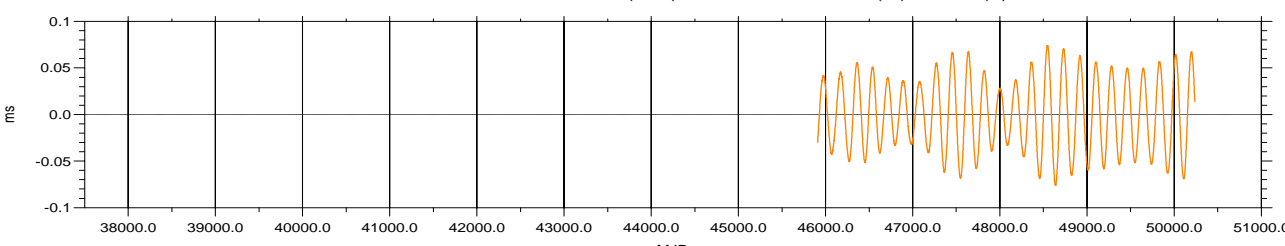

DIFFERENCE SERIES BETWEEN LOD (GFZ) L04+97P01 AND CHI3(W)10+CHI3(P) JMA

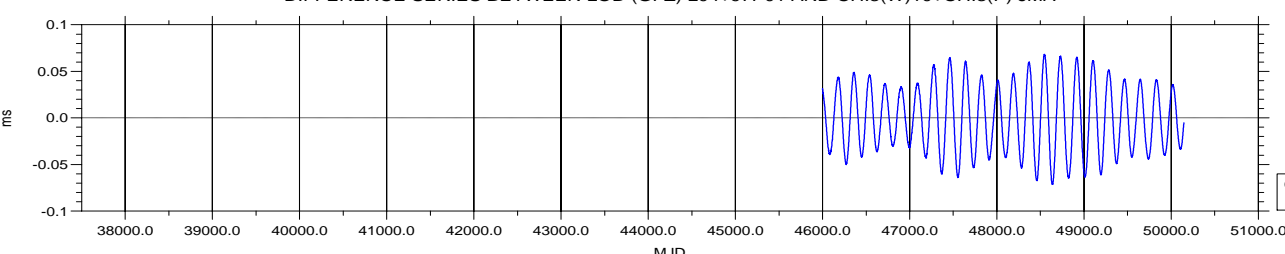

DIFFERENCE SERIES BETWEEN LOD (GFZ) L04+97P01 AND CHI3(W)10+CHI3(P) ECMWF

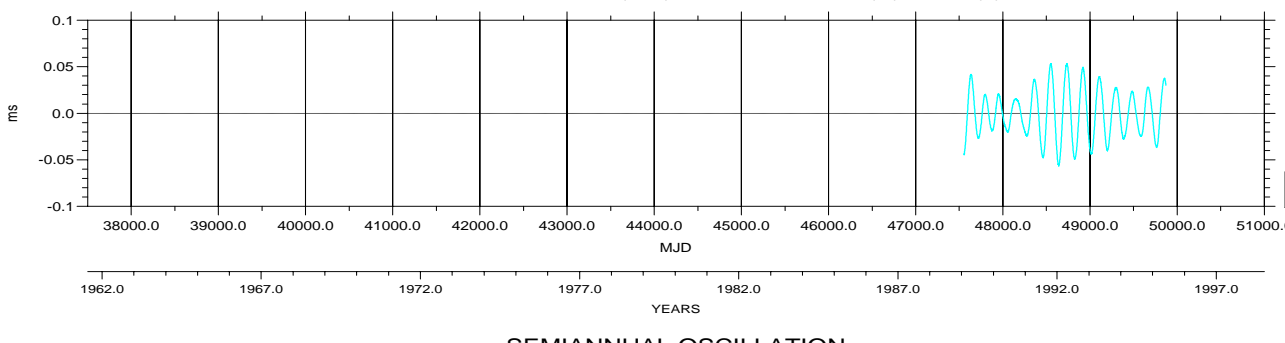

SEMIANNUAL OSCILLATION
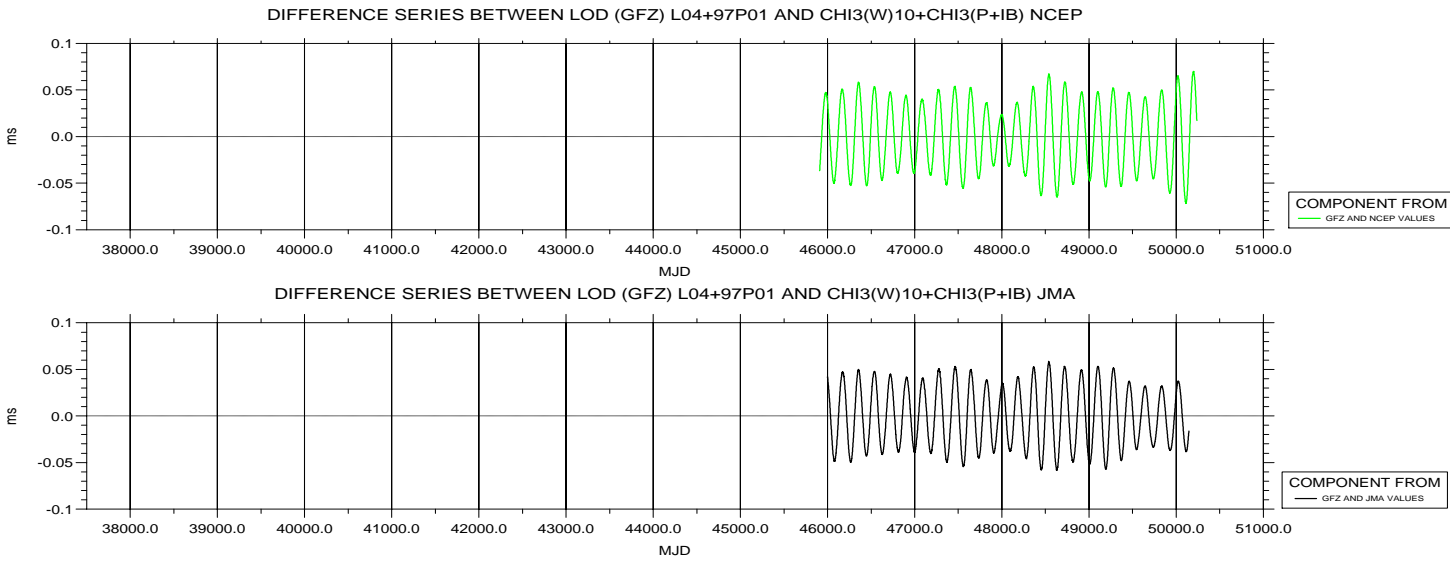

DIFFERENCE SERIES BETWEEN LOD (GFZ) L04+97P01 AND CHI3(W)10+CHI3(P+IB) ECMWF

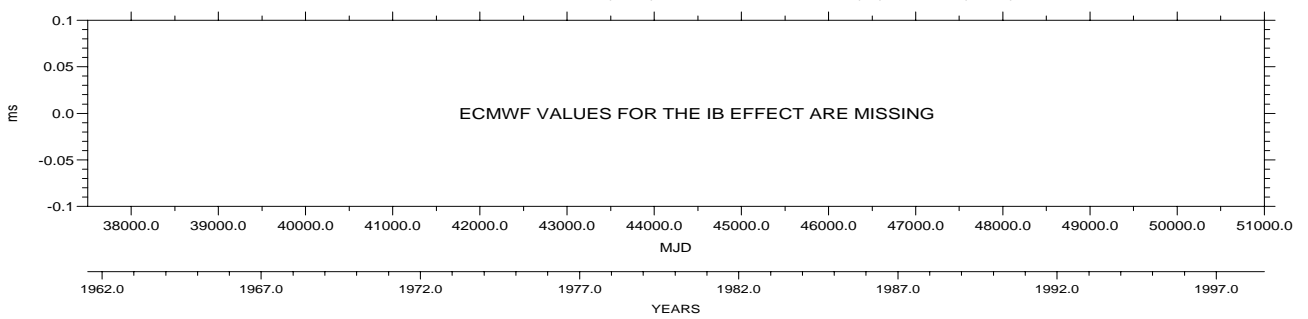

Figure 21. Same as Fig. 20, but for the LOD data in the GFZ system 
SEMIANNUAL OSCILLATION

DIFFERENCE SERIES BETWEEN LOD (JPL) 97C01 AND CHI3(W)10+CHI3(P) NCEP
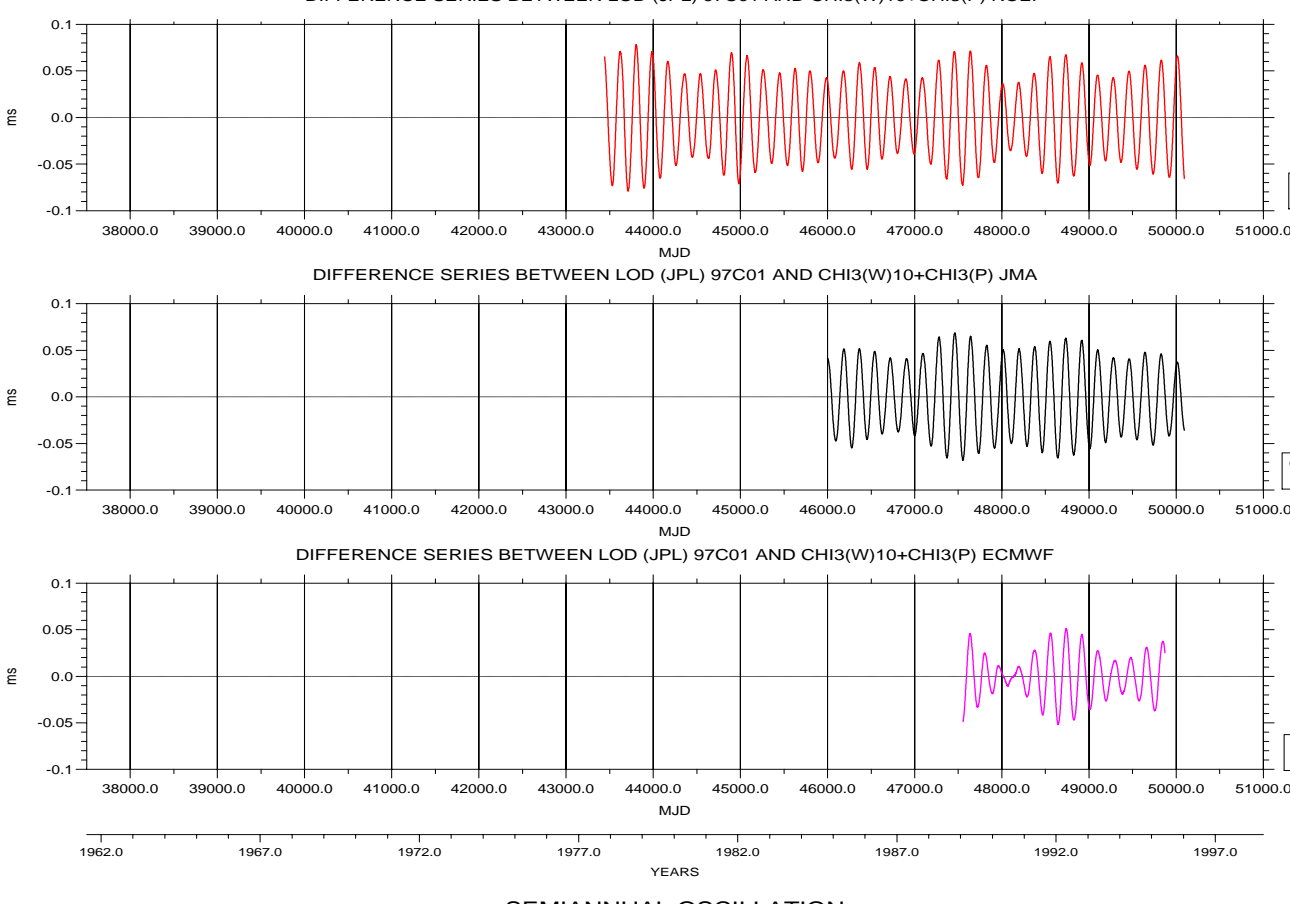

SEMIANNUAL OSCILLATION
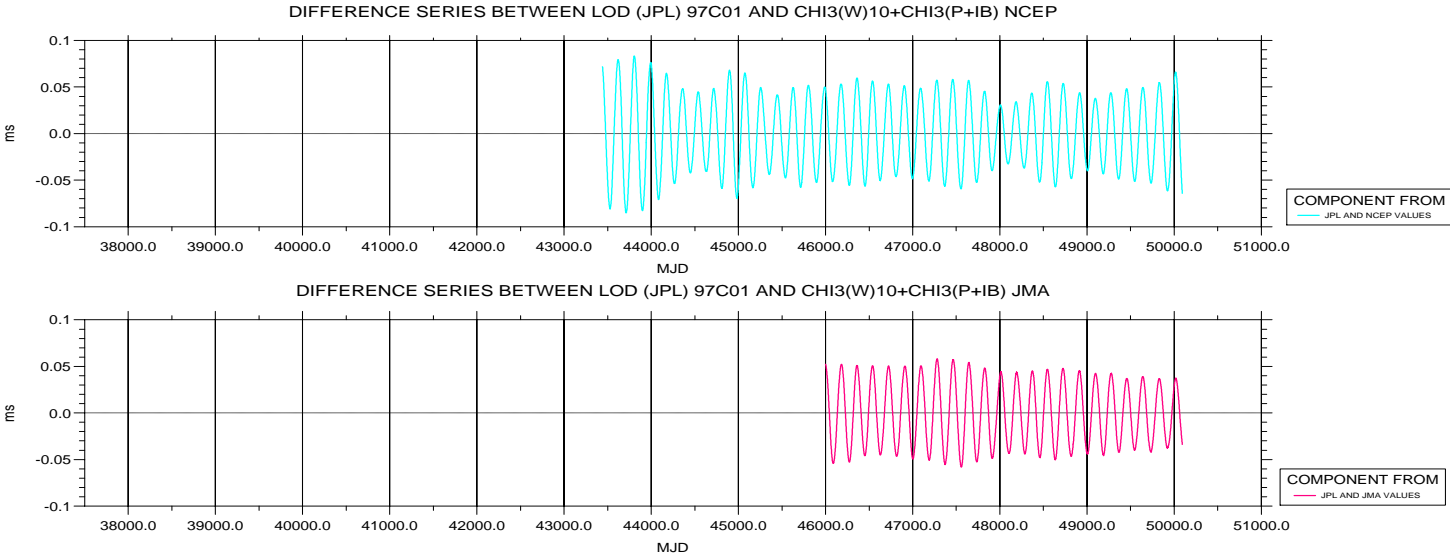

DFFERENCE SERIES BETWEEN LOD (JPL) 97C01 AND CHI3(W)10+CHI3(P+IB) ECMWF

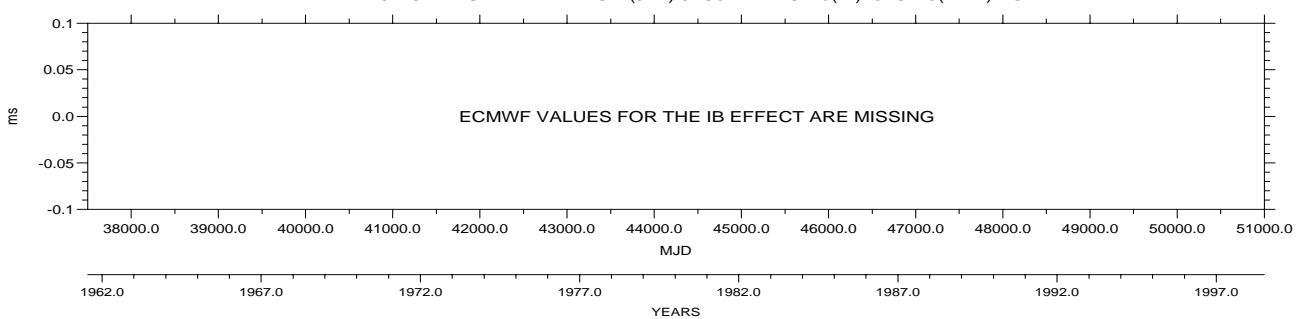

Figure 22. Same as Fig. 20, but for the LOD data in the JPL system 
ANNUAL OSCILLATION
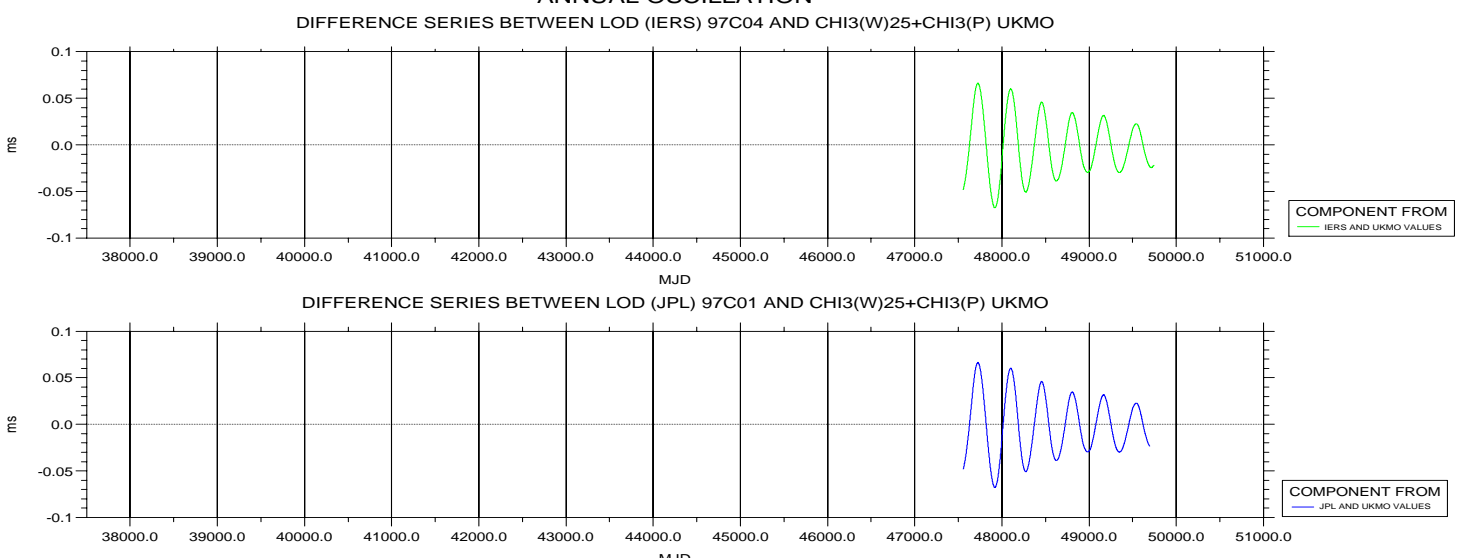

DIFFERENCE SERIES BETWEEN LOD (GFZ) L04+97P01 AND CHI3(W)25+CHI3(P) UKMO

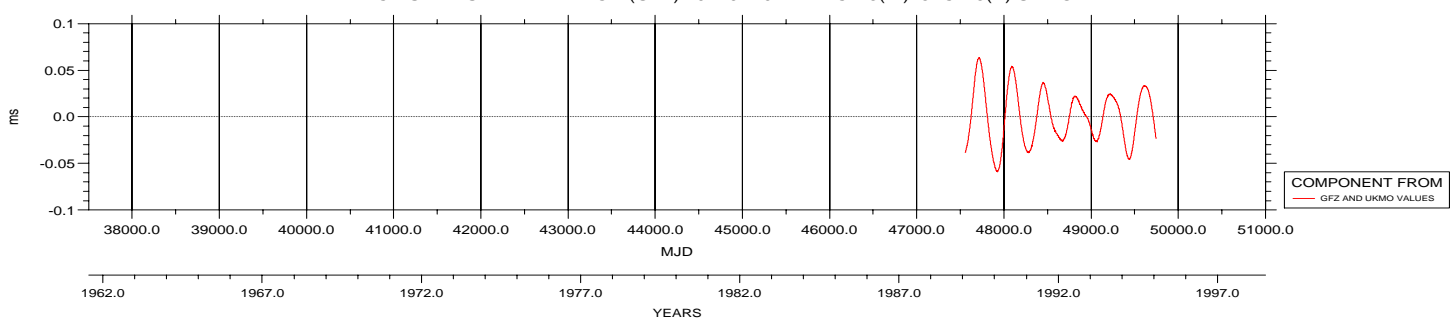

SEMIANNUAL OSCILLATION
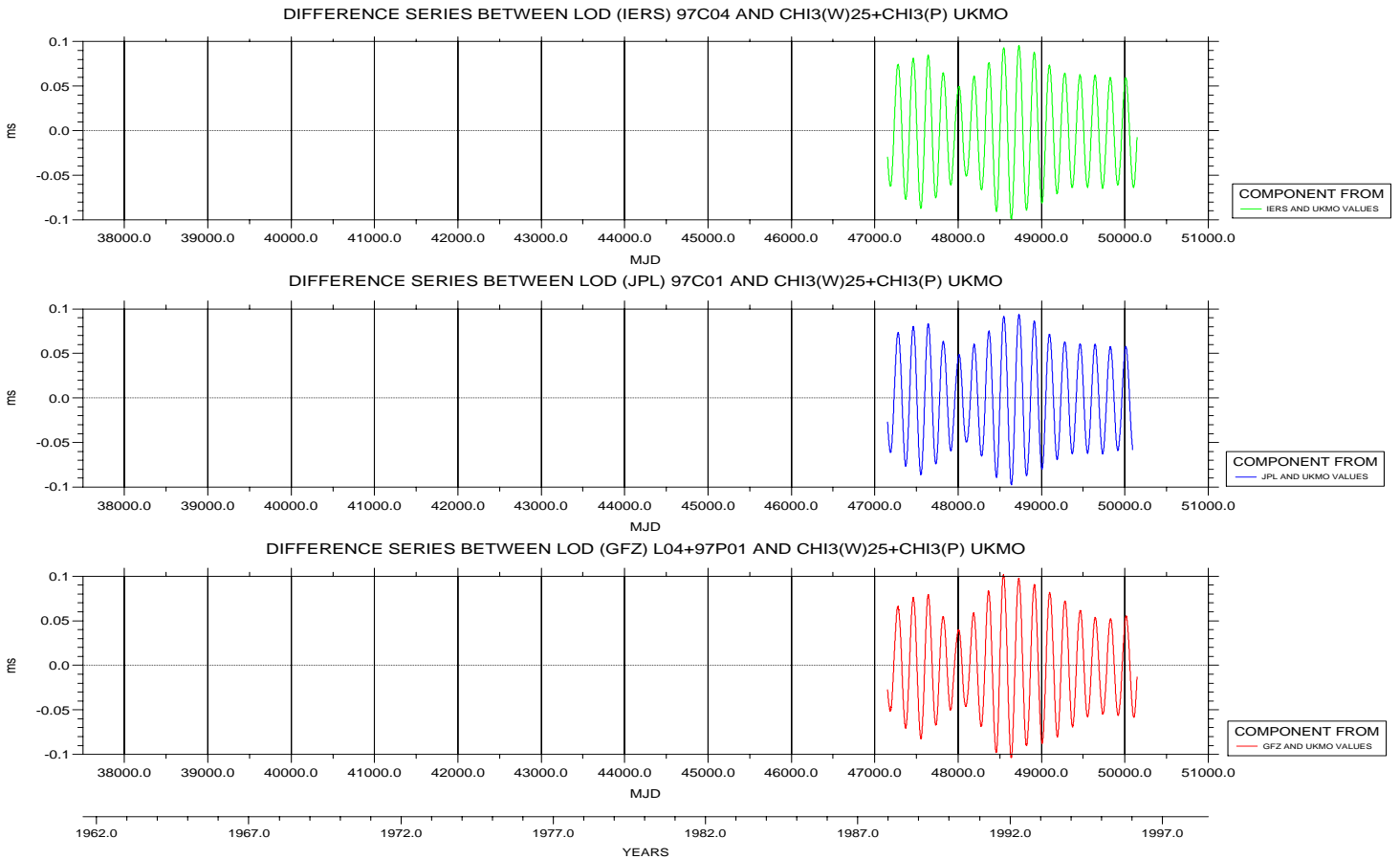

Figure 23. Seasonal oscillations of the difference series between the LOD data in the system of IERS (top),, of JPL (centre) and of GFZ (bottom)

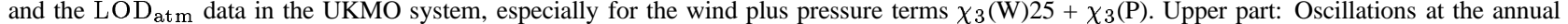
frequency. Lower part: Oscillations at the semiannual frequency 

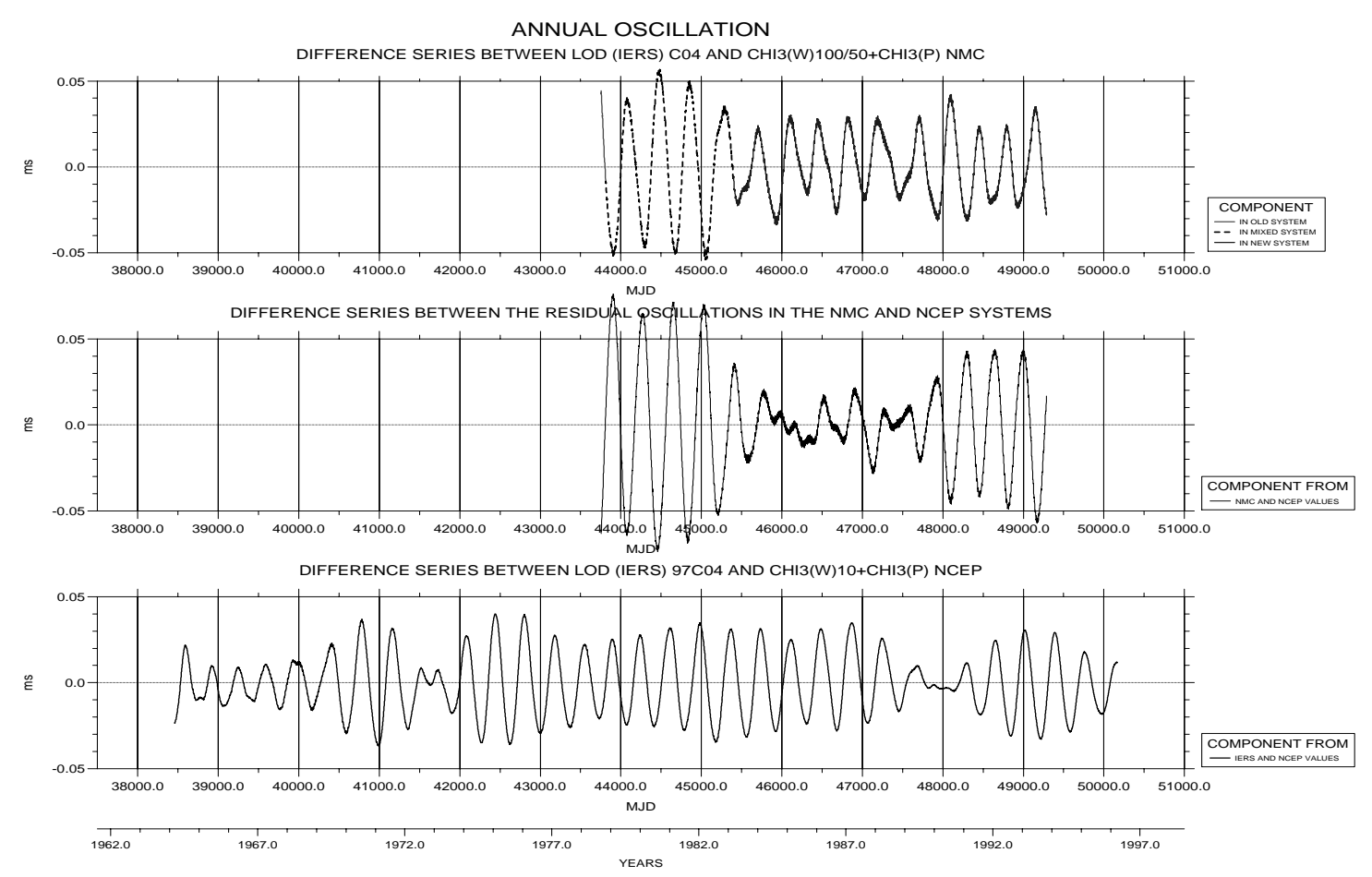

ANNUAL OSCILLATION
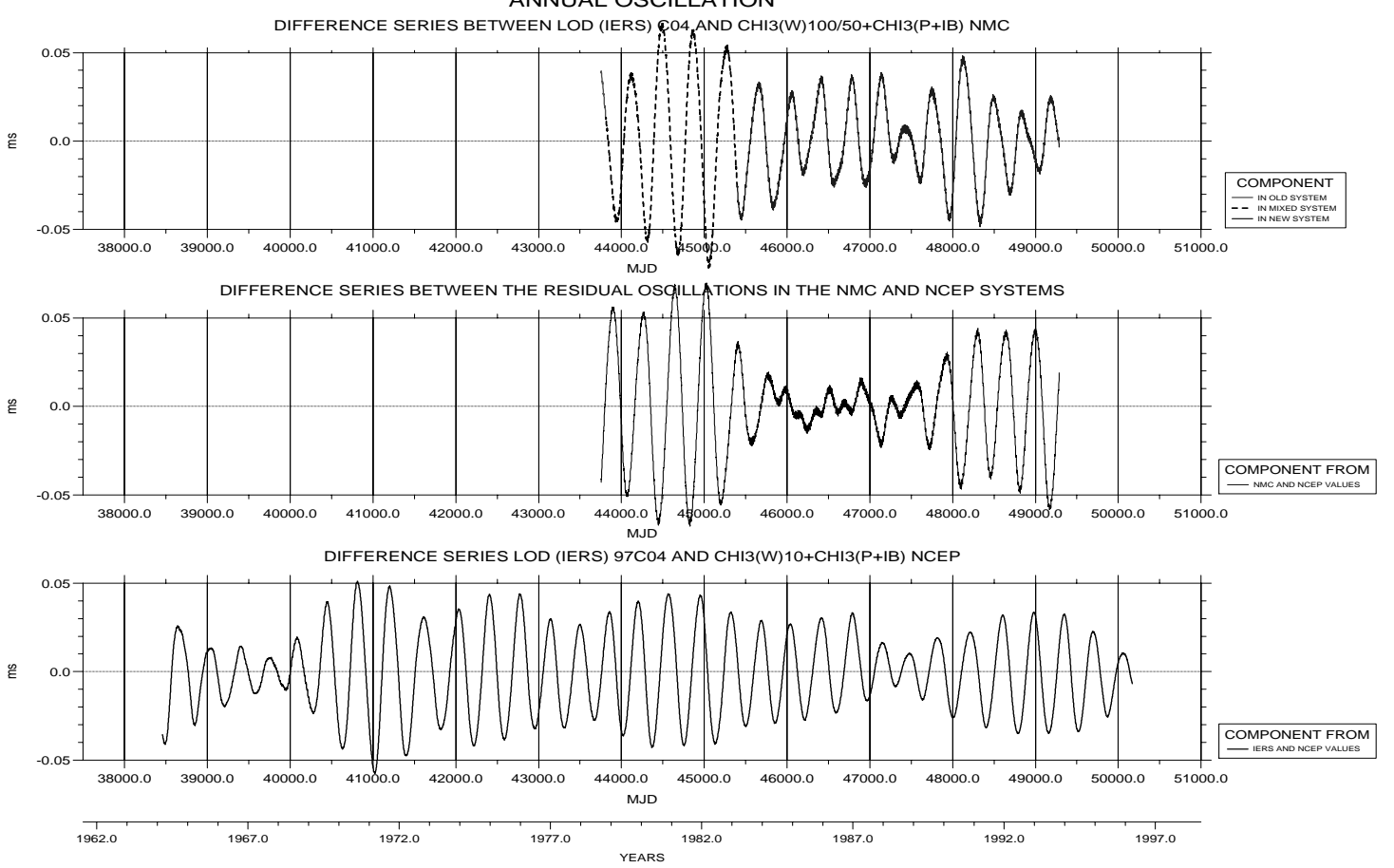

Figure 24. Annual residual oscillation between the LOD data of IERS and the LOD atm data of NMC (top), between the LOD ${ }_{\text {atm }}$ data of NMC and NCEP Reanalysis (centre) and between the LOD data of IERS and the LOD atm data of NCEP Reanalysis (bottom). Upper part: The LOD atm data are those of the $\chi_{3}(\mathrm{~W})+\chi_{3}(\mathrm{P})$ terms. Lower part: The LOD atm data are those of the $\chi_{3}(\mathrm{~W})+\chi_{3}(\mathrm{P}+\mathrm{IB})$ terms 
SEMIANNUAL OSCILLATION

DIFFERENCE SERIES BETWEEN LOD (IERS) C04 AND CHI3(W)100/50+CHI3(P) NMC

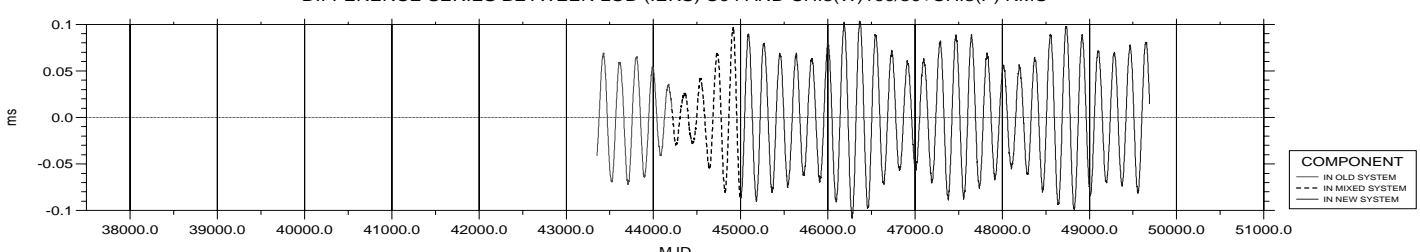

DIFFERENCE SERIES BETWEEN THE RESIDUAL OSCILLATIONS IN THE NMC AND NCEP SYSTEMS

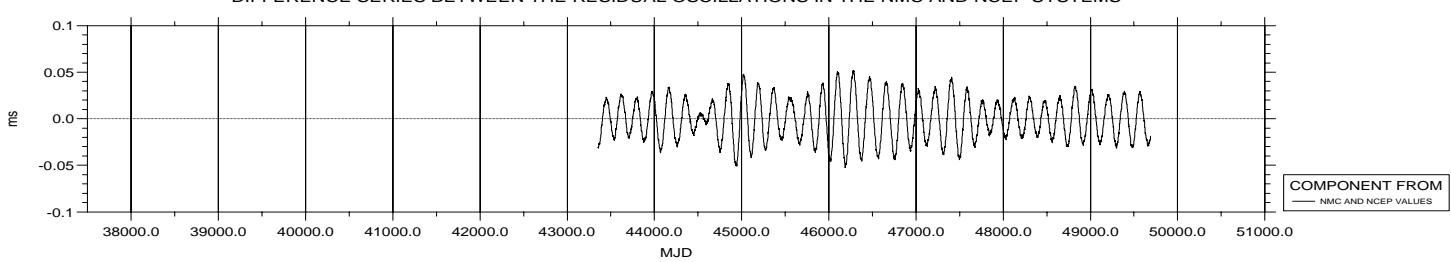

DIFFERENCE SERIES BETWEEN LOD (IERS) $97 \mathrm{CO} 4$ AND CHI3(W)10+CHI3(P) NCEP

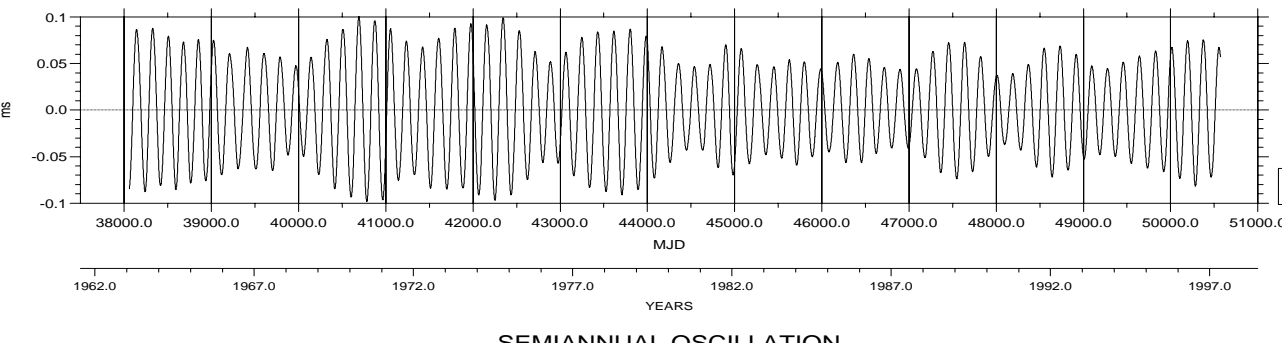

SEMIANNUAL OSCILLATION

DIFFERENCE SERIES BETWEEN LOD (IERS) C04 AND CHI3(W)100/50+CHI3(P+IB) NMC
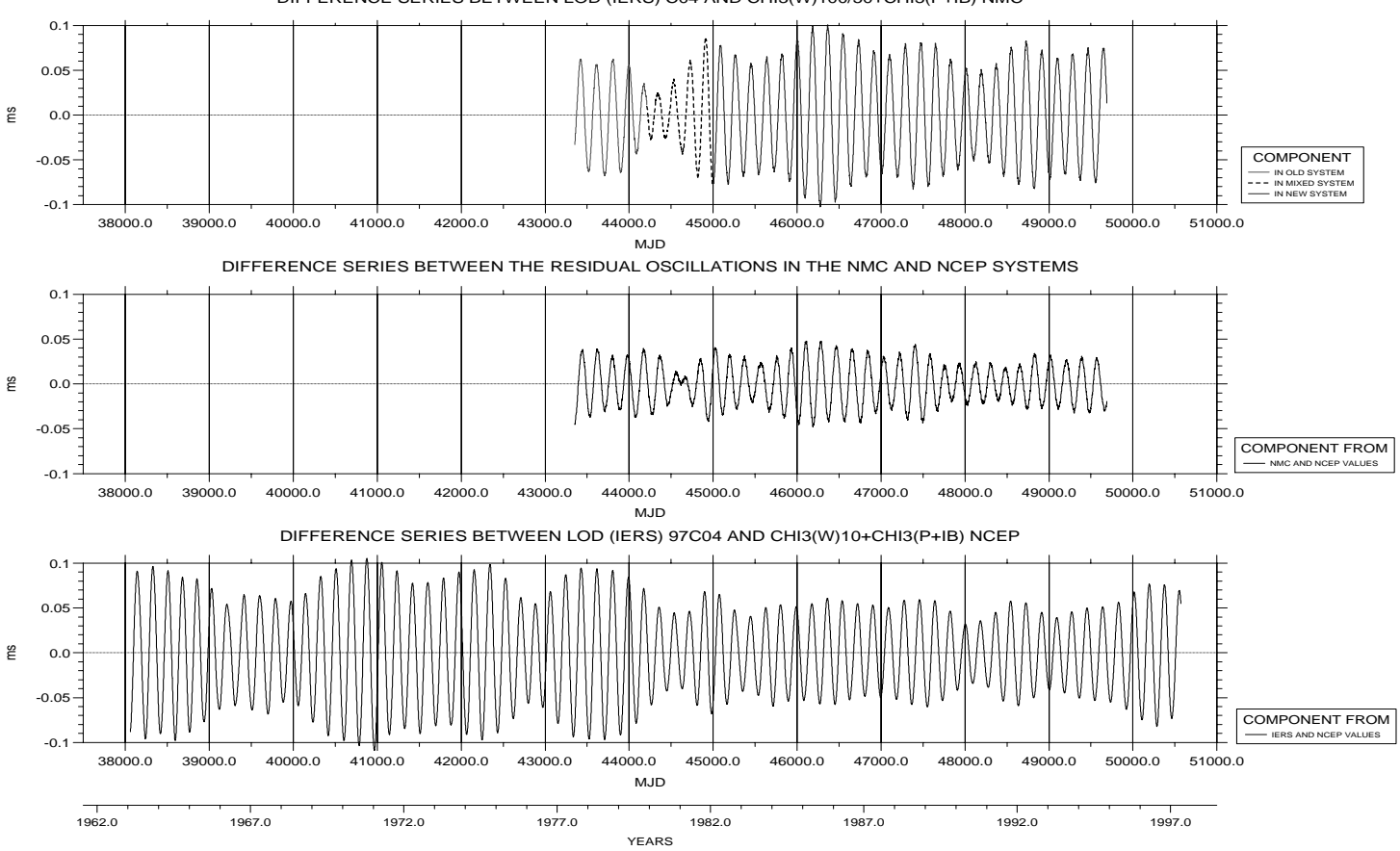

Figure 25. Same as Fig. 24, but for the semiannual residual oscillation 
ANNUAL OSCILLATION

WIND TERM OF THE 10-1 hPA ATMOSPHERIC LAYER

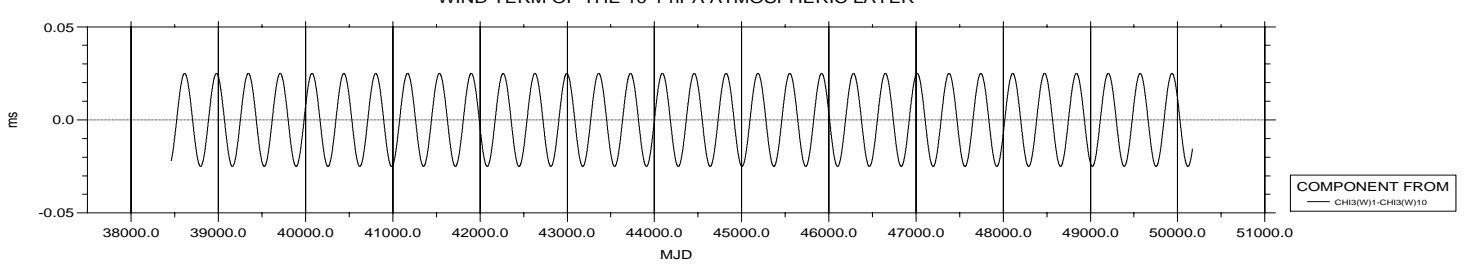

ANTARCTIC CIRCUM-POLAR CURRENT (ACPC)

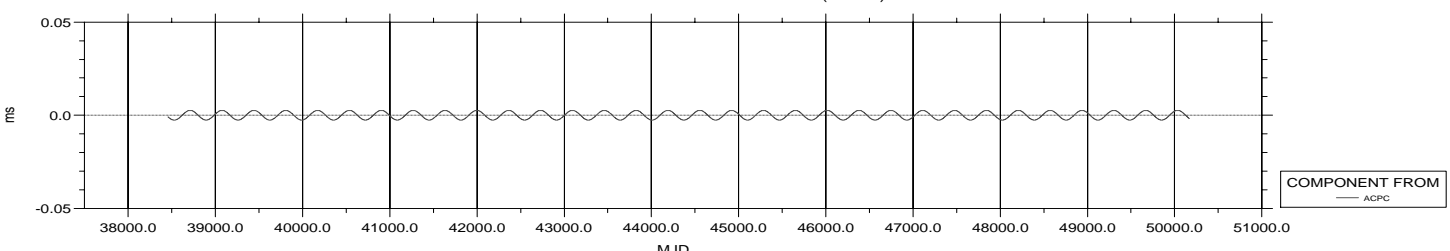

SURFACE WATER STORAGE

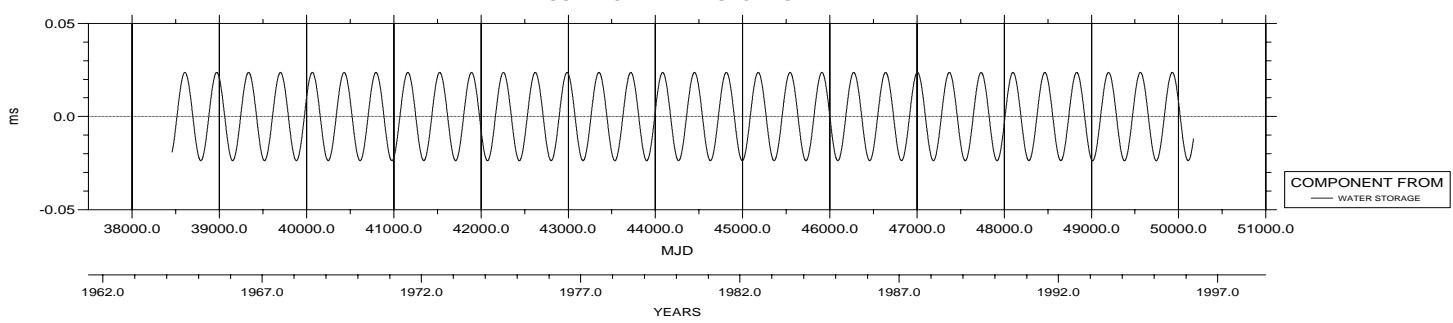

SEMIANNUAL OSCILLATION

WIND TERM OF THE 10-1 hPA ATMOSPHERIC LAYER

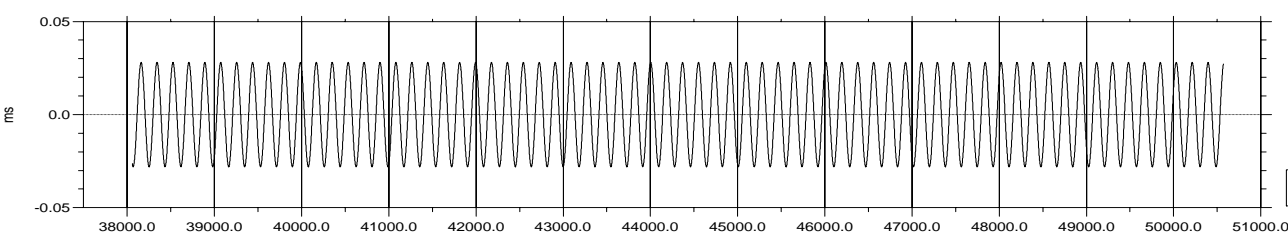

ANTARCTIC CIRCUM-POLAR CURRENT (ACPC)

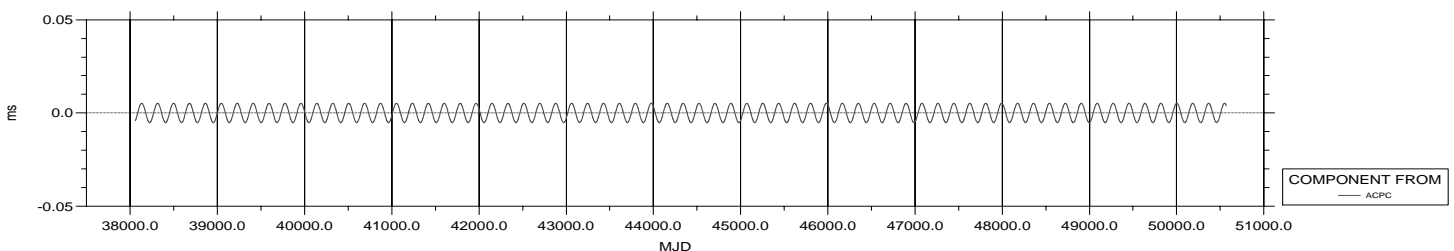

SURFACE WATER STORAGE

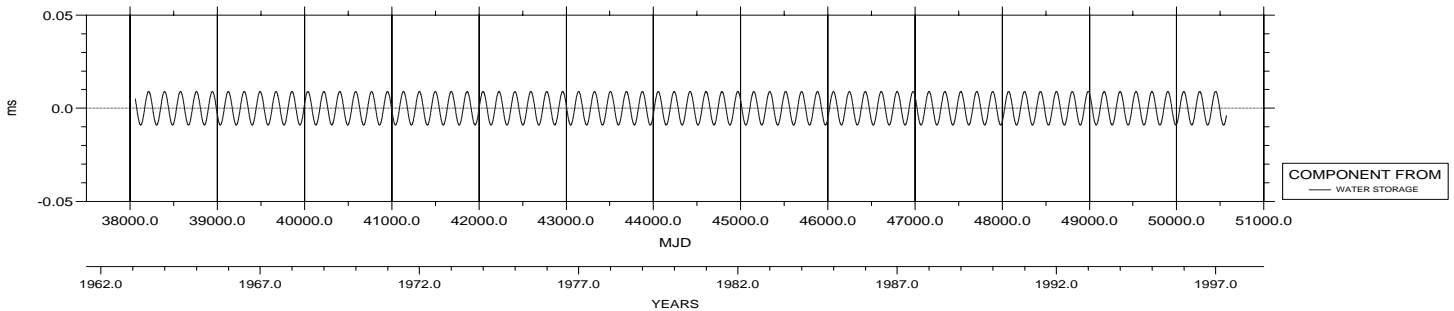

Figure 26. Seasonal oscillations of other contributions for explaining the significant imbalances in the solid Earth-atmosphere angular momentum budget. Upper part: Oscillations at the annual frequency. Lower part: Oscillations at the semiannual frequency. In either case: The component of the wind term neglected from the 10-1 hPa atmospheric layer (top), that of the Antarctic Circum-Polar Current (centre) and that of the Surface water storage (bottom) 
Publication: Scientific Technical Report

No.: STR98/10

Author: J. Höpfner

Table 11. Time spans of the seasonal residual oscillations derived as difference series between LOD and LOD atm results in the different systems given in calendar days and MJD. The upper two lines apply to the annual frequency and the lower two lines to the semiannual frequency

\begin{tabular}{lccc}
\hline Center / System & IERS & GFZ & JPL \\
\hline NCEP Reanalysis & March $1970 \ldots$ April 1995 & Sept. 1985 .. April 1995 & Dec. 1978 .. Dec. 1994 \\
& $40650.0 \ldots 49835.0$ & $46310.0 \ldots 49835.0$ & $43843.0 \ldots 49693.0$ \\
& Jan. $1969 \ldots$ June 1996 & July $1984 \ldots$ June 1996 & Oct. $1977 \ldots$ Jan. 1996 \\
& $40249.0 \ldots 50236.0$ & $45909.0 \ldots 50236.0$ & $43442.0 \ldots 50094.0$ \\
JMA & Nov. $1985 \ldots$ Jan. 1995 & Nov. $1985 \ldots$ Jan. 1995 & Dec. $1978 \ldots$ Dec. 1994 \\
& $46399.0 \ldots 49744.0$ & $46399.0 \ldots 49744.0$ & $46399.0 \ldots 49693.0$ \\
Oct. $1984 \ldots$ March 1996 & Oct. $1984 \ldots$ March 1996 & Oct. $1984 \ldots$ Jan. 1996 \\
& $45998.0 \ldots 50145.0$ & $45998.0 \ldots 50145.0$ & $45998.0 \ldots 50094.0$ \\
& March $1990 \ldots$ April 1994 & March $1990 \ldots$ April 1994 & March $1990 \ldots$ April 1994 \\
& $47955.0 \ldots 49470.0$ & $47955.0 \ldots 49470.0$ & $47955.0 \ldots 49470.0$ \\
UKMO & Jan. $1989 \ldots$ June 1995 & Jan. $1989 \ldots$ June 1995 & Jan. $1989 \ldots$ June 1995 \\
& $47554.0 \ldots 49871.0$ & $47554.0 \ldots 49871.0$ & $47554.0 \ldots 49871.0$ \\
& Jan. $1989 \ldots$ Jan. 1995 & Jan. $1989 \ldots$ Jan. 1995 & Jan. $1989 \ldots$ Dec. 1994 \\
& $47555.0 \ldots 49744.0$ & $47555.0 \ldots 49744.0$ & $47555.0 \ldots 49693.0$ \\
& Dec. $1987 \ldots$ March 1996 & Dec. $1987 \ldots$ March 1996 & Dec. $1987 \ldots$ Jan. 1996 \\
& $47154.0 \ldots 50145.0$ & $47154.0 \ldots 50145.0$ & $47154.0 \ldots 50094.0$ \\
\hline
\end{tabular}

In Figures 24 and 25, the difference series between the seasonal oscillations of the LOD atm data in the old NMC system with the top level of 100 and $50 \mathrm{hPa}$, respectively, and those in the new NCEP Reanalysis system with the top level of $10 \mathrm{hPa}$ are shown, with the $\mathrm{LOD}_{\mathrm{atm}}$ data of the $\chi_{3}(\mathrm{~W})+\chi_{3}(\mathrm{P})$ terms in the upper part and those of the $\chi_{3}(\mathrm{~W})$ $+\chi_{3}(\mathrm{P}+\mathrm{IB})$ terms in the lower part. The residual oscillation between the LOD data of IERS and the LOD atm data of NMC is given in the top panel, that between the $\mathrm{LOD}_{\text {atm }}$ data of NMC and NCEP Reanalysis in the middle panel and that between the LOD data of IERS and the LOD atm data of NCEP Reanalysis in the bottom panel, where the results apply to the annual frequency in Figure 24 and to the semiannual frequency in Figure 25. For more details on the results in the old NMC system, see Höpfner (1997).

Next, we shall discuss and assess the seasonal discrepancies in the solid Earth-atmosphere axial angular momentum budget. We first consider the annual and then the semiannual residual oscillations referred to the different LOD-LOD systems. If comparing the remainders relating to $\mathrm{LOD}_{\mathrm{atm}}$ systems having the same 10-hPa top level in computing the wind term $\chi_{3}(\mathrm{~W})$, note that the curves for $\chi_{3}(\mathrm{~W}) 10+\chi_{3}(\mathrm{P})$ and those for $\chi_{3}(\mathrm{~W}) 10+\chi_{3}(\mathrm{P}+\mathrm{IB})$ plotted in the panels of the upper and lower parts, respectively, of each figure should be similar to each other to reflect significant signals, whereas disagreements may be due to systematic differences between the $\mathrm{LOD}_{\mathrm{atm}}$ systems. Therefore, we compare the residual oscillations shown in Figures 17 to 19 at the annual frequency and those shown in Figures 20 to 22 at the semiannual frequency before discussing and assessing the other results.

(a) Annual residual oscillations

In order to assess the annual results from $\mathrm{LOD}_{\text {atm }}$ data in the NCEP Reanalysis, JMA and ECMWF systems with the same top level of $10 \mathrm{hPa}$, Figures 17 to 19 are used. In general, the figures show annual imbalances in the solid Earthatmosphere axial angular momentum budget as significant residual oscillations with an amplitude of about $0.025 \mathrm{~ms}$. However, a clear disagreement exists between the component referred to the NCEP Reanalysis system (top panel) and that referred to the JMA system (middle panel) over the common interval. Note the same, compared both the NCEP component and the JMA component to that referred to the ECMWF system (bottom panel). The influence of the IB assumption can be seen by comparison of the curves of the $\mathrm{LOD}_{\mathrm{atm}}$ component in terms of $\chi_{3}(\mathrm{~W}) 10+\chi_{3}(\mathrm{P})$ in the upper part of each figure with those of the $\mathrm{LOD}_{\mathrm{atm}}$ component in terms of $\chi_{3}(\mathrm{~W}) 10+\chi_{3}(\mathrm{P}+\mathrm{IB})$ in the lower part. Usually, the annual residual oscillations inferred without IB effect show smaller amplitudes than those inferred with IB effect. As can be seen in the upper part of Figure 15, the annual IB oscillation has an amplitude of about $0.030 \mathrm{~ms}$. Considering that the annual JMA residual oscillations are closer to harmonic than those of NCEP Reanalysis and those of ECMWF over the common interval, we regard the former as more significant than the latter.

The upper part of Figure 23 shows the annual residual oscillations referred to the LOD atm system of the UKMO with about $25-\mathrm{hPa}$ top level for the term $\chi_{3}(\mathrm{~W}) 25+\chi_{3}(\mathrm{P})$. Notice how each signal runs continuously. The curves should be compared to those of the $\mathrm{LOD}_{\text {atm }}$ systems that include the top level up to $10 \mathrm{hPa}$ shown in Figures 17 to 19 . Here, consider that the signal in the $25-10 \mathrm{hPa}$ atmospheric layer is missing for the UKMO system versus those of NCEP Reanalysis, JMA and ECMWF. Therefore, there is a larger amplitude difference (see also Section 5.2). However, the agreement between the curves of the UKMO and JMA systems in phase is good. This finding suggests that the annual 
Publication: Scientific Technical Report

No.: STR98/10

Author: J. Höpfner

Table 12. Ranges of the variations in amplitude, phase and period including the standard errors of the seasonal residual oscillations between the LOD data in IERS system and the LOD ${ }_{\mathrm{atm}}$ data in the different systems. Min, minimum; Max, maximum; Dif, difference between maximum and minimum; $\mathrm{s}_{0}$, standard error of a single estimate; $\mathrm{s}_{\text {amplitude, }}$ standard error of an amplitude mean; $\mathrm{s}_{\mathrm{phase}}$, standard error of a phase mean; $\mathrm{s}_{\mathrm{period}}$, standard error of a period three-point mean; n, number of the pairs; in case of the period, number of the differences

\begin{tabular}{|c|c|c|c|c|c|c|}
\hline \multirow{2}{*}{$\begin{array}{l}\text { Component from } \\
\text { IERS and ... }\end{array}$} & \multicolumn{3}{|c|}{ Ranges of the variations } & \multicolumn{2}{|c|}{ Standard deviations } & \multirow[b]{2}{*}{$\mathrm{n}$} \\
\hline & Min & Max & Dif & $\mathrm{s}_{0}$ & Smean & \\
\hline \multicolumn{7}{|l|}{ (a) Annual residual oscillation } \\
\hline \multicolumn{7}{|c|}{ Amplitude estimates (in $\mathrm{ms}$ ); $\mathrm{s}_{\text {mean }}=\mathrm{s}_{\text {amplitude }}$} \\
\hline $\operatorname{NCEP} \chi_{3}(\mathrm{~W}) 10+\chi_{3}(\mathrm{P})(1)$ & 0.027 & 0.037 & 0.010 & \pm 0.002 & \pm 0.002 & 2 \\
\hline$(2)$ & 0.017 & 0.040 & 0.023 & \pm 0.004 & \pm 0.003 & 15 \\
\hline (3) & 0.012 & 0.033 & 0.021 & \pm 0.004 & \pm 0.002 & 4 \\
\hline $\operatorname{NCEP} \chi_{3}(\mathrm{~W}) 10+\chi_{3}(\mathrm{P}+\mathrm{IB})$ & 0.009 & 0.058 & 0.049 & \pm 0.004 & \pm 0.003 & 24 \\
\hline JMA $\chi_{3}(\mathrm{~W}) 10+\chi_{3}(\mathrm{P})$ & 0.014 & 0.031 & 0.017 & \pm 0.003 & \pm 0.002 & 9 \\
\hline JMA $\chi_{3}(\mathrm{~W}) 10+\chi_{3}(\mathrm{P}+\mathrm{IB})$ & 0.006 & 0.032 & 0.026 & \pm 0.005 & \pm 0.003 & 9 \\
\hline ECMWF $\chi_{3}(\mathrm{~W}) 10+\chi_{3}(\mathrm{P})$ & 0.008 & 0.018 & 0.018 & \pm 0.002 & \pm 0.001 & 1 \\
\hline $\mathrm{UKMO} \chi_{3}(\mathrm{~W}) 25+\chi_{3}(\mathrm{P})$ & 0.023 & 0.068 & 0.045 & \pm 0.004 & \pm 0.003 & 6 \\
\hline \multicolumn{7}{|c|}{ Phase estimates (in degrees); $\mathbf{s}_{\text {mean }}=\mathrm{s}_{\text {phase }}$} \\
\hline $\operatorname{NCEP} \chi_{3}(\mathrm{~W}) 10+\chi_{3}(\mathrm{P})(1)$ & & & & \pm 11.77 & \pm 8.33 & 1 \\
\hline$(2)$ & 356.27 & 85.67 & 89.40 & \pm 8.54 & \pm 6.04 & 15 \\
\hline (3) & 31.97 & 41.23 & 9.26 & \pm 9.11 & \pm 6.44 & 4 \\
\hline $\operatorname{NCEP} \chi_{3}(\mathrm{~W}) 10+\chi_{3}(\mathrm{P}+\mathrm{IB})$ & 232.86 & 359.03 & 126.17 & \pm 9.15 & \pm 6.47 & 24 \\
\hline JMA $\chi_{3}(\mathrm{~W}) 10+\chi_{3}(\mathrm{P})$ & 55.13 & 209.75 & 156.63 & \pm 19.70 & \pm 13.93 & 7 \\
\hline JMA $\chi_{3}(\mathrm{~W}) 10+\chi_{3}(\mathrm{P}+\mathrm{IB})$ & 222.95 & 257.44 & 34.48 & \pm 13.11 & \pm 9.27 & 7 \\
\hline ECMWF $\chi_{3}(\mathrm{~W}) 10+\chi_{3}(\mathrm{P})$ & \multicolumn{2}{|c|}{148.54} & & \pm 11.80 & \pm 8.34 & 1 \\
\hline $\mathrm{UKMO} \chi_{3}(\mathrm{~W}) 25+\chi_{3}(\mathrm{P})$ & 174.41 & 213.71 & 39.30 & \pm 5.49 & \pm 3.88 & 4 \\
\hline \multicolumn{7}{|c|}{ Period estimates (in days) $; \mathrm{s}_{\text {mean }}=\mathrm{s}_{\mathrm{p} \text { eriod }}$} \\
\hline $\operatorname{NCEP} \chi_{3}(\mathrm{~W}) 10+\chi_{3}(\mathrm{P})(1)$ & 373.17 & 382.50 & 9.33 & \pm 12.58 & \pm 7.26 & 2 \\
\hline$(2)$ & 338.94 & 389.32 & 50.38 & \pm 6.26 & \pm 3.61 & 29 \\
\hline (3) & 365.17 & 375.36 & 10.19 & \pm 10.48 & \pm 6.05 & 6 \\
\hline $\operatorname{NCEP} \chi_{3}(\mathrm{~W}) 10+\chi_{3}(\mathrm{P}+\mathrm{IB})$ & 320.69 & 420.07 & 99.38 & \pm 6.47 & \pm 3.74 & 47 \\
\hline JMA $\chi_{3}(\mathrm{~W}) 10+\chi_{3}(\mathrm{P})$ & 333.03 & 432.01 & 98.98 & \pm 13.51 & \pm 7.80 & 15 \\
\hline JMA $\chi_{3}(\mathrm{~W}) 10+\chi_{3}(\mathrm{P}+\mathrm{IB})$ & 329.48 & 430.85 & 101.37 & \pm 7.63 & \pm 4.40 & 13 \\
\hline ECMWF $\chi_{3}(\mathrm{~W}) 10+\chi_{3}(\mathrm{P})$ & \multicolumn{2}{|c|}{366} & & \pm 35.36 & \pm 20.41 & 1 \\
\hline $\mathrm{UKMO} \chi_{3}(\mathrm{~W}) 25+\chi_{3}(\mathrm{P})$ & 349.15 & 377.45 & 28.30 & \pm 5.74 & \pm 3.31 & 10 \\
\hline
\end{tabular}

residual oscillation referred to the JMA system has more significance than to those referred to the NCEP Reanalysis and ECMWF systems.

(b) Semiannual residual oscillations

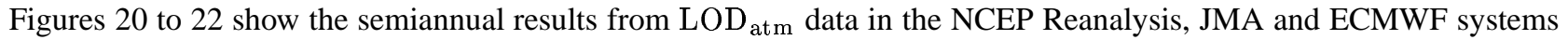
with the same 10-hPa top level. Semiannual imbalances in the solid Earth-atmosphere axial angular momentum budget are indicated by significant residual oscillations that have an amplitude of 0.050 to $0.070 \mathrm{~ms}$. In contrast to the annual residual oscillations, the semiannual curve referred to the NCEP Reanalysis system (top panel) is quite similar to that referred to the JMA system (middle panel) over the common interval. Moreover, both curves agree visibly better to that referred to the ECMWF system (bottom panel). As for the annual residual oscillations, a comparison of the curves for $\chi_{3}(\mathrm{~W}) 10+\chi_{3}(\mathrm{P})$ shown in the upper part with those for $\chi_{3}(\mathrm{~W}) 10+\chi_{3}(\mathrm{P}+\mathrm{IB})$ in the lower part of each figure reveals the role of the IB response to the semiannual residual oscillations. Disregarding the time span before 1980, the semiannual oscillations inferred without IB effect have somewhat larger amplitudes than those inferred with IB effect. This behaviour is opposite to that obtained for the annual residual oscillations. As shown in the lower part of Figure 15, the semiannual IB oscillation varies with an amplitude of only $0.015 \mathrm{~ms}$.

Concerning the significance of the semiannual residual oscillations, no distinction between the results of NCEP Reanalysis and JMA should be made since both are in good agreement not only in amplitude but also in phase over the same interval. The much larger amplitudes of the semiannual residual oscillation of NCEP Reanalysis before 1980 in Figures 20 and 22 indicate that the uncertainty of the LOD data is larger during that period (see Table 2). 
Table 12. Continued

\begin{tabular}{|c|c|c|c|c|c|c|}
\hline \multirow{2}{*}{$\begin{array}{l}\text { Component from } \\
\text { IERS and ... }\end{array}$} & \multicolumn{3}{|c|}{ Ranges of the variations } & \multicolumn{2}{|c|}{ Standard deviations } & \multirow[b]{2}{*}{$\mathrm{n}$} \\
\hline & Min & $\operatorname{Max}$ & Dif & $\mathrm{s}_{0}$ & Smean & \\
\hline \multicolumn{7}{|c|}{ (b) Semiannual residual oscillation } \\
\hline \multicolumn{7}{|c|}{ Amplitude estimates (in $\mathrm{ms}$ ); $\mathrm{s}_{\text {mean }}=\mathrm{s}_{\text {amplitude }}$} \\
\hline $\operatorname{NCEP} \chi_{3}(\mathrm{~W}) 10+\chi_{3}(\mathrm{P})$ & 0.037 & 0.100 & 0.063 & \pm 0.005 & \pm 0.003 & 54 \\
\hline $\operatorname{NCEP} \chi_{3}(\mathrm{~W}) 10+\chi_{3}(\mathrm{P}+\mathrm{IB})$ & 0.032 & 0.109 & 0.077 & \pm 0.004 & \pm 0.003 & 54 \\
\hline JMA $\chi_{3}(\mathrm{~W}) 10+\chi_{3}(\mathrm{P})$ & 0.039 & 0.070 & 0.031 & \pm 0.003 & \pm 0.002 & 22 \\
\hline JMA $\chi_{3}(\mathrm{~W}) 10+\chi_{3}(\mathrm{P}+\mathrm{IB})$ & 0.038 & 0.059 & 0.021 & \pm 0.002 & \pm 0.002 & 22 \\
\hline ECMWF $\chi_{3}(\mathrm{~W}) 10+\chi_{3}(\mathrm{P})$ & 0.012 & 0.053 & 0.041 & \pm 0.005 & \pm 0.004 & 12 \\
\hline $\mathrm{UKMO} \chi_{3}(\mathrm{~W}) 25+\chi_{3}(\mathrm{P})$ & 0.050 & 0.099 & 0.049 & \pm 0.005 & \pm 0.003 & 16 \\
\hline \multicolumn{7}{|c|}{ Phase estimates (in degrees) $;$ Smean $=\mathrm{s}_{\text {phase }}$} \\
\hline $\operatorname{NCEP} \chi_{3}(\mathrm{~W}) 10+\chi_{3}(\mathrm{P})$ & 195.12 & 239.39 & 44.25 & \pm 4.88 & \pm 3.45 & 54 \\
\hline $\operatorname{NCEP} \chi_{3}(\mathrm{~W}) 10+\chi_{3}(\mathrm{P}+\mathrm{IB})$ & 195.80 & 235.00 & 39.20 & \pm 5.08 & \pm 3.59 & 54 \\
\hline JMA $\chi_{3}(\mathrm{~W}) 10+\chi_{3}(\mathrm{P})$ & 205.82 & 245.90 & 40.08 & \pm 4.58 & \pm 3.24 & 22 \\
\hline JMA $\chi_{3}(\mathrm{~W}) 10+\chi_{3}(\mathrm{P}+\mathrm{IB})$ & 199.82 & 238.65 & 38.83 & \pm 6.92 & \pm 4.90 & 22 \\
\hline ECMWF $\chi_{3}(\mathrm{~W}) 10+\chi_{3}(\mathrm{P})$ & 217.81 & 242.91 & 25.10 & \pm 5.97 & \pm 4.22 & 9 \\
\hline $\mathrm{UKMO} \chi_{3}(\mathrm{~W}) 25+\chi_{3}(\mathrm{P})$ & 208.21 & 235.76 & 27.55 & \pm 4.63 & \pm 3.28 & 16 \\
\hline \multicolumn{7}{|c|}{ Period estimates (in days) $; s_{\text {mean }}=s_{\text {period }}$} \\
\hline $\operatorname{NCEP} \chi_{3}(\mathrm{~W}) 10+\chi_{3}(\mathrm{P})$ & 171.32 & 194.44 & 23.12 & \pm 2.23 & \pm 1.28 & 107 \\
\hline $\operatorname{NCEP} \chi_{3}(\mathrm{~W}) 10+\chi_{3}(\mathrm{P}+\mathrm{IB})$ & 171.77 & 189.72 & 17.96 & \pm 2.07 & \pm 1.19 & 107 \\
\hline JMA $\chi_{3}(\mathrm{~W}) 10+\chi_{3}(\mathrm{P})$ & 174.12 & 190.24 & 16.12 & \pm 2.44 & \pm 1.41 & 43 \\
\hline JMA $\chi_{3}(\mathrm{~W}) 10+\chi_{3}(\mathrm{P}+\mathrm{IB})$ & 173.46 & 190.07 & 16.61 & \pm 2.21 & \pm 1.27 & 43 \\
\hline ECMWF $\chi_{3}(\mathrm{~W}) 10+\chi_{3}(\mathrm{P})$ & 178.84 & 189.91 & 10.97 & \pm 3.41 & \pm 1.97 & 16 \\
\hline $\mathrm{UKMO} \chi_{3}(\mathrm{~W}) 25+\chi_{3}(\mathrm{P})$ & 176.96 & 187.46 & 10.50 & \pm 2.00 & \pm 1.15 & 30 \\
\hline
\end{tabular}

Analogous to the annual residual oscillations plotted in the upper part of Figure 23, the lower part shows the semiannual residual oscillations for the $\chi_{3}(\mathrm{~W}) 25+\chi_{3}(\mathrm{P})$ term referred to the UKMO system with about 25-hPa top level. Again compare these oscillations with those of the $\mathrm{LOD}_{\mathrm{atm}}$ systems with 10-hPa top level illustrated in Figure 20 to 22 . Similar to the annual residual oscillation, the semiannual residual oscillation of the UKMO system shows a larger amplitude than those of the other systems in consequence of the signal missing from the atmospheric layer between 25 and $10 \mathrm{hPa}$. Since the semiannual $\mathrm{LOD}_{\mathrm{atm}}$ oscillation has a smaller amplitude than that of LOD, this issue is opposite to that of the comparison of the $\mathrm{LOD}_{\mathrm{atm}}$ results described in Section 5.2. For the phase, the behaviour of the UKMO residual oscillation largely agrees with those of the NCEP Reanalysis and JMA residual oscillations and only slightly differs from that of the ECMWF residual oscillation.

Table 12 lists the ranges of amplitude, phase and period variations including standard deviations of the seasonal residual oscillations between the LOD data in the IERS system and the LOD atm data in the different systems. Obviously, the annual residual oscillations agree less well than the semiannual ones with respect to the variations of the oscillation parameters.

The middle panels of Figures 24 and 25 show the differences between the LOD atm data in the systems of NMC and NCEP Reanalysis at the annual and semiannual frequencies, respectively. For completeness, the upper panels show the residual oscillations between the LOD data of the IERS and the LOD atm $_{\text {data }}$ of the NMC and the lower panels those between the LOD data of the IERS and the LOD atm data of the NCEP Reanalysis. Here, the LOD atm data are those of the $\chi_{3}(\mathrm{~W})+\chi_{3}(\mathrm{P})$ terms in the upper parts and those of the $\chi_{3}(\mathrm{~W})+\chi_{3}(\mathrm{P}+\mathrm{IB})$ terms in the lower parts. The seasonal wind portions missing from the atmospheric layer between 100 or 50 and $10 \mathrm{hPa}$ are annual oscillations with amplitudes up to $0.070 \mathrm{~ms}$ and semiannual oscillations with amplitudes up to $0.050 \mathrm{~ms}$.

Significant imbalances in the solid Earth-atmosphere axial angular momentum budget may be caused by other excitation sources. To explain them, the following contributions come into question:

(1) Wind term neglected from the 10-1 hPa atmospheric layer; see Rosen and Salstein (1991)

(2) Antarctic Circum-Polar Current; see Naito and Kikuchi (1990) and

(3) Surface water storage; see Chao and O'Connor (1988). 
Detailed information on their effects to seasonal oscillations in LOD can be found in Höpfner (1997). For purposes of comparison with the residual signals obtained from the LOD and LOD atm $_{\text {data }}$ in the different systems, the seasonal components are illustrated in Figure 26, namely those at the annual frequency in the upper part and those at the semiannual frequency in the lower part. In either case, the contribution of the missing wind term $\chi_{3}(\mathrm{~W})(10-1)$ is shown in the upper panel, that of the Antarctic Circum-Polar Current in the middle panel and that of the Surface water storage in the lower panel.

For explaining the significant annual and semiannual discrepancies in the solid Earth-atmosphere axial angular momentum budget as computed here as residual oscillations, there is the need to extend the top level into the upper stratosphere up to $1 \mathrm{hPa}$ in computing the wind term $\chi_{3}(\mathrm{~W})$. After incorporating the wind term neglected from the 10-1 hPa atmospheric layer, the imbalances may largely be eliminated. As assessed by Höpfner (1997), the significant annual imbalance could be explained by the contribution of the missing wind term $\chi_{3}(\mathrm{~W})(10-1)$ counterbalancing the excess of the $\mathrm{LOD}_{\text {atm }}$ oscillation at the achieved level of uncertainty. Also, the significant semiannual imbalance could be largely due to the neglect of this term. A comparison of the imbalance curves with that of the related wind signal in the 10-1 $\mathrm{hPa}$ atmospheric layer, namely Figures 17 to 19 with the upper panel in the upper part of Figure 26 in case of the annual frequency and Figures 20 to 22 with the upper panel in the lower part of Figure 26 in case of the semiannual frequency, confirms this assessment.

Since the wind term $\chi_{3}(\mathrm{~W})(10-1)$ neglected until now does yet not achieve a balance in the solid Earth-atmosphere axial angular momentum budget at the semiannual frequency, a hydrological contribution may be likely. In the lower panels of Figure 26, the surface-water-induced oscillations as computed by Chao and O'Connor (1988) are shown. Notice that the annual contribution is too large whereas the semiannual one may have the estimated magnitude. Only if the precision of the $\mathrm{LOD}_{\mathrm{atm}}$ data is improved by an order of magnitude, an excitation source such as the Antarctic Circum-Polar Current as shown in the middle panels of Figure 26 can no longer be ignored. For a recent progress on studying the HydrologicalAngular-Momentum (HAM) and Oceanic-Angular-Momentum (OAM) variations and their role in the global angular momentum budget, see Chen et al. (1997).

\section{Summary and concluding remarks}

Recently, effective Atmospheric-Angular-Momentum (AAM) functions as calculated from the U. S. National Centers for Environmental Prediction (NCEP), formerly National Meteorological Center (NMC), and U. S. National Center for Atmospheric Research (NCAR) reanalyses have become available for the period 1968 to 1997 . Here, the top level in the atmosphere used for calculating the wind terms is $10 \mathrm{hPa}$. Compared with earlier NMC model versions which incorporate wind fields up to $100 \mathrm{hPa}$ since 1976 and up to $50 \mathrm{hPa}$ since 1981, the reanalyses have produced improved data series over a longer period than before. The axial AAM component $\chi_{3}$ is associated with changes in the Length-Of-Day (LOD). Its main contributors are the global zonal winds in the troposphere and the stratosphere. Motivated by better quality and continuity of the series AAM (NCEP) Reanalysis, the problem of the seasonal imbalances in the solid Earth-atmosphere axial angular momentum budget is re-examined.

To assess better the estimates of the annual and semiannual oscillations in LOD and AAM and of the residual oscillations derived as difference series between LOD and AAM, the series of LOD data from three analysis centers (IERS, GFZ, JPL), in particular

(a) EOP (IERS) 97C04 from 1962 to 1997 ,

(b) ERP (GFZ) L04 plus ERP (GFZ) 97P01 from 1983 to 1997 and

(c) EOP (JPL) 97C01 from 1976 to 1997 ,

and of AAM data including the wind term $\chi_{3}(\mathrm{~W})$, the pressure term $\chi_{3}(\mathrm{P})$ and the pressure term with Inverted-Barometer response $\chi_{3}(\mathrm{P}+\mathrm{IB})$ from four meteorological centers (NCEP, JMA, ECMWF and UKMO), in particular

(a) AAM (NCEP) Reanalysis from 1968 to 1997 ,

(b) AAM (JMA) from 1983 to 1997,

(c) AAM (ECMWF) from 1988 to 1996 and

(d) AAM (UKMO) from 1986 to 1997 ,

are used in this study. Concerning the top level in the atmospheric general circulation models (GCM) of the other meteorological centers, the wind terms computed by the JMA refer to the upper boundary of $10 \mathrm{hPa}$ beginning 1983 . Also, the ECMWF computes the AAM data from an atmospheric GCM up to $10 \mathrm{hPa}$, whereas the UKMO model has the upper boundary at $25 \mathrm{hPa}$. LOD variations inferred by AAM are defined to be $\mathrm{LOD}_{\mathrm{atm}}$. 
Using the wind term $\chi_{3}(\mathrm{~W})$, the pressure term $\chi_{3}(\mathrm{P})$ and the pressure IB term $\chi_{3}(\mathrm{P}+\mathrm{IB})$ as $\mathrm{LOD}$ atm components, the data processing includes the following main analysis steps:

(1) Removing gaps in the LOD (GFZ) and LOD ${ }_{\text {atm }}$ series, mostly by linear interpolation.

(2) Removing the tidal contribution from the LOD(IERS) data.

(3) Separating the major components, in particular trend and seasonal oscillations, by filtering the time series.

(4) Removing the tidal effects Sa and Ssa from the periodic LOD(GFZ) signals.

(5) Calculating optimal estimates of the amplitude, phase and period of each oscillation.

(6) Calculating the difference series between the annual and semiannual oscillations in the LOD systems over common intervals.

(7) The same as (6), but in the LOD atm systems.

(8) Calculating the annual and semiannual oscillations of the IB effect in the NCEP and JMA systems and the differences between them.

(9) Deriving the annual and semiannual contributions of the upper stratosphere between 50- and 10-hPa level to the LOD excitation in the NCEP Reanalysis system.

(10) The same as (9), but of the upper stratosphere between 100/50-hPa level of the old NMC system and $10 \mathrm{hPa}$ level of the new NCEP Reanalysis system.

(11) Calculating the annual and semiannual imbalances in the solid Earth-atmosphere axial angular momentum budget in the different LOD-LOD ${ }_{\text {atm }}$ systems over common intervals.

At the annual and semiannual periods, all the oscillations filtered out from the LOD and LOD atm time series show statistically significant variations in amplitude, phase and period with time. The role of systematic errors in them is discussed from an intercomparison of the LOD and $\mathrm{LOD}_{\mathrm{atm}}$ results.

The seasonal residual oscillations between the different LOD systems are shown in Figure 11. According to it, the seasonal LOD oscillations in the IERS system and those in the JPL system are equivalent over the common interval except that the uncertainty of the LOD series computed by the JPL is better at the beginning of the JPL interval. Concerning the LOD components in the GFZ system, note that the systematic discrepancies to those in the IERS and JPL systems are growing in amplitude with time at the annual frequency, whereas this does not hold at the semiannual frequency. Possibly, the reason is an unmodelled part of the orbit node motion in deriving LOD data from GPS observations.

Figures 12 to 15 allow an assessment of the $\mathrm{LOD}_{\text {atm }}$ results in the NCEP Reanalysis, JMA and ECMWF systems with the same top level of $10 \mathrm{hPa}$. An important feature are the significant differences between the seasonal oscillations referred to the three systems over the common intervals.

The annual and semiannual imbalances in the solid Earth-atmosphere axial angular momentum budget are distinguished by the fact that the annual $\mathrm{LOD}_{\mathrm{atm}}$ oscillation has an excess amplitude whereas the semiannual $\mathrm{LOD}_{\mathrm{atm}}$ oscillation has a shortage amplitude compared to the annual and semiannual LOD oscillations, respectively. The seasonal discrepancies, again referred to the three $\mathrm{LOD}_{\text {atm }}$ systems with $10 \mathrm{hPa}$ top level, are shown in Figures 17 to 22. Here, relating to the LOD systems of the IERS, GFZ and JPL, the remainders obtained at the annual frequency are illustrated in Figures 17 to 19 and those obtained at the semiannual frequency in Figures 20 to 22. Obviously, the results at the annual frequency do not agree so well as those at the semiannual frequency. The annual and semiannual discrepancies are residual oscillations having amplitudes of about 0.03 and $0.07 \mathrm{~ms}$, respectively, in the NCEP and JMA systems and of only 0.02 and $0.05 \mathrm{~ms}$, respectively, in the ECMWF system. Concerning the IB effect, we found no clear decrease of the annual imbalances, but of the semiannual ones. Better results for the oceanic contribution may be obtained with a more realistic model of the response of the oceans to atmospheric pressure changes.

The results derived for the different $L O D$ and $\mathrm{LOD}_{\mathrm{atm}}$ systems show to which extent the variations reflect systematic differences and significant signals, respectively, which is important for future activities in this field. For the annual frequency, it is necessary to explain the disagreements between the imbalances referred to the three $\mathrm{LOD}_{\mathrm{atm}}$ systems having the same top level of $10 \mathrm{hPa}$ in the atmospheric general circulation model. Considering the continuity of the component from IERS and JMA values, likely, there are larger systematic errors in the LOD atm data of NCEP and ECMWF versus JMA at times (compare the panels of Figure 17). If the missing contribution of wind from the 10-1 hPa atmospheric layer is included in the solid Earth-atmosphere axial momentum budget, seasonal imbalances may largely be eliminated. Therefore, in computing the wind term $\chi_{3}(\mathrm{~W})$, the upper limit should be extended to the 1-hPa level. At the achieved level of uncertainty, the Earth's axial angular momentum budget for the annual oscillation is most likely closed with the missing wind contribution alone and that for the semiannual oscillation with the missing wind contribution and some hydrological contribution. At a higher level of uncertainty, an excitation source such as the Antarctic Circum-Polar Current is not more neglectable.

To enhance our understanding of the dynamical interactions between the solid Earth, atmosphere, ocean and hydrosphere, we need high-precision angular momentum variations in terms of the LOD and LOD atm data on the one hand 
Publication: Scientific Technical Report

No.: STR98/10

Author: J. Höpfner

and of Oceanic-Angular-Momentum (OAM) and Hydrological-Angular-Momentum (HAM) data on the other hand. For monitoring the different geophysical fluids, future breakthroughs may require still great efforts.

Acknowledgement. Some results of this paper were presented at the XXIII General Assembly of the European Geophysical Society in Nice, France, from 20-24 April 1998. I wish to thank Dr Detlef Wolf for his suggestions that led to the improvement of this paper.

\section{References}

Barnes, R. T. H., Hide, R., White, A. A. and Wilson, C. A., 1983. Atmospheric angular momentum fluctuations, length-of-day changes and polar motion. Proc. Roy. Soc. Lond. A, 387, 31-73.

Chao, B. F. and O'Connor, W. P., 1988. Global surface-water-induced seasonal variations on the Earth's rotation and gravitational field. Geophys. J., 94, 263-270.

Chen, J., Wilson, C. R., Chao, B. F. and Shum, C. K., 1997. Hydrological and Oceanic Angular Momentum and Earth Rotation. Poster G31A-15. Fall Meeting of the AGU, San Francisco.

Dehant, V., Wilson, C. R., Salstein, D. A., Chao, B. F., Gross, R. S., Le Provost, Ch. and Ponte, R. M., 1997. Study of Earth's Rotation and Geophysical Fluids Progresses. EOS, 78, 34, 357+360.

Dickman, S. R., 1993. Dynamic ocean-tide effects on Earth's rotation. Geophys. J. Int., 112, 448-470.

Gambis, D. and Eisop, E., 1997. Combined EOP solution derived from GPS technique: EOP (IERS) 97P01. IERS/CB, Observatoire de Paris.

Gendt, G., Dick, G., Reigber, Ch., Sommerfeld, W., Nischan, Th. and Beeskow, G., 1997. Earth rotation parameters, station coordinates and velocities from GFZ using GPS data. Private communication.

Gross, R. S., 1996. Combinations of Earth Orientation Measurements: SPACE94, COMB94, and POLE94. J. Geophys. Res., 101, 8729-8740.

Höpfner, J., 1995. Atmosphärische und nicht-atmosphärische Erregung der saisonalen Erdrotationsschwankungen. AVN, 102, 2, 65-74.

Höpfner, J., 1996. Seasonal Oscillations in Length-Of-Day. Astron. Nachr., 317, 4, 273-280.

Höpfner, J., 1997. Seasonal Variations in Length-Of-Day and Atmospheric-Angular-Momentum. Scientific Technical Report STR97/08, GeoForschungsZentrum Potsdam.

Höpfner, J., 1998. Seasonal Variations in Length-Of-Day and Atmospheric-Angular-Momentum. Geophys. J. Int., 135, $407-437$.

IERS, 1997. 1996 IERS Annual Report. Central Bureau of IERS. Observatoire de Paris.

IERS, 1998. IERS Gazette, No 27. Nomenclature and use of UT-like arguments derived from astronomical or satellite geodesy observations.

Jochmann, H. and Greiner-Mai, H., 1996. Climate Variations and the Earth's Rotation. J. Geodynamics, 21, 2, 161-176.

Kalnay, E., Kanamitsu, M., Kistler, R. et al., 1996. The NCEP/NCAR 40-Year Reanalysis Project. Bull. Amer. Meteor. Soc., 77, 3, $437-471$.

McCarthy, D. D. (ed.), 1992. IERS Conventions (1992). IERS Technical Note 13, Central Bureau of IERS. Observatoire de Paris.

Montag, H., Gendt, G., Dick, G., Reigber, Ch., Nischan, Th. and Sommerfeld, W., 1993. Earth rotation parameters and station coordinates by Lageos laser ranging data updated till mid-September, 1992. IERS Technical Note 14, Central Bureau of IERS. Observatoire de Paris, L23-L29.

Montag, H., Reigber, Ch., Sommerfeld, W. and Dick, G., 1994. Station coordinates and Earth rotation parameters based on Lageos laser ranging data. IERS Technical Note 17, Central Bureau of IERS. Observatoire de Paris, L25-L30.

Munk, W. H. and MacDonald, G. J. F., 1960. The rotation of the Earth. Cambridge University Press, New York.

Naito, I. and Kikuchi, N., 1990. A seasonal budget of the Earth's axial angular momentum. Geophys. Res. Lett., 17, 5, 631-634.

Naito, I., Kikuchi, N. and Yokoyama, K., 1987. Results of Estimating the Effective Atmospheric Angular Momentum Functions Based on the JMA Global Analysis Data. Publ. Int. Lat. Obs. Mizusawa, 20, 1 \& 2, 1-11.

Nastula, J. and Manabe, S., 1997. Influence of the Shallow Seas on the Pressure Terms of the Eaam Function. Polish Academy of Sciences, Space Research Centre, Warszawa, Preprint No 34.

Reigber, Ch. and Feissel, M. (eds.), 1997. IERS missions, present and future. Report on the 1996 IERS Workshop. IERS Technical Note 22. Central Bureau of IERS. Observatoire de Paris.

Rosen, R. D., 1993. The axial momentum balance of Earth and its fluid envelope. Surveys in Geophysics, 14, 1-29.

Rosen, R. D. and Salstein, D. A., 1991. Comment on "A seasonal budget of the Earth's axial angular momentum" by Naito and Kikuchi. Geophys. Res. Lett., 18, 10, 1925-1926.

Rosen, R. D., Salstein, D. A. and Wood, T. M., 1990. Discrepancies in the Earth-Atmosphere Angular Momentum Budget. J. Geophys. Res., 95, B1, $265-279$.

Salstein, D. A., Kann, D. M., Miller, A. J. and Rosen, R. D., 1993. The Sub-bureau for Atmospheric Angular Momentum of the International Earth Rotation Service: A Meteorological Data Center with Geodetic Applications. Bull. Amer. Meteorol. Soc., 74, 1, 67-80.

Salstein, D. A. and Rosen, R. D., 1997. Global momentum and energy signals from reanalysis systems. Reprint volume. 7th Conference on Global Climate Variations. American Meteorological Society, 344-348.

Yoder, C.F., Williams, J. G. and Parker, M. E., 1981. Tidal variations of Earth rotation. J. Geophys. Res., 86, 881-891. 